\title{
Clonal diversity and population genetic structure of the grain aphid Sitobion avenae (F.) in central Europe
}

\author{
Dissertation \\ zur Erlangung des Doktorgrades \\ der Fakultät für Agrarwissenschaften \\ der Georg-August-Universität Göttingen
}

vorgelegt von

Lars Reimer

geboren in Düren

Göttingen, Juli 2004 
D 7

1. Referent:

Prof. Dr. S. Vidal

2. Referent:

Prof. Dr. T. Tscharntke

Tag der mündlichen Prüfung: 16. Juli 2004 
Soli Dei Glaria 


\section{Table of Contents}

SUMMARY

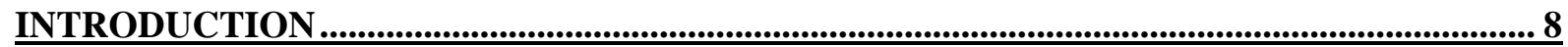

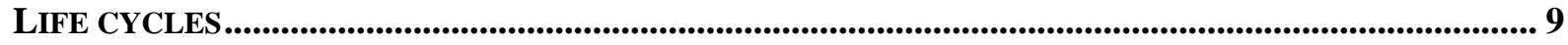

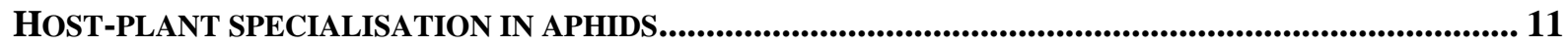

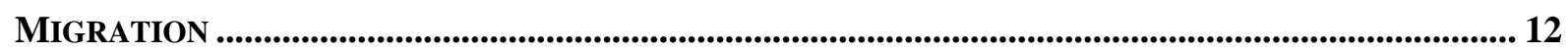

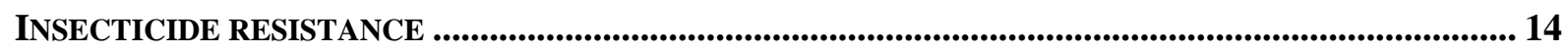

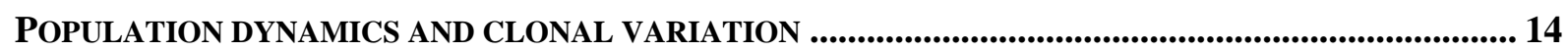

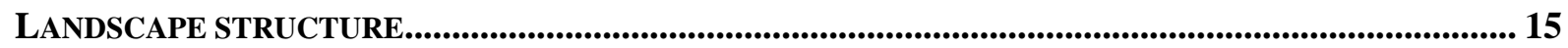

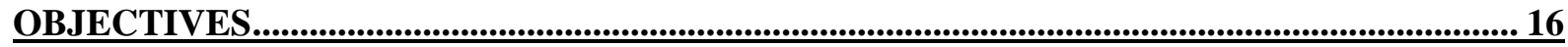

SPATIAL AND TEMPORAL GENETIC VARIATION BETWEEN GERMAN

POPULATIONS OF THE GRAIN APHID, SITOBION AVENAE (F.) ................................... 18

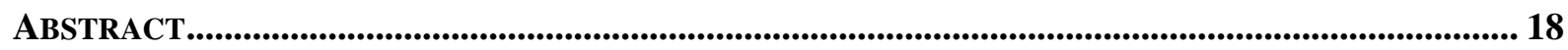

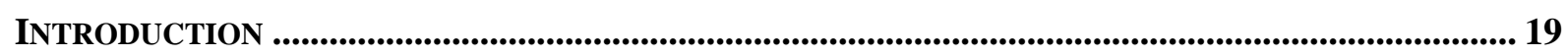

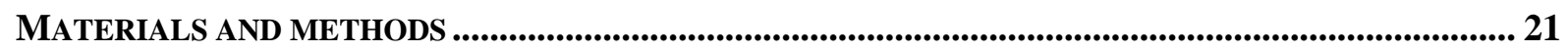

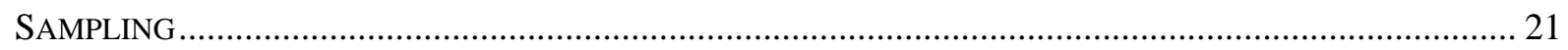

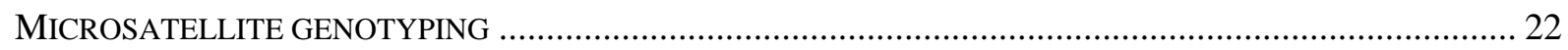

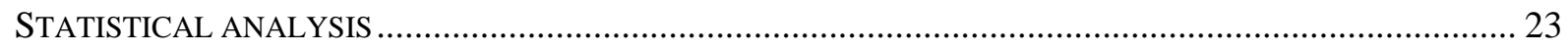

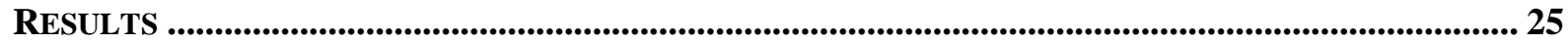

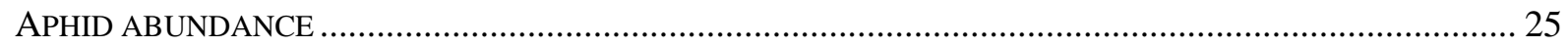

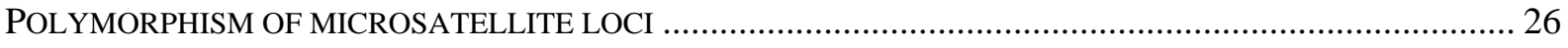

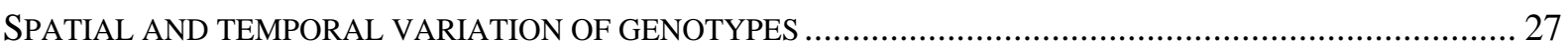

GENETIC STRUCTURE OF GERMAN S. AVENAE POPULATIONS IN 2001.............................................. 33

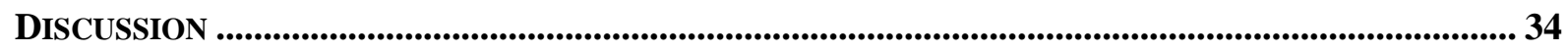

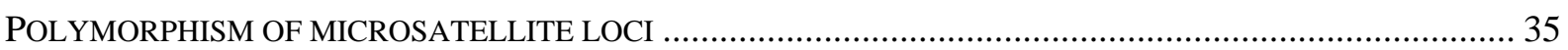

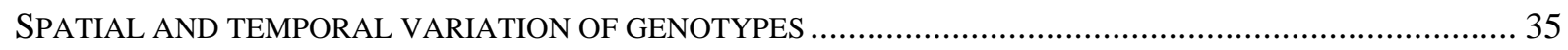

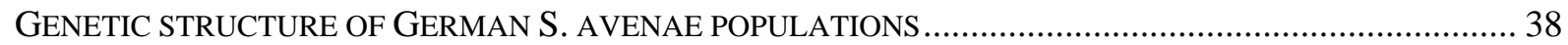




\section{CLONAL DIVERSITY OF THE GRAIN APHID, SITOBION AVENAE (F.) IN RELATION}

TO LANDSCAPE STRUCTURE

ABSTRACT

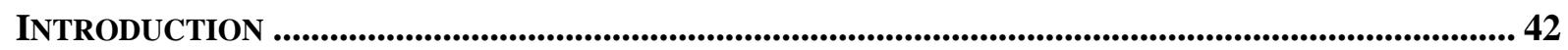

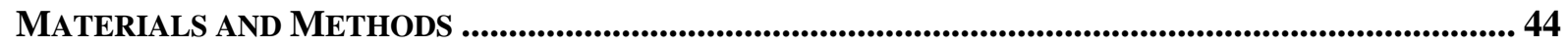

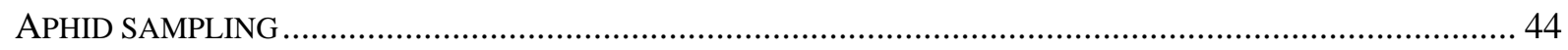

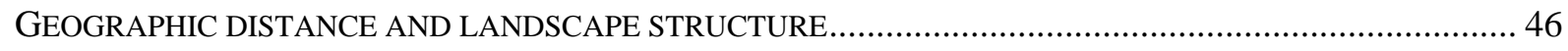

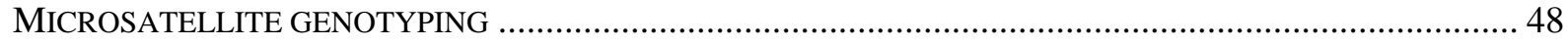

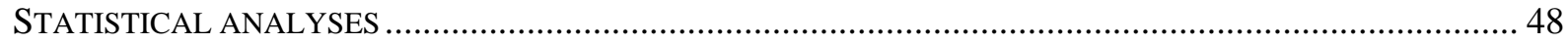

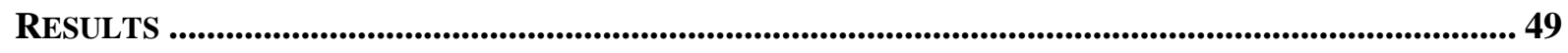

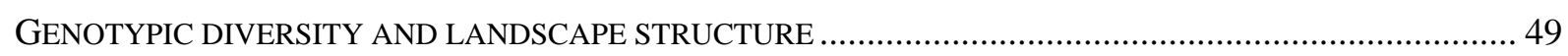

SEASONAL DEVELOPMENT OF GENOTYPES DURING SUMMERTIME ...................................................... 51

MIGRATION OF GENOTYPES WITHIN A SEASON IN REGARD TO LANDSCAPE STRUCTURE ....................... 54

POPULATION DIFFERENTIATION BY GEOGRAPHIC DISTANCE AND LANDSCAPE STRUCTURE ................. 55

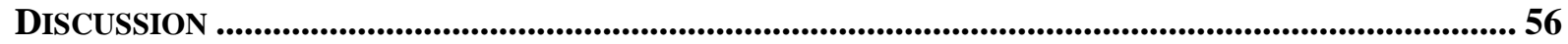

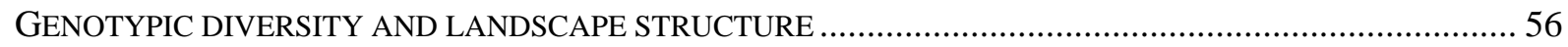

SEASONAL DEVELOPMENT OF GENOTYPES DURING SUMMERTIME .................................................... 57

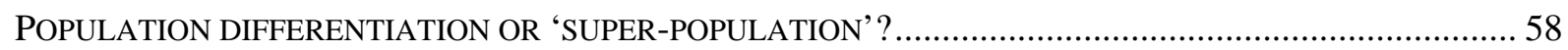

COEXISTENCE OF SEXUAL AND ASEXUAL POPULATIONS OF THE GRAIN APHID, SITOBION AVENAE (F.) UNDER VARIABLE CLIMATE CONDITIONS IN CENTRAL

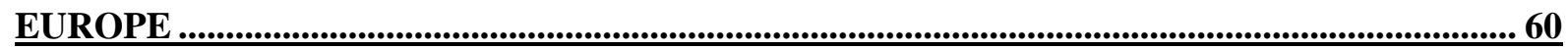

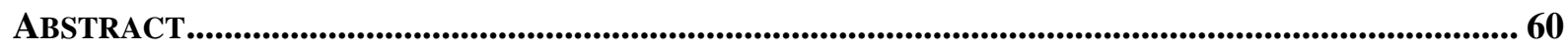

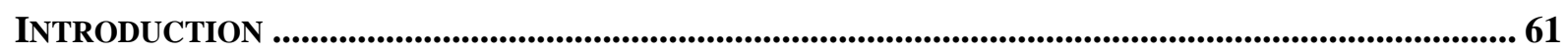

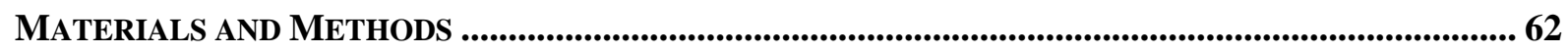

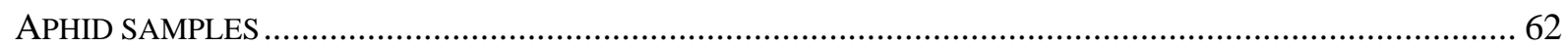

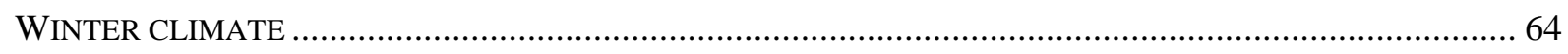

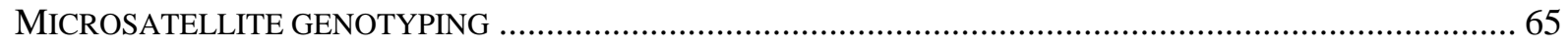

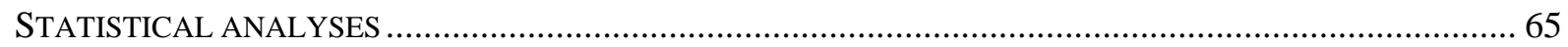

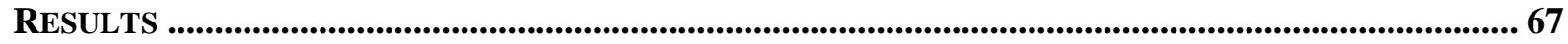

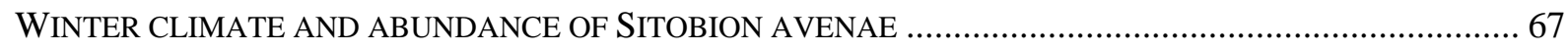

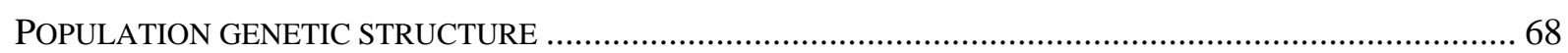

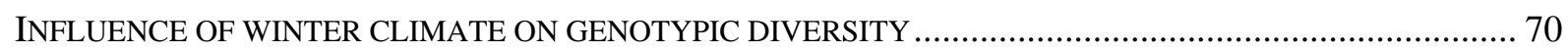

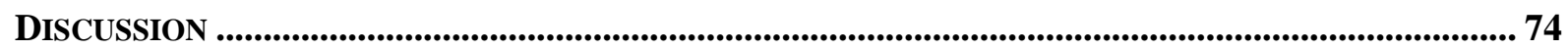

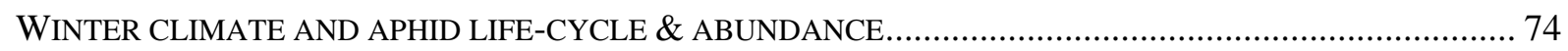

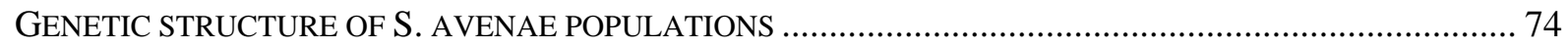


INFLUENCE OF WINTER CLIMATE ON GENOTYPIC DIVERSITY 76

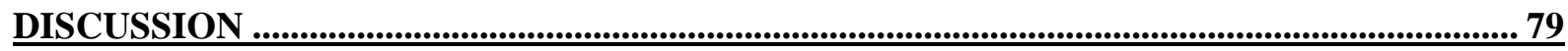

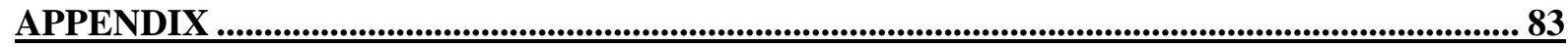

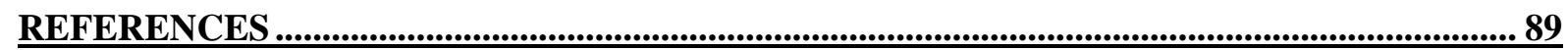

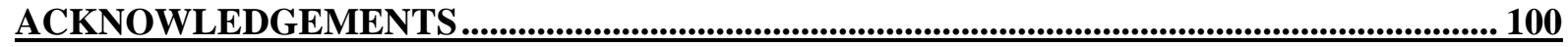

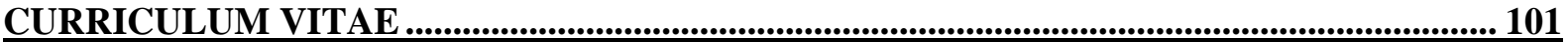




\section{Summary}

The grain aphid, Sitobion avenae (F.), displays a number of different life-cycles. These range from complete asexual viviparous and frost-sensitive lineages (anholocyclic) to those including a single sexual generation and which produce frost resistant eggs (holocyclic). In addition, combinations of both life cycles can occur. The spread of life-cycles in a population is known to be dependent on winter climate and earlier studies have used highly polymorphic DNA-markers (microsatellites) to elucidate the influence of seasonal factors on life-cycle variation. However, to date, no such field studies have been performed in geographic areas were mild and cold winters vary between years. Therefore, the central aim of this project was to analyse populations of $S$. avenae from four diverse geographic regions, viz. northern Germany, two regions from central Germany and one from southern Hungary in three consecutive years. Changes of clonal diversity and population genetic structure were compared within and between years at 32 locations from central and northern Germany differing in the complexity of their landscape structure. The results revealed that seven asexual clones (= multilocus microsatellite genotypes) of $S$. avenae were common on wheat (Triticum aestivum) and widespread over locations and regions in Germany, including a single clone that was also present in Hungary over two consecutive years. Furthermore, genotypic diversity was dependent on winter climate in Hungary and central Germany, although the two parameters were apparently not correlated in northern Germany. Beside climate effects, genotypic diversity showed a significant positive relationship to simple structured landscapes in central and northern Germany in 2001, but this effect was outweighed in central Germany by successive colder winters in 2002 and 2003. Analysis of the 'within-season' dynamics of clones revealed contrary development in time and space in a yearly repeating pattern. The change in clonal communities was probably dependent on regional insecticide management, clonal variation in host-plant shifts and a restriction of short distance migration by natural geographic barriers. However, long distance migration was high enough to prevent the genetic isolation of populations from northern Germany to Hungary. Overall, the present results confirmed the homogenising effects of migration at a scale of $<50 \mathrm{~km}$ and differentiation in genotypic diversity at regional scales $>100 \mathrm{~km}$. This project was part of the project BIOPLEX ('Biodiversität und räumliche Komplexität in Agrarlandschaften unter Global Change', Project ID: 01LC0020), financed by the Federal Ministry of Education and Research. 


\section{Introduction}

\section{"Aphids bave fascinated and frustrated man for a very long time"}

A. F. G. Dixon, 1998

The English grain aphid, Sitobion avenae (F.), is an important pest in agricultural systems, especially in temperate climates on the northern and southern hemisphere (Blackman \& Eastop 1984, Vickerman \& Wratten 1979, Wangai et al. 2000, Apablaza 1974, Sunnucks et al. 1996). Thus, scientists have focused on this group since one and a half century (Hardy 1850). Aphids are ideal for studying many of the topical issues in ecology, including hostplant alternation, sympatric speciation by host-plants shifts, resistance to insecticides, migration and virus transmission, cyclic parthenogenesis and life-cycle variation, insect-plant interactions (including endophytes), population dynamics and population genetics.

The latter started with investigations on phenotypic variation and rapidly progressed by the advent of molecular markers. As allozymes showed low variation (Tomiuk \& Woehrmann 1980), hypervariable DNA-markers like RAPD (Random amplified polymorphic DNA) (DeBarro et al. 1995b), (GATA) 4 -Probe (DeBarro et al. 1994, 1995a) and finally microsatellites (Sunnucks et al. 1996, present study) were used for population genetic studies. The high resolution of microsatellites enabled scientists to study both population genetic structure and identification of individuals that belong to different asexual lineages under field conditions. Therefore the 'wax and wane' of aphid clones under field conditions and lifecycle variation between sexual and asexual lineages can be observed in the field and be combined with laboratory experiments on defined aphid clones. The use of microsatellites as molecular markers in population genetics should be viewed in the light of ongoing research. Because of their noncoding sequences, microsatellites were supposed to be 'selective neutral, co-dominant markers' (Jarne \& Lagoda 1996, Schloetterer \& Wiehe 1999, Schloetterer 2000). However, there is growing evidence for multiple functions of microsatellites in the genome (see Li et al. 2002 for a review). Second, even if loci were neutral, they can associated with loci under selection, especially in clonal organisms: a process known as genetic hitchhiking (Avise 1994). Therefore results concerning population genetic structure should be interpreted with care. 
As the position and function of the microsatellites used in the present study is still unknown, we analysed the variability of single loci of populations using a hierarchical spatial and temporal sampling design (Chapter 1). By subsequent up-scaling we analysed population genetic structure and clonal diversity from the field scale to a regional scale and focused on the effects of landscape structure on intraspecific variation (Chapter 2). Further, the effect of annual and regional changes in winter climate was studied at a regional and nation-wide scale (Chapter 3). In addition, we included short time series in central Germany in two consecutive years to include within seasonal changes of clonal diversity within the vegetation period (Chapter 1 \& 2).

\section{Life cycles}

Aphids became ideal model organisms to assess the importance of sexual reproduction in organisms. The predominance of sexual reproduction in metazoan taxa was explained by (i) the advantage to create new gene combinations for adaptation to a variable environment (Bauer \& Schmid 1996) and (ii) to eliminate recurrent deleterious mutations (Mueller 1964, West et al. 1999). On the other hand intraspecific variation could be the result of an imperfect adaptation due to disruptive random forces like mutation and drift (Bauer \& Schmid 1996).

In aphids sex is linked to the general twofold costs of producing males that cannot reproduce independently (Maynard Smith 1978) and the reduced fecundity of sexual reproducing females compared with parthenogenetic females (Newton \& Dixon 1988, Helden \& Dixon 2002). Therefore, a combination of both reproductive modes in a dynamic conditionresponse system could combine the advantages of both rapid asexual proliferation and genetic variability. Alternating reproductive modes are displayed in various plant species (Meikle et al. 1999, Van Der Velde et al. 2001), pathogenic fungi (e.g. Zhan et al. 2002) and animals like crustaceans (Vanoverbeke \& DeMeester 1997) and aphids (e.g. Papura et al. 2003).

The grain aphid, Sitobion avenae, includes all life-cycles known from aphids (Fig. 1). A transition of cyclic parthenogens to new asexual lineages was demonstrated for the bird cherry-oat aphid, Rhopalosiphum padi, and was called 'contagious parthenogenesis' (Delmotte et al. 2001, 2003, Fig. 1). All of these life-cycles were determined by observing the production of sexual morphs under experimental simulated autumn conditions. These experiments evaluate the potential of single clones to produce sexual morphs, but cannot reveal whether sexual morphs are produced under field conditions and which of these successfully mate. Hypervariable molecular markers offer the possibility to identify identical 
individuals from field samples and to analyse the amount of sexual recombination under field conditions (Chapter 1, 3). They also offer the possibility to identify the occurrence of asexual clones in different years. However, they are restricted to discriminate between all asexual lineages ('functional parthenogens', see Llewellyn et al. 2003 and Fig.1) and lineages including sexual morphs. For both methods the time of collecting aphids is crucial, as all individuals reproduce asexual during summertime triggered by intrinsic and extrinsic factors (Dixon 1998). This is crucial for experimental tests. Further, whilst asexual clonal proliferation during summertime diminishes clonal differences in reproductive modes (Moran 1992), it was necessary to analyse the genetic structure of 'single-copy per genotype' data sets (Chapter 1-3).

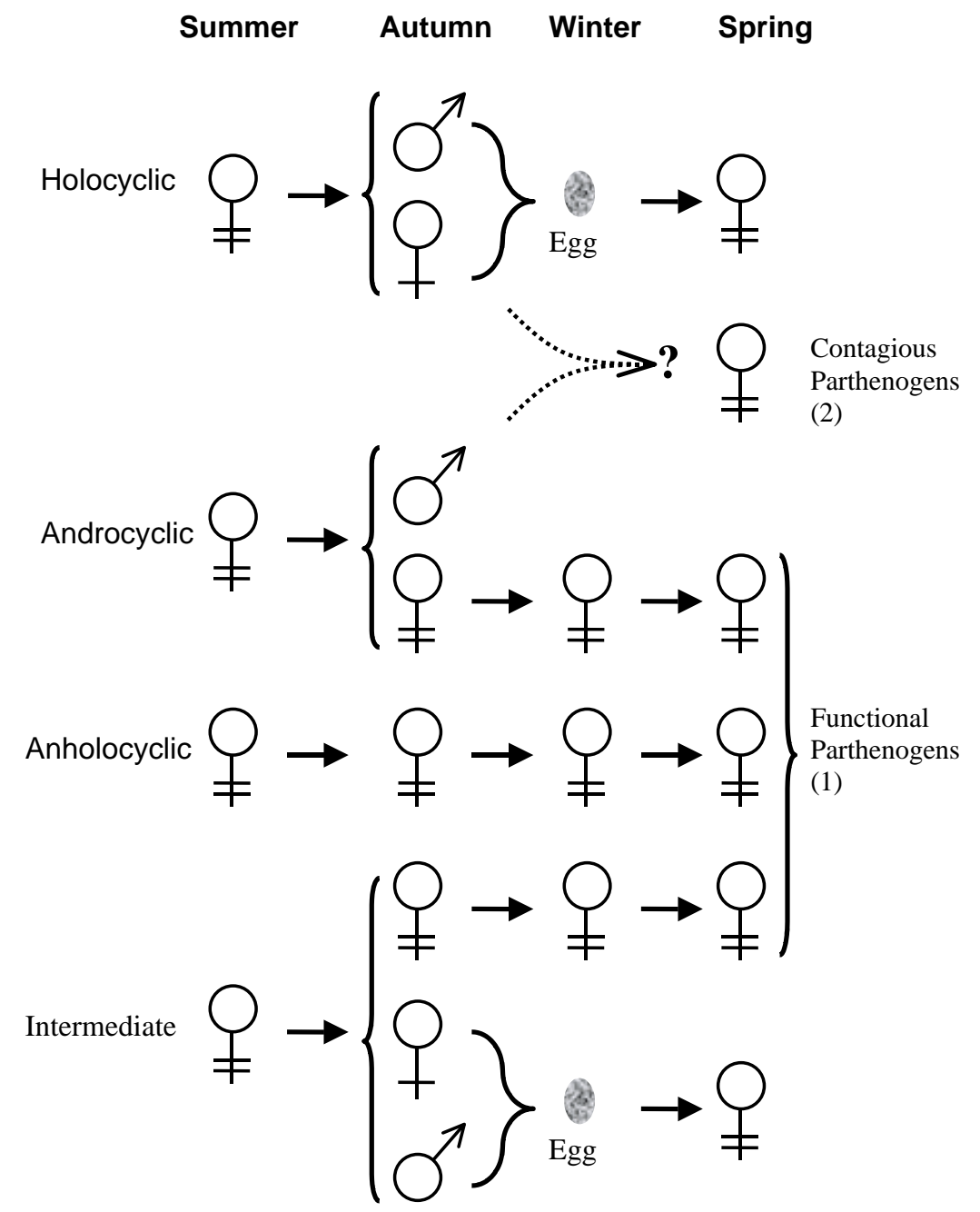

Fig. 1 Reproductive modes of Sitobion avenae. 1: see Llewellyn et al. (2003), 2: see Delmotte et al. (2001, 2003) demonstrated for Rhopalosiphum padi. $\underline{q}=$ Parthenogenetic female, $\boldsymbol{q}=$ Sexual female.

Within the grain aphid S. avenae, complete asexual lineages (anholocyclic) can coexist with cyclic parthenogens (holocyclic, intermediate and androcyclic) under certain 
environmental conditions, the best known of which is winter climate. Several studies proposed that cold winters select for cold tolerant eggs from sexual reproduction, whilst aphids from viviparous parthenogenesis could survive only under mild winter conditions (Rispe et al. 1998, Rispe \& Pierre 1998; Halkett et al. 2004). Two studies were performed in central Germany that investigated the composition of sexual and asexual lineages of $S$. avenae with laboratory experiments (Wientgen et al. 1994, Weber 1985). Whereas Weber (1985) found exclusively holocyclic clones after a cold winter, Wientgen et al. (1994) found a large proportion of anholocyclic clones after a series of consecutive mild winters that survived the following cold winter or immigrated from milder climates, but definitely diminished after two consecutive cold winters. As both studies were limited in sample size by the method of rearing individual clones for at least three months under laboratory conditions, a field approach using molecular markers on a large number of aphids sampled from consecutive years of different winter climate was necessary. The objective of this study was to determine the factors leading to coexistence of asexual and cyclic-parthenogenetic lineages under annual varying climate conditions and to compare these results to a geographic area were permanent cold winter climates occur. Further we tested the hypothesis that intermediate life-cycles dominate in areas were winter climate is varying and unpredictable (Rispe and Pierre 1998; Rispe et al. 1998, Halkett et al. 2004).

\section{Host-plant specialisation in aphids}

In theory, aphid species that eliminated primary hosts (where sexual morphs from immigrated aphids from secondary hosts assemble to mate) should be more susceptible to speciation processes, because of the greater potential for inbreeding and consequent genetic drift and the fact that the herbaceous hosts constitute a diverse, abundant, and favourable set of resources (Moran 1992). The grain aphid, S. avenae, is such a non alternating species and there are hostpreferences assumed for single lineages although clones were not totally restricted to different hosts of Poaceae (Haack et al. 2000, DeBarro et al. 1995a,b, Lushai et al. 2002). To discriminate between the impact of environmental conditions on population genetics and the effect of host-plant, it was therefore necessary to focus on a single host, which should be preferable the most common one in the regions studied. Therefore, all results of this study that were obtained from populations sampled from wheat, do exclude lineages that where restricted to other hosts and include wheat specialised clones as well as 'generalists' (Lushai et al. 2002). 


\section{Migration}

Migration of winged aphids is determined by intrinsic and extrinsic factors. For S. avenae it is known that dispersal induction depends on crowding and food quality (Watt \& Dixon 1981). Further S. avenae takes of at higher wind speeds than tree-dwelling aphids (Mercer 1979, Walters \& Dixon 1984) and therefore might passively disperse over large areas. In addition apterous S. avenae showed a high disposition to migrate within fields (Dean 1973, Holmes 1988, DeBarro et al. 1994). The high mobility of this aphid is supported by studies using molecular markers that revealed a rather homogenous population structure all over Great Britain (Llewellyn et al. 2003). From this we hypothesised that this aphid species is randomly dispersing over large geographic areas. The alternative hypothesis is that aphids actively control migration or that most alatae travel at lower altitudes and hence are influenced in their dispersal by natural barriers. Long distance dispersal was probably overestimated (Loxdale et al. 1993). However, the importance of long distance to short distance migration is difficult to assess. It was Moericke (1955) who first stated the difference between long distance dispersal of winged morphs at high altitudes, the so-called alighting flight ('Distanzflug') and short flights above the vegetation layer, the so-called targeted flight ('Befallsflug'). In addition the fuel reserves and quality of a located host determines whether an aphid settles down or continues flight activity. This differential behavioural pattern of flight might allow to control flight to some extent. There is a trade of between investment in reproduction and in fuel reserves in aphids (Dixon 1998). This trade off between investment in lipids for flight activity and gonads for reproduction is apparently intermediate in $S$. avenae compared with other species (Dixon et al. 1993). Therefore, it may be hypothesised that S. avenae is less likely to be an exclusively long or short distance migratory species, but may combine both strategies.

Earlier studies on $S$. avenae in Germany tested single individuals under laboratory conditions for their life-cycle (Wientgen et al. 1994, Weber 1985, Hoeller 1990). It has been proven that anholocyclic clones were present in northern Germany, but usually the rather cold winters are likely to eliminate these clones during wintertime (Hoeller 1990). It was postulated that these clones immigrate from milder climates, as it was observed for entire anholocyclic species like Rhopalosiphum maidis (Fitch) that were also found in northern Germany, or S. avenae in Sweden or China (Wiktelius 1984, Dong et al. 1987). With the advent of molecular markers, present research including this study focused on the unanswered questions to what extend anholocyclic clones are able to survive cold winters and to evaluate 
threshold values for survival, to estimate from where and to what extend these clones cloud immigrate and last but not least if new anholocyclic lineages could be generated by either contagious parthenogenesis (see section "life-cycle”) or hybrids with closely related species.

By the examination of alleles and their distribution, local differences in genetic structure between populations on the field scale were recently observed by Llewellyn et al. (2004). The authors argued that clonal selection during the vegetation period might cause these differences. Similar local differentiation were found by DeBarro et al. (1995b) who observed changes in clonal diversity of $S$. avenae sampled from cereals and cocksfoot (Dactylis glomerata). There is strong evidence that aphids migrate between different host plants mainly because of finding host patches of high nutritional value (Dixon 1998). In case of S. avenae, however, it is unknown, which grass species (Poaceae) are colonised by which clones at a different time during the vegetation period.

Microsatellites are a useful tool to indirectly measure changes in clonal diversity on a field scale, including a larger set of different localities that could not be analysed by visual inspections. However, as this species includes several different life-cycles, only those that reproduce anholocyclic might be followed in their reproduction and dispersal over years, whilst all others that include a sexual generation can only be tracked during summertime, when they reproduce asexual. Observing individual dispersal with indirect methods (molecular markers) have beside all advantages a major disadvantage: if an anholocyclic clone appears at a certain locality at a high abundance, it is not possible to distinguish between an exceptional reproduction of this clone at that locality and between migration effects. Hence it is necessary to evaluate a broad range of important environmental factors and clonal variation to create a model of dispersal for migrating species.

This study included time series within and between years as well as a hierarchical spatial sampling regime to estimate possible influence of migration. As data of landscape structure were available, possible physical barriers that influence short range dispersal could be analysed (Chapter 2). 


\section{Insecticide resistance}

Several aphid species have developed resistance to insecticides, e.g. Aphis gossypii (Delorme et al. 1997, Grant et al. 2001), Myzus persicae and M. nicotianae (Devonshire \& Sawicki 1979, Field \& Blackman 2003, Wolff et al. 1994), Terioaphis trifolii (Holtkamp et al. 1992), Nasonovia ribis-nigri (Barber et al. 1999), Phorodon humuli (Muir 1979) and Schizaphis graminum (Ono et al. 1999). However, no insecticide resistance has been reported so far for S. avenae (Llewellyn et al. 2003). Therefore insecticide applications reduce the abundance of clonal individuals of $S$. avenae during the vegetation period, but does not select for resistant clones. Hence, if single clones proliferate better in fields or areas without insecticide treatment than in insecticide applied areas, this would indicate the absence of resistance in this species (Chapter 2).

\section{Population dynamics and clonal variation}

Aphid abundance peaks during summertime in cereal crops with additional smaller peaks in autumn are a well known annual recurrent phenomenon observed for many aphid species, whereas aphid abundance varies between years. Field studies using molecular markers revealed that changes in clonal composition during summertime occur (Tomiuk \& Woehrmann 1981, Haack et al. 2000), indicating that clones proliferate differentially during summertime. Therefore this study included a short time series within two consecutive years. Moreover, we wanted to investigate if the number of asexual overwintering clones effects the build up of aphid abundance in the following season, as this is still argued to be a reason for aphid outbreaks (Hasken 2001). 


\section{Landscape structure}

The influence of a heterogeneous landscape on species communities and intraspecific variation became a field of intense studies in the last decades although the pattern of geographical parthenogenesis was observed long ago (Vandel 1928). New approaches that include quantitative information of shape and land-use of large geographic areas revealed new insights in how heterogeneous landscapes interact with intraspecific variability, either directly by physical barriers or habitat fragmentation. (Keyghobadi et al. 2003, this study). This study focused on two objectives addressed to landscape structure, (i) do physical barriers influence short-term migration of $S$. avenae within a season? and (ii) does landscape structure influence the clonal composition of grain aphids over years as a rather constant variable compared with variable winter climate changes in Germany? 


\section{Objectives}

The factors that determine clonal diversity and population genetic structure of the grain aphid, Sitobion avenae (F.), were investigated in central Europe to gain new insights into the dynamic condition-response system of intraspecific variation due to environmental changes.

1) A hierarchical sampling design from field scale to nation-wide scale was performed addressed to the questions:

- Which geographic scale determines population substructure in terms of (i) allelic variation and (ii) clonal variation?

- Does landscape structure, defined by land-use parameters and elevation profile, effect clonal diversity at different spatial scales?

2) Short time series were included to study changes in clonal diversity of asexual summer generations within a vegetation period.

- Is clonal diversity dependent on individual abundance?

- Is migration influenced by geographical barriers?

3) Samples were taken from four regions and three consecutive years to investigate the annual changes in population genetic structure and clonal diversity.

- Which life-cycle is selected by winter climate?

- Do mild winters lead to outbreaks in abundance, because of parthenogenetic overwintering? 
The following chapters have been submitted under the following titles:

Chapter 1: Reimer L, Loxdale HD, Clark SJ, Vidal S (2004a) Spatial and temporal genetic variation between German populations of the grain aphid, Sitobion avenae (F.). Molecular Ecology (submitted).

Chapter 2: Reimer L, Loxdale HD, Vidal S (2004b) Clonal diversity of the grain aphid, Sitobion avenae (F.), in relation to landscape structure. Heredity (submitted).

[Dd Chapter 3: Reimer L, Loxdale HD, Vidal S (2004c) Coexistence of sexual and asexual clones of Sitobion avenae (F.) under variable climate and environmental conditions in central Europe. Heredity (submitted). 


\title{
Spatial and temporal genetic variation between German populations of the grain aphid, Sitobion avenae (F.)
}

\author{
Lars REIMER ${ }^{1}$, Hugh D. LOXDALE ${ }^{2}$, Suzanne J. CLARK ${ }^{3}$, Stefan VIDAL ${ }^{1}$ \\ ${ }^{1 .}$ Institute of Plant Pathology and Plant Protection, Goettingen University, Grisebachstrasse 6, 37077 \\ Goettingen, Germany; ${ }^{2}$ Plant and Invertebrate Ecology Division and ${ }^{3}$ Biomathematics Unit, \\ Rothamsted Research, Harpenden, Hertfordshire, AL5 2JQ, UK
}

\begin{abstract}
The grain aphid, Sitobion avenae (F.) is major pest of cereal crops in Europe. The main factors contributing to its success in different landscapes are not understood in detail; the complex life cycle strategies involving sexual and asexual phases, the long distance migratory range and the ability to colonise a wide host plant range (grasses and cereals, Poaceae), may be involved. However, it is not known if populations of this aphid are ubiquitous in terms of clonal (=genotypic) structuring or if they show subpopulation heterogeneity due to a variety of locally-differentiating selective forces. In this study, five polymorphic microsatellite markers were used to investigate the spatial structuring and dynamics of $S$. avenae populations at two regions, more than 100 kilometres apart within central Germany, including a subset of 14 and 17 locations within regions. Aphids were sampled from winter-sown wheat (Triticum aestivum). The results support the view that population structuring occurs at a regional scale between populations on wheat. The spatial heterogeneous distribution of aphid clones is more important than the short temporal one included in this study, i.e. three to four asexual aphid generations, although short term changes in clonal composition were observed that could not be explained by aphid abundance. The data also clearly indicate that the patterns of population structure are governed by numerous forces, including selection, and that these operate in a subtle and interacting manner, even within regions. From the genetic structure of $S$. avenae summer populations, we further postulate the coexistence of sexual and asexual lineages in Germany.
\end{abstract}




\section{Introduction}

Recent investigations using a range of polymorphic molecular markers, including microsatellites, have enabled individuals within clonal systems to be tracked in time and space, something that was hitherto impossible (e.g. Sunnucks et al. 1997, Simon et al. 1999, Haack et al. 2000, Delmotte et al. 2002, Massonnet et al. 2002, Llewellyn et al. 2003, Guillemaud et al. 2003). By such means, it has been possible to elucidate population structure and dynamics and discover the factors governing these. Aphids are especially interesting model organisms to study clonality because of their fast reproduction rate and short life span and the fact that they have a number of life-cycle types (Dixon 1998, Dedryver et al. 1998, 2001). These range from lineages with numerous asexual generations (about 14 per year) alternating between a single annual sexual generation (= holocyclic) to obligate asexual lineages (= anholocyclic). In addition, some lineages are male producing only (= androcyclic) whilst some produce a few males and females only (= intermediate) (Delmotte et al. 2001, see Simon et al. 2002 for further details). The production of sexual forms is governed by both light and temperature (Dixon 1998, Lushai et al. 1996): the eggs produced upon mating are cold hardy and of overwintering survival value (Hand 1989), whilst overwintering nymphs of obligate asexuals or 'functional' asexuals (i.e. those from intermediate or androcyclic lineages surviving through mild winters) are susceptible to cold conditions (Knight \& Bale 1986, Parish \& Bale 1993).

The grain aphid, Sitobion avenae (F.) (Hemiptera: Aphididae), a major pest of cereals in Europe (Vickerman \& Wratten 1979), displays all these life cycle forms whilst remaining on the same host, i.e. it is autoecious, mainly on Poaceae, grasses and cereals (Hardy 1850, Hille Ris Lambers 1939, Watt 1981). It is therefore an especially convenient organism to investigate factors related to its population structure and dynamics using hypervariable molecular (DNA) markers such as microsatellites. The main problem with tracking aphids is their small size such that individuals within populations are rapidly diluted on take off and may be carried long distances borne on the wind above their flight speed in still air (Loxdale et al. 1993). Direct tagging has generally proved impossible at large spatial scales because of this problem, although indirect analysis of individuals and clones using molecular genetic markers has provided novel insights into the population biology of these insects (Loxdale 2001, Osborne et al. 2002).

S. avenae is apparently highly migratory. This has been demonstrated at peak abundance using suction trapping (Woiwod et al. 1988) and from population analysis with microsatellite 
markers in which genetic (= allelic) homogeneity was found over large geographic distances (Llewellyn et al. 2003). However, weak differentiation in population genetic structure was observed on regional scales ( $<60 \mathrm{~km}$ and $>100 \mathrm{~km}$ ) in Romania that could not be explained by geographical distance (Papura et al. 2003). In contrast, other previous molecular genetic work have revealed the existence of genetic heterogeneity in terms of clonal (= genotype) structuring. Differences in clonal diversity were observed on regional scales $>100 \mathrm{~km}$ (Llewellyn et al. 2003) and small spatial scales < 60 km (DeBarro et al. 1995a,b; Llewellyn et al. 2004).

S. avenae clearly occupies habitats in different localities exerting putatively different locally selective forces, i.e. habitat size, host plant quality, natural enemies and climate. In addition, many of its habitats - for example fields, are ephemeral in nature. All these influences could lead to a dynamic condition-response system. However, the forces directing such dynamics are still unclear and because of this, further studies are required that involve sampling from a single crop during the summer and at a variety of spatial scales ranging from small (field) to large (regional). The influence of factors during the crop growing season can be elucidated by collecting aphids only during a short period of the summer from regions of different habitat complexity, but similar in climate.

It may be hypothesised on the basis of what is known about the population biology of $S$. avenae, including its fast rate of asexual reproduction, that extensive aerial migration is likely to homogenise populations genetically over a wide geographic range. Alternatively, selection, genetic drift/founder events and host preference, and even mutation events (Loxdale \& Lushai 2003a,b), are likely to counteract such homogenisation and lead to spatial and temporal genetic heterogeneity. In this study, five polymorphic microsatellite markers were used to examine the population biology of $S$. avenae in two regions of central Germany to test whether differentiation at small spatial scales is of significance in distribution of genotypes and shaping of population structure. This was done by collecting and genotyping large $S$. avenae samples at increasing spatial scales from 14 and 17 wheat fields within two regions and at two sampling periods during the peak abundance of the insect in the field. As this was the first study of genetic structure of $S$. avenae populations in Germany under frequent cold and mild winter conditions, we also tested the hypothesis of coexistence of sexual and asexual life-cycle types. 


\section{Materials and methods}

\section{Sampling}

A hierarchical sampling regime was used over spatial and short term temporal scales (one month, i.e., three to four generations, assuming generation period to be about 7 to 10 days in S. avenae; Dean 1974, Dixon 1998). Only individuals in the parthenogenetic phase of reproduction and collected during peak abundance were considered, thereby reducing effects of sexual recombination on genotypic composition. In total, 1172 S. avenae adults were collected from 31 winter-sown wheat fields (Triticum aestivum) from two regions in central Germany, respectively, 106 to $167 \mathrm{~km}$ apart (Fig. 1). Each region included 14 and 17 wheat fields, distributed over an area of approximately $50 \mathrm{~km}$ maximum distance between fields (Fig. 1). The first sample in June 2001 included seven fields in the south of Lower Saxony around the city of Goettingen (LS) on the $19^{\text {th }}$ and $20^{\text {th }}$ June and from 13 fields in the centre of Hesse near Giessen $(\mathrm{H})$ on the $25^{\text {th }}$ and $26^{\text {th }}$ June 2001. in the same year. At that time, wheat plants were fully flowering (BBCH 65). Samples were also collected on a second occasion from 16 fields within region LS on the $15^{\text {th }}$ and $16^{\text {th }}$ July and from 13 fields in region $\mathrm{H}$ during the period $11^{\text {th }}$ to $13^{\text {th }}$ July 2001. At these times, plants were at the milky-ripe growth stage (BBCH 75). In region LS six fields were sampled at both occasions, whilst one field was exclusively sampled in June and all others exclusively in July, as aphid densities were too low in these fields to achieve a representative sample size in adequate time. In region $\mathrm{H}$, twelve sites were identical between months of sample, with one field sampled exclusively in June and one field in July 2001.

At each site, sweep-net samples were taken along transects through the centre of the field along field rows, and excluding the outer margins by at least three metres. A distance of at least two metres was kept between sample units. From each catch, only one adult female $S$. avenae was chosen at random, in order to minimise re-sampling of individuals of the same clone and hence, obtain an unbiased sample of the genetic variance present. Additionally, $8 \mathrm{x}$ 5 shoots per plots along a drill row through the centre of fields excluding field margins of 2 metres were examined per field, in order to estimate the abundance of S. avenae. All individuals were stored at $-20^{\circ} \mathrm{C}$ prior to DNA extraction and genotyping. 


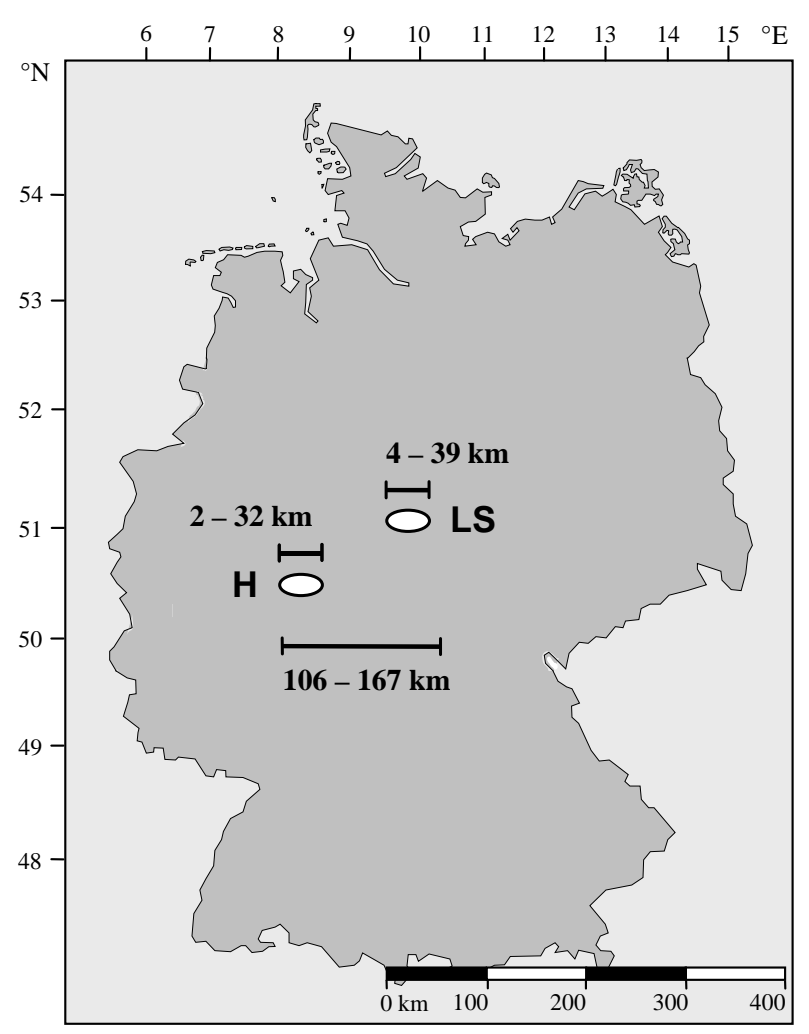

Fig. 1 Locations of field samples of S. avenae in Germany in 2001. LS = region Lower Saxony, near Goettingen; $\mathrm{H}$ = region in the centre of Hesse, near Giessen. Bars indicate minimum and maximum distances between wheat-fields within and between regions.

\section{Microsatellite genotyping}

DNA was extracted from individual aphids following the 'salting out' protocol of Sunnucks \& Hales (1996). Genotypes were determined at five microsatellite loci: Sm10, Sm11, Sm17

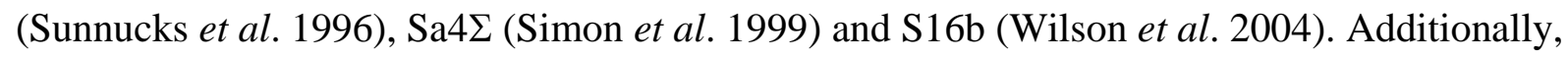
a 6th locus, called Sm12 (Sunnucks et al. 1996), with primers modified by Llewellyn et al. (2003), was applied to a subset of genotypes to compare these with the common genotypes published in Llewellyn et al. (2003). Sm11 is linked to the X-chromosome (Wilson et al. 1997), whereas all the others are autosomal (Simon et al. 1999, Wilson, pers. comm.). Polymerase chain reactions (PCRs) were performed in $10 \mu \mathrm{l}$ volumes containing 0.5 units of recombinant Taq (rTaq TAKARA) polymerase, $\mathrm{Mg}^{2+}$-free reaction buffer, $200 \mu \mathrm{M}$ dNTPs (TAKARA), 5 pmol of each primer (ROTH), 10\% DMSO, $2 \mathrm{mM} \mathrm{Mg}^{2+}$ (as $\mathrm{MgCl}_{2}$ ) and $2 \mu \mathrm{l}$ of the ten fold diluted DNA extract (approx. $2-10 \mathrm{ng}$ ) for Sm17 and $2.5 \mathrm{mM} \mathrm{Mg}^{2+}$ and $5.8 \mu \mathrm{l}$ of DNA extract (5.8 - 29 ng) for all other loci. All PCRs were performed in a BIOMETRA gradient thermocycler with an initial denaturation at $94{ }^{\circ} \mathrm{C}$ for $2 \mathrm{~min}$. This was followed by 
five touch-down cycles (first cycle $7{ }^{\circ} \mathrm{C}$ higher than final annealing temperature) and 29 cycles with denaturation at $94{ }^{\circ} \mathrm{C}$ for $15 \mathrm{sec}$., and annealing of primers at $55^{\circ} \mathrm{C}$ (30 sec) for $\mathrm{Sm} 17$ and $\mathrm{Sm} 10,47^{\circ} \mathrm{C}$ for $\mathrm{Sm} 11$, or $60{ }^{\circ} \mathrm{C}$ for S16b and Sa $4 \Sigma$ respectively. Elongation took place at $72^{\circ} \mathrm{C}$, ending with a $10 \mathrm{~min}$. termination step at $72^{\circ} \mathrm{C}$. Gel electrophoresis with $6 \%$ denaturating polyacrylamide and silver staining was performed as described in Llewellyn et al. (2003). Individuals were removed from the data set (about 3.4\%) when one or more locus was unscorable. In these samples, the DNA was probably degraded or the concentration was too low rather than null alleles being the source of mis-amplification. In some cases, successful amplification was achieved by repeating PCRs up to three times (Massonnet et al. 2002). The number of mutations during PCR being known to increase with allele size (Lai \& Sun 2003), could be partially reduced for alleles with smaller size by using a recombinant Taq.

The term 'clone', as used in this study, refers to a multilocus microsatellite genotype which have been shown to be consistent up to 12 loci with regard to allele and genotype variation within and between population samples (Wilson et al, 1999; Haack et al, 2000; Llewellyn et al, 2004;.Figueroa et al. in press; but see Loxdale \& Lushai 2003a and Lushai et al. 2003 for discussion concerning possible mutation at other regions of the genome in socalled clonal organisms).

\section{Statistical analysis}

Differences between abundance of aphids at different periods or regions were tested using the Wilcoxon Signed Ranks and Mann Whitney U test available in SYSTAT (1998). For analysis of the influence of winter climate on the genetic structure of the total S. avenae population in Germany, all individuals of the same clone were counted only once for analysing deviations from Hardy-Weinberg equilibrium (HWE), linkage analysis and population subdivision (Sunnucks et al. 1997, Simon et al. 1999, Haack et al. 2000, Llewellyn et al. 2003). These tests were performed using the program GENEPOP, version 3.3 (Raymond \& Rousset 1995).

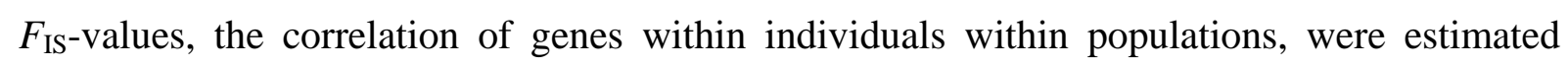
after Weir \& Cockerham (1984). Deviations from HWE were tested against the alternative hypothesis of heterozygote deficit/excess using the score test (U test) with a Markov chain for estimating unbiased $p$-values (Guo \& Thompson 1992). To evaluate the heterogeneity of microsatellite alleles across the sampling landscape and time, we used a nested AMOVA (Analysis of Molecular Variance) with sampling sites collected at two different times nested 
within regions. AMOVA was performed using the program ARLEQUIN (Schneider et al. 2000). For the analyses of genotypic diversity within the parthenogenetic summer population, the entire data set containing all individuals was used.

Genotype diversity was described by the simple measure $k=\mathrm{G} / \mathrm{N}$, where $\mathrm{G}$ is the number of genotypes and $\mathrm{N}$ the number of individuals. Because this index depends on sample size, it was calculated both for the total sample of a region and month $\left(k_{\text {all }}\right)$ and as an arithmetic mean over all $k$-values from single field collections $\left(k_{\text {mean }}\right)$. The squared coefficient of variation $(\mathrm{CV})$ of species abundance measures the degree of heterogeneity among species in a sample (Chao \& Shen 2003a,b). Replacing species by genotypes or alleles, it indicates whether allele/genotype frequency distributions are homogenous or heterogeneous in a sample. In the case of CV-values > 1.0, some genotypes/alleles were probably not included in the sample. This is especially true for genotypes that are frequently newly generated via sexual recombination between years, whereas exclusively asexual lineages are consistent over years. Therefore, a non-parametric estimator of Shannon's index $H_{\text {est }}$ (Chao \& Shen 2003a,b) was used to estimate the diversity of genotypes. To estimate the number of missing genotypes/alleles in a sample, an abundance-based coverage estimator (ACE) was employed. Both estimators are available in the program SPADE (Species Prediction And Diversity Estimation) (Chao \& Shen 2003b). To test whether alleles or genotypes could be compared with species, allele and genotype accumulation curves, i.e. accumulative number of alleles/genotypes vs. accumulative sample size, were performed for both sampling regions and sampling dates. Here, field samples were combined from the two sites with smallest physical distance up to the largest distance within each region and sampling date. In addition, to compare the accumulation of genotypes by increasing distance between fields with genotypic variation between fields independent from geographical distance, the order of accumulated fields was randomised four times.

Differences between genotype frequency distributions in different regions and months were tested by $\chi^{2}$-independence tests. To reduce the number of cells including absolute counts less than an expected value of five, all unique genotypes and genotypes with two individuals were grouped in two frequency classes. The levels of significance were corrected for type I error according to the Dunn-Šidák method for pairwise comparisons (Sokal \& Rohlf 1995).

As previously used by Llewellyn et al. (2003, 2004), multivariate analysis methods were performed to relate clonal genotype to spatial and temporal parameters. In contrast to the aforementioned $\chi^{2}$-tests, unique genotypes were excluded from the analyses, but all genotypes $\mathrm{n}>1$ were included separately. A similarity matrix based on the presence or absence of 
clones at particular sites was constructed using the Jaccard's similarity coefficient (Digby \& Kempton 1987) to test whether the same clones were present in samples from the two main sampling regions, LS and $\mathrm{H}$, and at the two sampling dates. A similar matrix was constructed from the genotype counts, standardised for sample size (dividing no. of aphids per genotype by sample size) from the genotype counts based on a Euclidean similarity coefficient, to test whether particular clones were equally successful at different regions and dates. Each matrix was then analysed using principal co-ordinate analysis, PCO (Digby \& Kempton 1987), to produce a three-dimensional representation of the variance between samples in space and time. As there were only four samples (two regions and months), the data in each case could be completely represented by three PCO axes.

\section{Results}

\section{Aphid abundance}

On average, $<0.5$ individuals per plant were found in both regions and months. There were no significant differences in aphid abundance between regions (June: $\chi_{\text {approx }}^{2}=0.009,1 \mathrm{df}, \mathrm{p}$ $=0.924$ and July: $\left.\chi_{\text {approx }}{ }^{2}=0.713, \mathrm{df}=1, \mathrm{p}=0.399\right)$. Between months in contrast, the number of individuals increased significantly from June to July in both regions (Wilcoxon; region LS: $\mathrm{Z}=+2.201, \mathrm{p}=0.028$ and region $\mathrm{H}: \mathrm{Z}=+2.824, \mathrm{p}=0.005)$.

Table 2 Genotypes in central Germany in 2001. Genotypes with the size of microsatellite alleles for each locus are given in base pairs. Number of collected individuals (n) and their relative abundance [\%]. $\Sigma$ Rare $=$ sum of all other non-unique genotypes, Unique $=$ unique genotypes in the entire data set.

\begin{tabular}{cccccccc}
\hline ID & Sm10 & Sm11 & Sm17 & S16b & Sa4 & n & $\%$ \\
\hline H & 164164 & 144144 & 178178 & 209209 & 162162 & 144 & 12.3 \\
I & 164166 & 144149 & 178179 & 209274 & 168168 & 129 & 11.0 \\
A & 152166 & 144144 & 178178 & 173189 & 156172 & 76 & 6.5 \\
M & 164164 & 144144 & 183183 & 173209 & 162162 & 67 & 5.7 \\
L & 164166 & 144144 & 179179 & 159173 & 162168 & 48 & 4.1 \\
N & 164254 & 148156 & 178179 & 159205 & 162162 & 41 & 3.5 \\
D & 164208 & 144144 & 178178 & 173181 & 156172 & 24 & 2.0 \\
$\Sigma$ Rare & & & & & & 188 & 16.0 \\
Unique & & & & & & 451 & 38.5 \\
\hline
\end{tabular}




\section{Polymorphism of microsatellite loci}

The samples collectively contained 89 different alleles at five loci. Of these, 26 alleles were located at locus Sm10, seven at each of Sm11 and Sm17, 37 at S16b and 13 at Sa4 2 . The accumulative number of alleles reached a maximum dependent on the variability of the different microsatellite loci (Fig. 2).

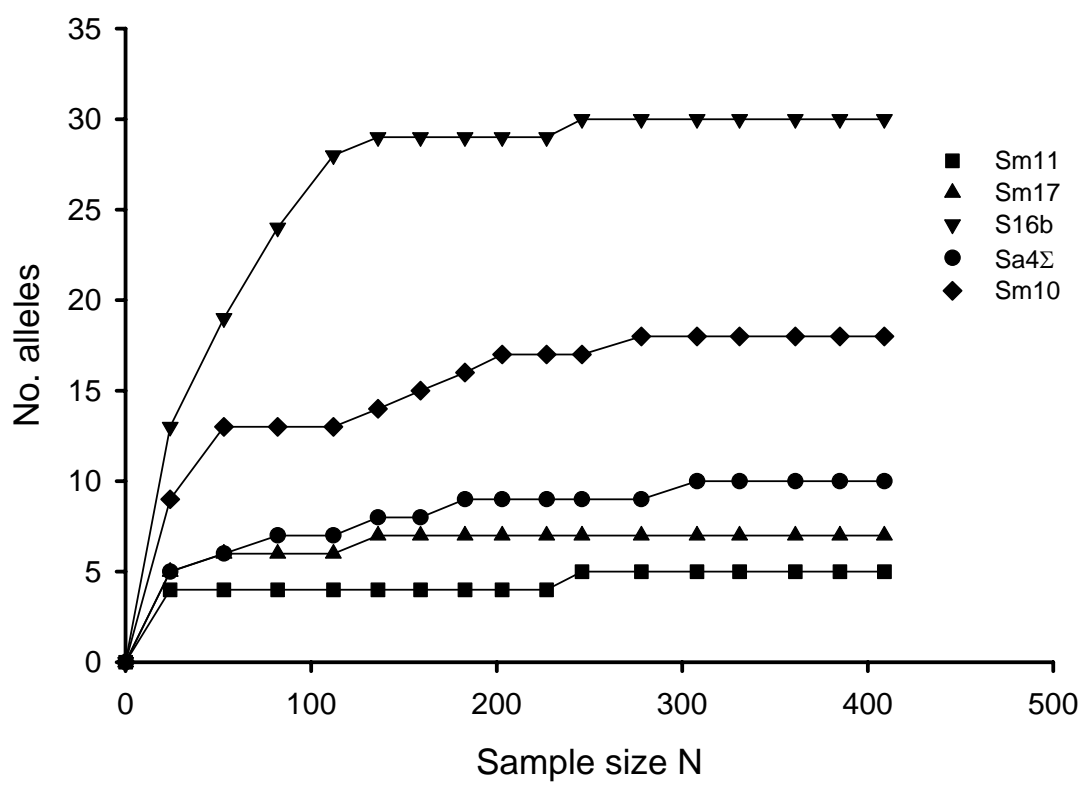

Fig. 2 Accumulative allele curves for five microsatellite loci from region LS in July 2001. Accumulative sample size was achieved by combining field samples by increasing geographical distance between fields.

The accumulative number of alleles combined for five loci was almost identical for all loci between both regions and months of collection (data not shown). Allele numbers were reaching a maximum at a sample size of 300 individuals (Fig. 2). The ACE-estimator indicated that all alleles at the loci $\operatorname{Sm} 11$ and $\operatorname{Sm} 17$ were detected in the sample, whereas 13 further alleles not sampled should also exist at the other loci (Table 1). 
Table 1 Estimation of missing alleles in the total sample of 1172 individuals in central Germany in 2001 using ACE (Chao \& Shen 2003a). CV = coefficient of variation (sample heterogeneity), estimated number of alleles with standard error estimate ( $\left.\mathrm{SE}_{\text {est }}\right)$ and $95 \%$ Confidence interval (CI).

\begin{tabular}{lcccccc}
\hline & CV & estimated alleles & SE $_{\text {est }}$ & CI & $\begin{array}{c}\text { observed } \\
\text { alleles }\end{array}$ & missing alleles \\
\hline Sm10 & 0.717 & 31.7 & 4.8 & $27.3-50.2$ & 26 & 6 \\
Sm11 & 0.000 & 7 & 0 & $7-7$ & 7 & 0 \\
Sm17 & 0.000 & 7 & 0 & $7-7$ & 7 & 0 \\
S16b & 0.476 & 37.5 & 1.9 & $36.2-46.1$ & 36 & 2 \\
Sa45 & 1.061 & 18.1 & 6.1 & $13.8-45.4$ & 13 & 5 \\
\hline
\end{tabular}

\section{Spatial and temporal variation of genotypes}

Seven genotypes with a frequency of $2-12.3 \%$ of the total sample were collected from all regions and both sampling dates (Table 2, Fig. 3) and were found in the majority of fields (74.9 \% $\pm 5.9 \mathrm{SE}$ ). Ten individuals of genotype ' $C$ ' were distributed over both regions and months, but its frequency was $<1 \%$. Each of these genotypes covered a maximum geographic distance between fields from 134 to $167 \mathrm{~km}$. Genotype 'GI' included $1.4 \%$ of all S. avenae adults, but only one individual was found in the region LS, whereas all others were found in region $H$. All other 42 non-unique genotypes were found in frequencies of $<1 \%$ and were unevenly distributed among regions and sampling dates (Fig. 3). Fifteen genotypes were exclusively found in region $\mathrm{H}$ compared with eight in region LS (Fig. 3). Fourteen rare genotypes increased in their spatial distribution from June to July and twelve decreased in the number of occupied wheat fields. 


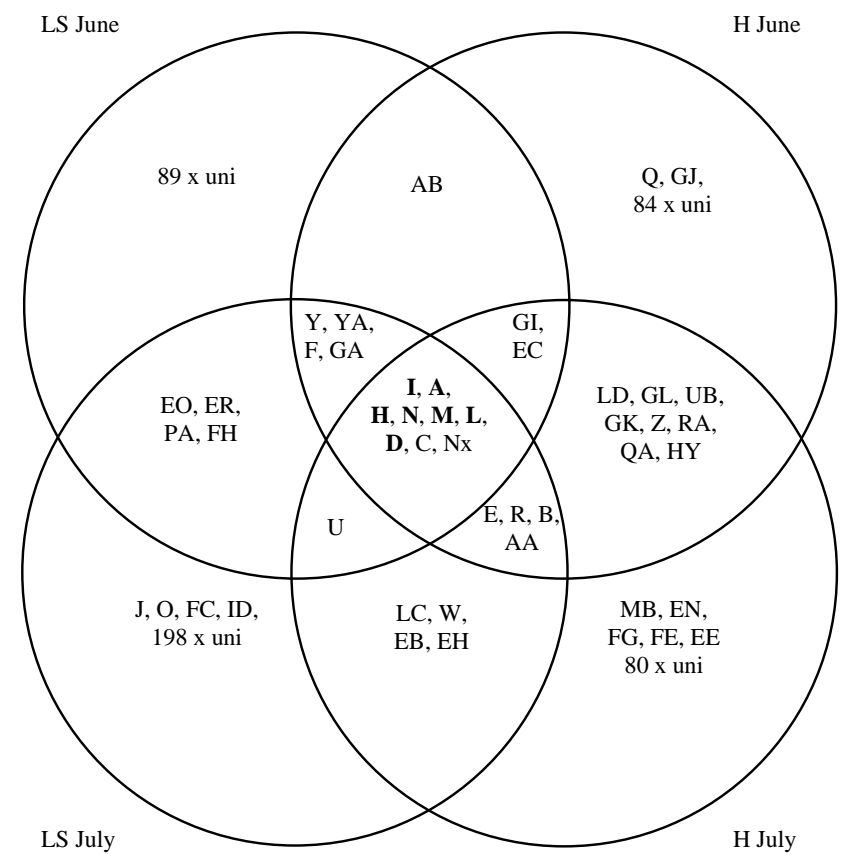

Fig. 3 Venn diagram showing the genotypes present in combinations of different samples in two months and regions (LS, H) in central Germany in 2001. 'uni' = unique genotypes. In addition to the shown combinations, the following overlaps occurred: genotypes ' $\mathrm{HX}$ ' and 'LA' were shared exclusively between region $\mathrm{H}$ in June and LS in July, whilst genotype ' $\mathrm{X}$ ' was shared between region LS in June and H in July. Genotypes with a frequency of $>2 \%$ in the entire sample are highlighted in bold.
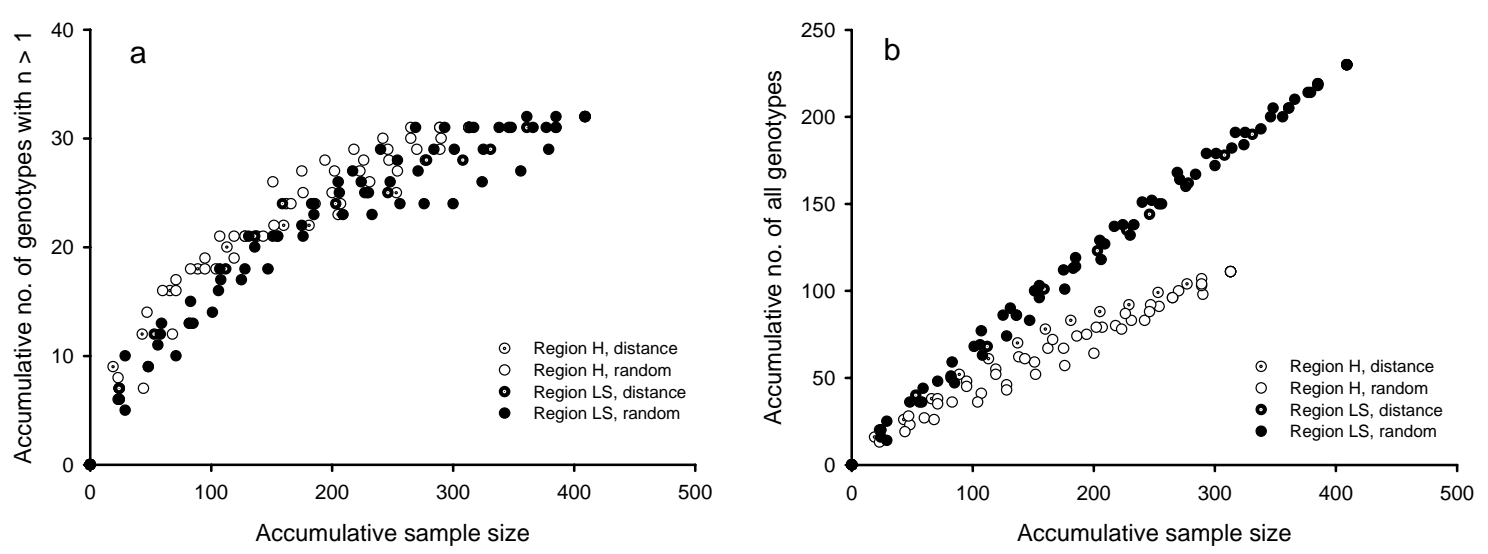

Fig. 4 Accumulative genotype curves for both regions LS and H, Germany in 2001, including exclusively genotypes with more than one individual per genotype in the total sample 2001 (a) and all genotypes per sample (b). The accumulated sample size was achieved by stepwise adding field samples ( $\mathrm{n}=16$ region $\mathrm{LS}, \mathrm{n}=13$ region $\mathrm{H}$ ) either by increasing distance between fields or random (four replicates). 
The accumulative curves of non-unique genotypes (Fig. 4a) indicated a limitation in number of non-unique genotypes by increasing sample size and were almost identical between regions and months (data not shown). The randomised accumulation curves were similar to the accumulative curves with increasing distance between fields, with the exception of region $\mathrm{H}$ in June, where more genotypes were detected at smaller sample sizes than by accumulating fields by increasing distance. The accumulative number of all genotypes, including unique genotypes, was consistent within regions between months (data not shown), but varied between regions (Fig. 4b), as the number of all genotypes in region $\mathrm{H}$ increased less by sample size than that of region LS. In contrast to the accumulation of non-unique genotypes, the increase was almost linear with no approximation to a maximum.

The indicator of heterogeneity of all genotypes within samples (CV) is above the value of 1.0, indicating a high number of missing genotypes in samples, which corresponded to the large number of all genotypes estimated by ACE (Table 3). The estimated number of all genotypes was higher in region LS than $\mathrm{H}$, although the sample size in June was smaller in region LS than in region $\mathrm{H}$. In both regions, genotypic diversity $\left(k_{\mathrm{all}}, k_{\text {mean }}\right)$ decreased from June to July (Fig. 5), but differences were not significant in the case of $k_{\text {mean }}$ (Wilcoxon; region LS: $\mathrm{Z}=-0.943, p=0.345$ and region $\mathrm{H}: \mathrm{Z}=-1.647, p=0.099$ ).

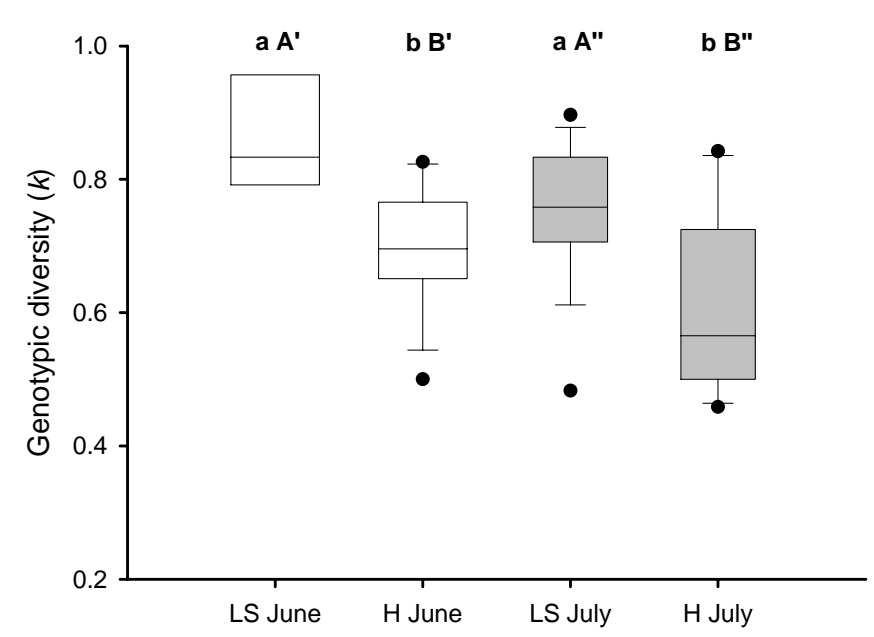

Fig. 5 Box-plots showing the genotypic diversity of $S$. avenae, defined as ' $k_{\text {mean }}$ ' (no. of genotypes / sample size) for both regions and months 2001. Box-plots with different characters to show significant differences in the mean of k-values of all fields collected in a region/month (Wilcoxon tests between months a,b within regions and Mann Whitney $\mathrm{U}$ tests between regions A', B' (June) and A', B', (July) within months). 
The diversity of genotypes was obviously different between regions. The decrease in genotypic diversity measured by $H_{\text {est }}$ and ACE in time was only observed in region $\mathrm{H}$, but not in region LS (Table 3). In addition, a significant higher diversity ( $k_{\text {mean }}$, Fig.5) was observed in both months between regions (region LS vs. H in June: $\chi_{\text {approx. }}^{2}=7.93$; $\mathrm{df}=1, p=0.005$ and in July: $\chi_{\text {approx. }}^{2}=7.66$; $\mathrm{df}=1, p=0.006$ ).

Table 3 Diversity of S. avenae genotypes in central Germany 2001.

The table includes the number of wheat fields $\left(\mathrm{N}_{\mathrm{l}}\right)$, individuals $\left(\mathrm{N}_{\mathrm{i}}\right)$ and genotypes $\left(\mathrm{N}_{\mathrm{g}}\right.$, all all genotypes per sample and $\mathrm{N}_{\mathrm{g}, \mathrm{n}>1}$ non-unique genotypes), $k_{\mathrm{all}}=$ proportion of genotypes in a sample; $\mathrm{CV}=$ estimated squared coefficient of variation of genotypes, $H_{\text {est }}=$ estimated Shannon Index; ACE = estimated number of genotypes in the entire population.

\begin{tabular}{|c|c|c|c|c|c|c|c|}
\hline & $\begin{array}{l}\text { Region } \\
\text { LS June }\end{array}$ & $\begin{array}{l}\text { Region } \\
\text { LS July }\end{array}$ & $\begin{array}{c}\text { Region H } \\
\text { June }\end{array}$ & $\begin{array}{c}\text { Region H } \\
\text { July }\end{array}$ & $\begin{array}{l}\text { Region } \\
\text { LS total }\end{array}$ & $\begin{array}{c}\text { Region } \mathrm{H} \\
\text { total }\end{array}$ & Total \\
\hline $\mathrm{N}_{\mathrm{l}}$ & 7 & 16 & 13 & 13 & 17 & 14 & 31 \\
\hline $\mathrm{N}_{\mathrm{i}}$ & 155 & 411 & 294 & 312 & 566 & 606 & 1172 \\
\hline $\mathrm{N}_{\mathrm{g}, \text { all }}$ & 110 & 233 & 119 & 111 & 325 & 207 & 504 \\
\hline $\mathrm{N}_{\mathrm{g}, \mathrm{n}>1}$ & 22 & 32 & 35 & 31 & 36 & 43 & 51 \\
\hline $\begin{array}{l}k_{\text {all }}\left(\mathrm{N}_{\mathrm{g}} / \mathrm{N}_{\mathrm{i}}\right) \\
\text { all genotypes }\end{array}$ & 0.710 & 0.567 & 0.405 & 0.356 & 0.574 & 0.342 & 0.430 \\
\hline CV & 1.623 & 1.344 & 1.302 & 1.373 & 1.251 & 1.303 & 1.642 \\
\hline $\begin{array}{l}H_{\text {est }} \\
\left( \pm \mathrm{SE}_{\text {est }}\right)\end{array}$ & $\begin{array}{c}5.33 \\
(0.37)\end{array}$ & $\begin{array}{c}5.39 \\
(0.34)\end{array}$ & $\begin{array}{c}4.36 \\
(0.26)\end{array}$ & $\begin{array}{c}4.03 \\
(0.33)\end{array}$ & $\begin{array}{c}5.71 \\
(0.34)\end{array}$ & $\begin{array}{c}4.46 \\
(0.31)\end{array}$ & $\begin{array}{c}5.42 \\
(0.36)\end{array}$ \\
\hline $\begin{array}{l}\text { ACE } \\
\left( \pm \mathrm{SE}_{\text {est }}\right) \\
\text { genotypes } \mathrm{n}\end{array}$ & $\begin{array}{l}1255 \\
(423)\end{array}$ & $\begin{array}{c}3751 \\
(1138)\end{array}$ & $\begin{array}{c}611 \\
(151)\end{array}$ & $\begin{array}{c}594 \\
(156)\end{array}$ & $\begin{array}{l}3913 \\
(950)\end{array}$ & $\begin{array}{l}1335 \\
(271)\end{array}$ & $\begin{array}{c}6520 \\
(1125)\end{array}$ \\
\hline $\mathrm{CV}_{\mathrm{n}>1}$ & 0.937 & 0.806 & 0.681 & 0.726 & 0.414 & 0.457 & - \\
\hline $\begin{array}{l}H_{\text {est, } \mathrm{n}>1} \\
\left( \pm \mathrm{SE}_{\text {est }}\right)\end{array}$ & $\begin{array}{c}2.87 \\
(0.20)\end{array}$ & $\begin{array}{c}2.86 \\
(0.14)\end{array}$ & $\begin{array}{c}2.96 \\
(0.15)\end{array}$ & $\begin{array}{c}2.60 \\
(0.16)\end{array}$ & $\begin{array}{c}2.86 \\
(0.09)\end{array}$ & $\begin{array}{c}2.84 \\
(0.15)\end{array}$ & - \\
\hline $\begin{array}{l}\mathrm{ACE}_{n>1} \\
( \pm \mathrm{SE})\end{array}$ & $\begin{array}{c}37.0 \\
(10.5)\end{array}$ & $\begin{array}{c}63.5 \\
(15.6)\end{array}$ & $\begin{array}{l}45.7 \\
(6.5)\end{array}$ & $\begin{array}{l}42.5 \\
(7.2)\end{array}$ & $\begin{array}{l}40.4 \\
(3.4)\end{array}$ & $\begin{array}{l}47.0 \\
(3.0)\end{array}$ & - \\
\hline
\end{tabular}

Excluding the unique genotypes from the sample, genotypic diversity was rather equal between both regions, except for a lower diversity in region $\mathrm{H}$ in July, (Table 3), showing that unique genotypes mostly contributed to the difference in genotypic diversity between regions. However, not all non-unique genotypes occurred in all regions and months, which was reflected by ACE, indicating that there were more non-unique genotypes present in the field than observed in the sample. 
The frequency distributions of genotypes (Fig. 6) were significantly different between regions (Table 4). Within region LS, no significant differences were found in the distribution of genotypes between months. In region $\mathrm{H}$ however, the frequency of genotypes significantly changed between months (Table 4). This change was caused by an increase in the frequency of genotype 'I' and the decrease of genotype 'A' from June to July. Excluding these two genotypes from the analysis, no differences between the frequency of genotypic classes were observed between time periods in region $\mathrm{H}\left(\chi^{2}\right.$ Pearson $\left.=7.136, \mathrm{df}=6, p=0.308\right)$.
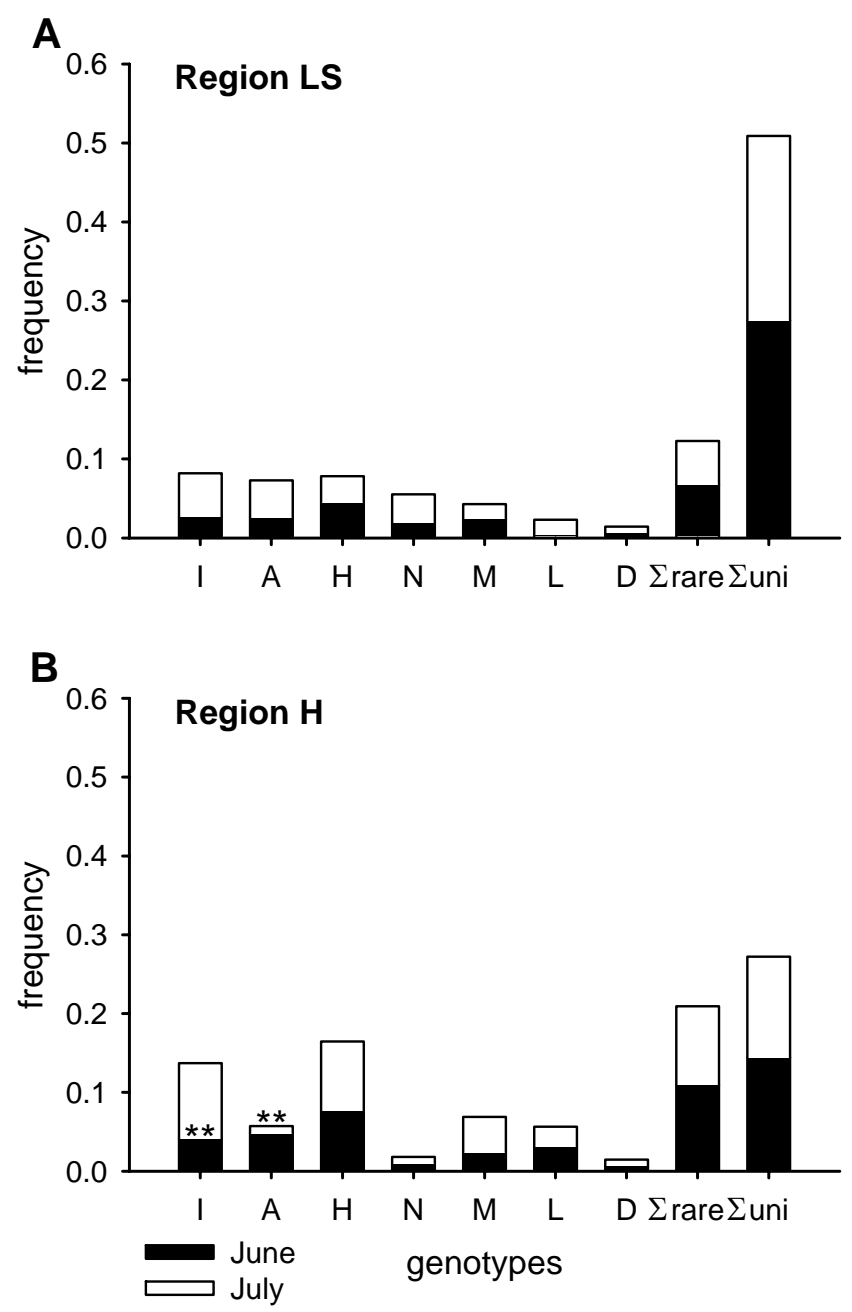

Fig. 6 Frequency distribution of genotypes $(\Sigma$ rare $=$ non-unique genotypes with a frequency $<2 \%$ of the total sample; $\Sigma$ uni = unique genotypes) in two regions in central Germany and relative abundance in June and July 2001. Region LS (Lower Saxony), region H (centre of Hesse). ${ }^{* *}$ significant differences in frequency counts of genotypes between months $p<0.01$. For differences between regions, see Table 4. 
Table 4 Results of pairwise comparisons in genotype frequency distributions ( $\chi^{2}$-tests) between both regions and months.

\begin{tabular}{llll}
\hline & $\begin{array}{l}\text { Region LS } \\
\text { June }\end{array}$ & $\begin{array}{l}\text { Region LS } \\
\text { July }\end{array}$ & $\begin{array}{l}\text { Region } \mathrm{H} \\
\text { June }\end{array}$ \\
\hline $\begin{array}{l}\text { Region LS } \\
\text { July }\end{array}$ & $\begin{array}{l}\chi^{2}=13.98 \\
\mathrm{df}=8\end{array}$ & & \\
& $p=0.082 \mathrm{NS}$ & & \\
Region $\mathrm{H}$ & $\chi^{2}=40.71$ & $\begin{array}{l}\chi^{2}=53.47 \\
\mathrm{df}=8\end{array}$ & $\begin{array}{l}\mathrm{df}=8 \\
p<0.001\end{array}$ \\
June & $p<0.001$ & $p$ & \\
& $\begin{array}{l}\chi^{2}=87.47 \\
\text { Region } \mathrm{H}\end{array}$ & $\begin{array}{l}\chi^{2}=59.41 \\
\mathrm{df}=7\end{array}$ & $\begin{array}{l}\chi^{2}=36.58 \\
\mathrm{df}=8\end{array}$ \\
July & $p<0.001$ & $p<0.001$ & $p<0.001$ \\
\hline
\end{tabular}

Around $75 \%$ of the genotypic variability in similarity matrices was represented in the first two dimensions of the PCO analysis (Fig. 7). The first dimension represents a separation of both regions (44\% and 43\%, respectively, for Jaccard and Eucledian metrics), whilst the second dimension (30\% and $40 \%$, respectively) represented separation in time.

Jaccard metric (presence/absence of genotypes)

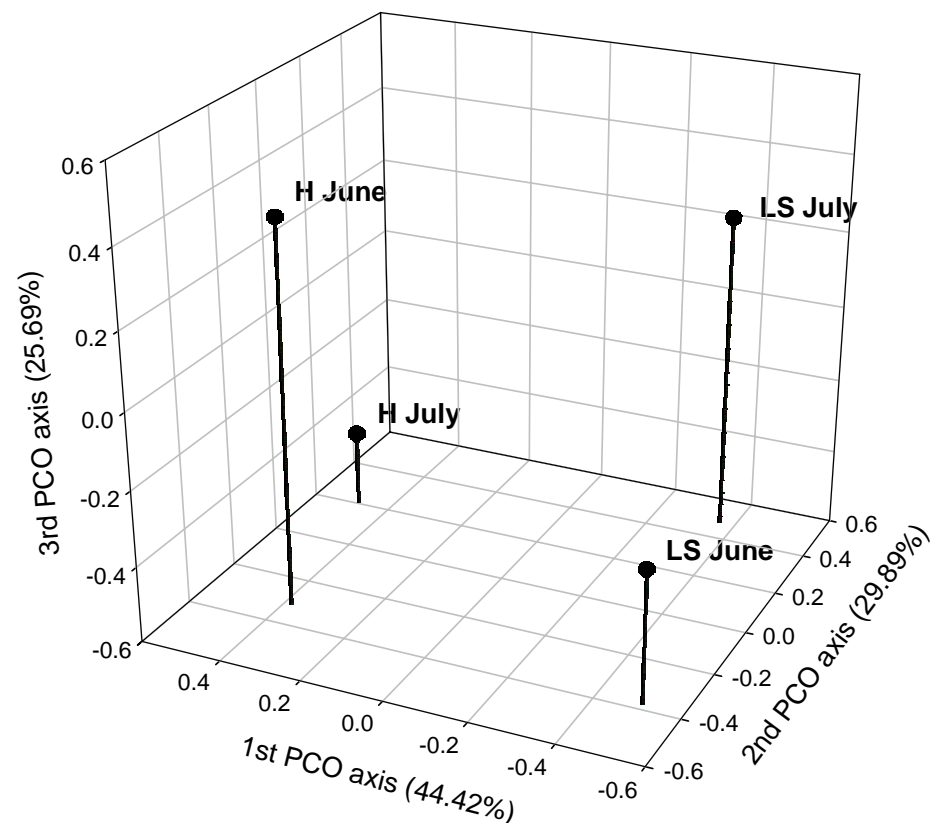

Fig. 7 Principal coordinates analysis of the genotypic similarity matrices based on presence/absence of genotypes in two regions in central Germany (H \& LS) and two sampling dates (mid June and July 2001). 
Significant differences between both regions in allelic variation where shown from the AMOVA results (Table 5). Between collections of both months within each single region, no variation was found.

Table 5 AMOVA results for bi-monthly field samples within two regions (H and LS) in 2001.

\begin{tabular}{lcccc}
\hline Source & df & Percentage of variation & $\Phi$ & $p$ \\
\hline Regions & 1 & 0.35 & 0.0035 & $<0.001$ \\
sites/months & 47 & 0.09 & 0.0008 & $0.117 \mathrm{NS}$ \\
Error & 1623 & & & \\
\hline
\end{tabular}

Genetic structure of German S. avenae populations in 2001

The entire sample of 1172 S. avenae collected in 2001 revealed 504 multilocus genotypes in total. The overall genotype diversity was $k=0.430$ and the estimated Shannon index, $5.42 \pm$ 0.36 SE (Table 4). $F_{\text {IS }}$ estimates were all positive for the loci Sm10, Sm11 and Sm17 and

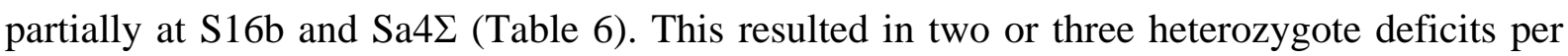
sample. In addition one or two loci showed significant linkage, except in region LS in June. In the total sample of 'one copy per genotype', all loci showed positive $F_{\text {IS }}$ values, as reflected in a significant deficit of heterozygotes. One of ten locus comparisons performed showed significant linkage (Table 6). The subdivision of the total sample into 'non-unique' vs. 'unique' genotypes, however, revealed differences between these groups. The group of nonunique genotypes showed a negative $F_{\text {IS }}$ value at locus S16b and there was no significant deficit in heterozygotes, except at Sm17. Three locus combinations were linked (Sm10 and

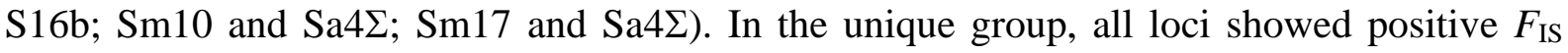
values, a significant deficit in heterozygotes and no linkage disequilibrium between any combination of loci. Heterozygote excess was never significant in any group. 
Table 6 Genetic structure of genotypes in central Germany in 2001. Shown are estimates of Fis (Weir \& Cockerham 1984), tests for heterozygote excess and deficit and number of significantly linked pairs of loci (LD) for the entire sample (total), unique genotypes ( $\mathrm{n}=$ 1) and non unique $(n>1)$ genotypes.

\begin{tabular}{lccccccc}
\hline Tests & LS & LS & $\mathrm{H}$ & $\mathrm{H}$ & Genotypes & Genotypes & \multirow{2}{*}{ Total } \\
& June & July & June & July & $\mathrm{n}>1$ & $\mathrm{n}=1$ & \\
\hline$F_{\text {IS Sm10 }}+0.054$ & +0.170 & +0.026 & +0.030 & +0.182 & +0.085 & +0.094 \\
$F_{\text {IS }}$ Sm11 & +0.062 & +0.087 & +0.105 & +0.164 & +0.101 & +0.076 & +0.086 \\
$F_{\text {IS Sm17 }}$ & +0.244 & +0.223 & +0.209 & +0.336 & +0.392 & +0.205 & +0.229 \\
$F_{\text {IS S16b }}$ & -0.036 & +0.018 & +0.035 & -0.030 & -0.061 & +0.017 & +0.011 \\
$F_{\text {IS Sa4 }}$ & +0.089 & +0.040 & -0.017 & +0.030 & +0.107 & +0.028 & +0.037 \\
H deficit & $2 / 5$ & $3 / 5$ & $2 / 5$ & $3 / 5$ & $1 / 5$ & $5 / 5$ & $5 / 5$ \\
H excess & all NS & all NS & all NS & all NS & all NS & all NS & all NS \\
LD & $0 / 10$ & $2 / 10$ & $2 / 10$ & $1 / 10$ & $3 / 10$ & $0 / 10$ & $1 / 10$ \\
\hline
\end{tabular}

\section{Discussion}

The present data must be viewed in the light of previous studies on the population genetics of Sitobion avenae using molecular markers, viz. allozymes, RAPDs (random amplified polymorphic DNA), synthetic oligonucleotides probes, i.e. (GATA) $)_{4}$ and most recently, microsatellites (see Loxdale \& Lushai 1998 for discussion of these marker types). These various studies show, amongst other things, that this aphid species is highly migratory over large geographical distances (national and international), as deduced from allele frequency/ genetic distance data (Loxdale et al. 1985, Llewellyn et al. 2003, Papura et al. 2003 ). In addition, other aspects to be shown using the molecular markers include: clinal differences in genotype frequency, apparently related to climatic factors at national geographic scales (Simon et al. 1999 Llewellyn et al. 2003; Papura et al. 2003); host plant associations (DeBarro et al. 1995b, Sunnucks et al. 1997, Lushai et al. 2002, Papura et al. 2003) and at a smaller spatial scale, unexplained differences in genotypic composition, possibly related to clonal selection (DeBarro et al. 1995b, Llewellyn et al. 2004). There are contradictory findings in terms of host plant associations (Haack et al. 2000 vs. Papura et al. 2003) and large migration vs. small scale differentiation (Llewellyn et al. 2003 vs. Llewellyn et al. 2004), which therefore necessitate further research into the population biology of this aphid.

In this study, we have extended several of the above observations by the sampling strategy adopted. This involves collecting aphids from a single host (wheat), and spatial 
sampling at two scales, - from field to regional (100+ km apart), but with minimal temporal separation of samples (a few generations' worth of asexual aphid lineages). From the analyses performed, involving 'constants' with regard to host plant and growing season, yet involving a large set of variable locations in two regions, it has here been possible to show that $S$. avenae populations in central Germany are highly heterogeneous in terms of allelic/genotypic composition on a regional level, more than a function of temporal separation, as might be expected by the sampling regime adopted. Clearly from the analyses performed, the population structuring of this aphid species with regard to allelic and genotypic composition is highly dynamic in space, more so than in time.

\section{Polymorphism of microsatellite loci}

The AMOVA analysis shows that number of alleles and their distribution was more different in space than in time. The accumulative allele curves reached a maximum similar to that of accumulative species curves, as recently found by Loxdale \& MacDonald (2004) for the braconid parasitoid wasp, Diaeretiella rapae (M’Intosh). Hence, it is possible to estimate the number of missing alleles in a sample using the species estimator ACE. The estimated number of missing alleles from German wheat field collections indicate that within a sample size of > 1000 aphids, some rare alleles might not be detected at the three variable loci, Sm10 and S16b and $\mathrm{Sa} 4 \Sigma$, but were detectable (by estimation) at loci Sm11 and Sm17. The sample size and number of alleles detected in this study were compared with a previous study in France (Haack et al. 2000), with the exception of locus S16b, which was not examined in this earlier study. The present study included a 26.0\% larger sample size (1172 to 867 individuals) and showed a $23.1 \%$ increase in the number of alleles compared with that found by Haack et al. (2000), i.e. 52 to 40 alleles. Therefore, it may be concluded that differences in sample size mostly contribute to the different numbers of alleles found in both studies. It is noteworthy that the number of alleles is not higher in the French collection, although it included different host plants (maize, Zea mays, wheat, wheat volunteers and barley, Hordeum vulgare).

\section{Spatial and temporal variation of genotypes}

Genotypic and allelic structure was clearly separated between regions. To begin with, the number of genotypes shared between regions was less than between months. Secondly, the genotypic diversity measured by $k_{\text {all }}, k_{\text {mean }}, H_{\text {est }}$, ACE and accumulative curves of all 
genotypes was larger in region LS than in region $\mathrm{H}$, mainly due to differences in the frequency of unique genotypes between regions. Thirdly, $\chi^{2}$-tests of genotype classes and the results of the PCO-analyses of genotype similarity matrices indicated that populations were separated more in space than in time, although region- specific short term changes in genotypic distribution occurred, i.e. clone 'A' and 'I' showed significant contrary changes in frequency in region $\mathrm{H}$ between June and July, but not in region LS ( $\chi^{2}$-test), and that genotypes with were represented by two individuals in the entire sample, contributed to a differentiation between months within a region. Lastly, the accumulative curves of nonunique genotypes showed, in contrast to region LS, that the distribution of non-unique genotypes in region $\mathrm{H}$ in June was dependent on geographical distance. This is because the randomised accumulative curves in region $\mathrm{H}$ in June did not fit to the accumulative curve over distance. This observation demonstrates the heterogeneous distribution of non-unique genotypes at single locations in region $\mathrm{H}$ in June, and which disappeared in July, revealing a homogenisation of genotypes within this region.

Temporal changes in abundance and genotypic distribution were observed even within two to four generations of aphids. The abundance of individuals increased from June to July indicating a proliferation of clones due to parthenogenesis. As expected as a result of such parthenogenetic proliferation of clones during the spring and summertime, the estimated Shannon index $\left(H_{\text {est }}\right)$ declined and the number of genotypes in a sample $(k)$ decreased from June to July. However, genotypes varied in terms of their frequency (especially the contrary development of genotype 'A' and ' $I$ ' in region $H$ ) and spatial distribution, shown from the observation that one half of all genotypes spread out in space within the observed period, whereas the other half decreased in the number of occupied fields.

These findings are contrary to the expectation that all clones should proliferate equally during summertime and should spread equally in space. A similar contrary shift in genotype reproduction rates was found in the rosy aphid, Macrosiphum rosae (L.), revealed using allozymes (Tomiuk \& Woehrmann 1981). The authors argued that this shift was density dependent. In the present study, however, we showed that genotypic presence and contrary frequency shifts were different between regions, although aphid abundance increased in both regions in time.

Selection, migration or behavioural differences of genotypes that differed in both regions under study may explain these changes in genotypic distribution. Clonal selection in summer populations of S. avenae was recently advocated (Llewellyn et al. 2004) and in this particular study, there was no obvious relationship between genotypic variance and geographic distance 
between collection sites, i.e. environmental forces may act on genotypic diversity. In the present study, the accumulative genotype curves and all statistical tests performed on genotypic diversity indicate differences of genotypic diversity between both regions rather than differences between both months of collection. Thus different environmental forces appear to act on $S$. avenae population genetic structure in both regions, and are more substantial than short-term changes within two to four asexual summer generations. On the field scale, local differences in insecticide applications or accumulations of predators and parasitoids (Schmidt et al. 2003), could have resulted in a mosaic of local extinctions, from which some genotypes might have suffered more than others. The decrease of certain genotypes in wheat fields could also be the result of directional migration to other host plants, as differential host-plant preference have been previously shown for S. avenae using

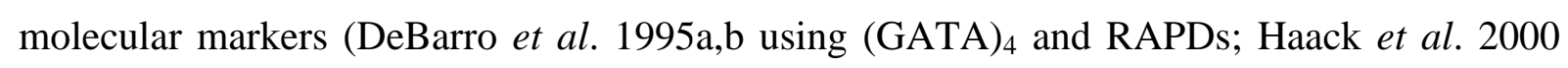
using microsatellites, and Lushai et al. 2002 using RAPDs). The two common genotypes in maize collected in France (Haack et al. 2000) were not detected in our survey on wheat. We assume that the genotypes that increased in frequency and distribution from June to July successfully proliferated on wheat. Whether or not these particular genotypes were specialised on this host plant or were in general more successful when reproducing asexually during the growing season is currently the topic of further research.

Beside the forces acting on proliferation, selection and migration of asexual reproducing genotypes during the summer, differences in genotypic diversity between regions may well be the result of different genotype composition at the beginning of the growing season. Although both regions were located in central Germany and were supposed to be similar in climate, minor differences in winter climate at both regions could have contributed to the observed regional differences in genotypic diversity and genetic structure of both subpopulations, respectively. To demonstrate this and show which genotypes were consistent over years by asexual reproduction, a comparison of the influence of winter climate upon aphid population dynamics during summertime over several consecutive years would be necessary. The numerous individuals with a unique genotype occurring exclusively in July may have been too rare to be detected in previous samples, or were the result of ongoing immigration. The simultaneous occurrence of unique and non-unique genotypes indicates coexistence of different life-cycles within regional populations of $S$. avenae. To estimate, whether holocyclic and facultative parthenogens coexist in Germany, the genetic structure of the populations collected in 2001 were analysed. 


\section{Genetic structure of German S. avenae populations}

It is assumed that a cold winter climate, as found in Germany, lead to the predominance of sexual recombination and hence, a highly genetically diverse $S$. avenae population (Weber 1985, Dedryver et al. 2001). Clearly, the preceding autumn/winter life cycle (i.e. sexual with eggs or asexual overwintering nymphs in mild winters) contributes to the genotypic composition the following spring and thereby, is the basis for the observed genetic diversity seen during the field growing season. Although the winter in central Germany 2000/2001 is comparatively colder than in the UK (see Llewellyn 2000 for meteorological values given for the late 1990s), both studies reveal similar genotypic diversity as measured by ' $k$ ' and shared two common clones (Llewellyn et al. 2003, present study). This indicates that $S$. avenae was able to reproduce asexually even under the colder climate conditions in Germany.

In theory, anholocyclic clones could migrate to central Germany from regions with mild winters, as similarly proposed in North America for the corn leaf aphid, Rhopalosiphum maidis (Fitch) ('northward migration hypothesis'; see Irwin \& Thresh 1988). Weber (1985) demonstrated in laboratory experiments that $S$. avenae from the Rhine Valley in southern Germany included 20\% of anholocyclic clones, suggesting there could be a migration from the Rhine Valley to central Germany. Yet in the present study, the broad and even distribution of the common S. avenae clones within and between both regions examined makes it less likely that they were immigrants to all locations in both regions simultaneously in 2001. Rather, they had more likely survived the previous winter. As genotypes 'I' and 'A' showed high genetic similarity to the most two common genotypes found in England (genotypes that had also had been found in France; Llewellyn et al. 2003, present study), these two genotypes, at least, appear to have a European wide distribution and are consistent in appearing over different years, so that we consider them to be anholocyclic or at least facultative parthenogens.

The genotypic diversity of the total German population in 2001 was intermediate between those found for holocyclic S. avenae populations from Romania with harsh winters and France with mild winters (Papura et al. 2003). Similar $k$ values as found for the German $S$. avenae population, were earlier reported from asexual populations of the host-alternating species, the bird cherry-oat aphid, Rhopalosiphum padi (L.), on its secondary host Poaceae, whereas sexual populations of this species on its primary woody host bird cherry, Prunus padus, included only unique genotypes (Delmotte et al. 2002).

These comparisons provide conflicting evidence against the belief that German S. avenae populations should be predominantly holocyclic, i.e. with sexual phase. Instead, such 
populations have both genotypes with sexual and obligate asexual life cycles. To support these observations, we analysed the genetic structure of unique and non-unique genotypes. It is more likely that facultative parthenogens survive the winter as numerous individuals sharing the same genotype, whereas in sexual lineages, a single fundatrix with a unique genotype hatches from each sexual egg in springtime. In contrast therefore, although all of these genotypes proliferate parthenogenetically during the spring and summertime, and it may be assumed that the group of unique genotypes found in summer is more likely to include clones with sexual life cycles than those occurring in subpopulations as more than one individual per clone, and which include predominantly facultative parthenogens. Even so, the possibility cannot be excluded that some clones, the product of sexual reproduction, have proliferated well and occur in more than a single case, nor on the other hand, that anholocyclic clones are less abundant and therefore detected as unique clones.

The data set of non-unique genotypes show no heterozygote deficit at four of five loci, and three of ten pairs of loci were significantly linked, indicating that non unique genotypes included a higher proportion of asexual clones. The group, comprising unique genotypes, had significant heterozygote deficits and no linkage between all pairs of loci. Heterozygote deficit and no linkage between alleles of different loci was reported from sexual $S$. avenae populations in Romania (Papura et al. 2003) and sexual R. padi in France (Delmotte et al. 2002), whereas $S$. avenae populations from France showed a heterozygote excess with five of ten pairs of loci linked (Papura et al. 2003). Furthermore, a recent study on the peach-poato aphid, Myzus persicae (Sulz.), using microsatellites and experimental determination of reproduction modes (Vorburger et al. 2003) proved that clonal diversity increased with the proportion of cyclical parthenogens in a sample because they tended to have unique multilocus genotypes, whereas many obligate parthenogens were clonal copies.

Discovery of a population heterozygote deficit is an indicator for population substructuring, inbreeding or selection. The high migratory potential of S. avenae should diminish population subdivision, certainly over the longer term, i.e. several field seasons. Inbreeding of sexual forms on the other hand, is brought about by assortative mating, which has not been reported for S. avenae so far (Papura et al. 2003). If host plant preference leads to distinct subpopulations, inbreeding could theoretically happen on some hosts with a restricted distribution. Further field and laboratory studies are needed to test this assumption.

Clonal selection acting on the parthenogenetic generations through the growing season could reduce the number of genotypes contributing to the sexual generation in autumn. Heterozygote excess was reported from asexual lineages of S. avenae in France (Papura et al. 
2003 and references therein). In contrast, a heterozygote excess was not observed in either unique or common genotypes in Germany. As heterozygote deficit was common, but heterozygote excess absent in German populations, we conclude that both sexual and asexual lineages coexist in Germany during the particular year of study.

In conclusion, this study clearly supports the hypotheses that population differentiation at small spatial scales within a single host plant is of significance in shaping population structure during the crop growing season. The spatial differences are more important than small temporal differences observed within a few weeks (i.e. aphid generations) during the peak abundance of the aphid. To throw further light on the life cycles and consistency of single genotypes, and the factors involved in this spatial structuring process, including the dynamics of aphid movement and migration, additional studies are required. This of necessity needs to involve analyses of landscape structure of regions different in genotypic and allelic variation and sampling from consecutive field seasons. Such studies should enable the influences of environmental forces as landscape structure (consistent over years) and winter climate (i.e. life cycle composition changing in colder regions between years) on population structure within growing seasons to be compared and elucidated.

\section{Acknowledgements}

This work was supported by the German Ministry of Education and Science (BMBF). We are especially grateful to Steven Lockton for technical advice, Dr. Alex Wilson for kindly supplying primer S16b and Prof. Dr. Anne Chao for providing the program SPADE. We are also especially grateful to Drs. Ian Denholm, Charles Dedryver and Jean-Christophe Simon for their helpful comments on the manuscript, which have greatly improved the paper. 


\title{
Clonal diversity of the grain aphid, Sitobion avenae $(F$.) in relation to landscape structure
}

\author{
Lars REIMER ${ }^{1}$, Hugh D. LOXDALE ${ }^{2}$, Stefan VIDAL ${ }^{1}$ \\ ${ }^{1}$ Institute of Plant Pathology and Plant Protection, Goettingen University, Grisebachstrasse 6, 37077 \\ Goettingen, Germany; ${ }^{2}$ Plant and Invertebrate Ecology Division, Rothamsted Research, Harpenden, \\ Hertfordshire, AL5 2JQ, UK
}

\begin{abstract}
Five polymorphic microsatellite markers were used to study the population genetic structure and genotypic diversity of the grain aphid, Sitobion avenae (F.), in relation to landscape structure over two consecutive years involving examination of genotype frequency changes within a season. Sampling was performed in a hierarchical regime from field to region scale. Landscape structure surrounding each study site was analysed by the percentage area of major land-use types, as well as the height profile at different scales. The study revealed seven common multilocus genotypes with a wide distribution over all fields in three regions studied in both years, but varying in frequency within a season and between regions different in landscape structure and separated by $>100 \mathrm{~km}$. No evidence was found that these results were caused by insecticide application. The random genotypic diversity and population genetic structure within regions of $<50 \mathrm{~km}$, and the significant influence of large scales of surrounding landscape on genotypic diversity within fields, is suggestive of the homogenising effects resulting from local aerial migration of aphids. However, locations in hilly landscapes showed a higher consistency of genotypes during summer time, showing that the majority of individuals flying at low altitudes are limited in terms of their range of spread. This was reflected in temporary isolation of populations between regions that differed in landscape structure.
\end{abstract}




\section{Introduction}

Diverse agro-ecosystems with complex landscape structure can contribute to a reduction in pest populations, mainly as a result of an enhanced diversity of natural biological control agents (predators, parasitoids and pathogens) stemming from the increased habitat heterogeneity (Russell, 1989; Thies and Tscharntke, 1999). This being so, studies integrating landscape scales are necessary to identify key factors of the environment that influence single species (Kareiva and Wennergren, 1995). In the recent past, several studies have focused on the influence of landscape at larger scales on species diversity and abundance with special regard to habitat fragments (Tscharntke et al, 2002). In order to assess intraspecific diversity, the introduction of molecular DNA markers like microsatellites have proven to be a powerful approach, more especially in terms of resolving ecological and evolutionary interactions at the finest level of population structuring and dynamics (Goldstein and Schlötterer, 1999). Such approaches have also revealed the effects of landscape structure on population genetic structure, more especially in relation to the influence of dispersal rates (e.g. Keyghobadi et al, 1999). However as yet, most studies were performed on beneficial or endangered species, whereas virtually nothing is known about how landscape structure acts upon on intra-specific diversity in a pest insect species.

In the present study, the genetic diversity of the grain aphid, Sitobion avenae (F.), an abundant pest species of cereal agro-ecosystems (Vickerman and Wratten, 1979), was analysed with regard to landscape heterogeneity. Parthenogenetic organisms like aphids include two levels of intraspecific variation on which environmental factors could possibly act. These are at the clonal (= multilocus genotypic) level, i.e. the development and spatial and temporal dispersal of genetically identical or more realistically, genetically very similar individuals (Loxdale and Lushai, 2003a), and secondly, the population genetic structure, i.e. the frequency and composition of genetic structure within and between these subpopulations.

In several aphid species, cyclic parthenogenetic (=holocyclic) lineages co-exist with obligate parthenogenetic (= anholocyclic) ones, whilst parthenogenetic lineages that produce a minor proportion of sexuals or males only are also known for some species, including $S$. avenae (i.e. intermediate and androcyclic forms, respectively; see Wilson et al, 2003; Simon et al, 2003 for details). Studies on aphids using molecular markers have revealed that winter climate determines the patterns of geographic parthenogenesis on nation-wide scales, as frostresistant eggs from the annual sexual generation survive in cold climates, whilst parthenogenetic and viviparous frost-susceptible lineages dominate in areas with mild winter 
conditions (Dedryver et al, 2001; Simon et al, 2002; Papura et al, 2003; Llewellyn et al, 2003). Even so, winter climate is seemingly not alone in shaping different patterns in genotypic diversity and the population genetic structure observed at a regional or field scale (Dedryver et al, 2001; Vorburger et al, 2003). Furthermore, isolation by distance effects have been demonstrated for $S$. avenae at large (international) scales (Loxdale et al, 1985), whilst significant differences have also been found between regions (Papura et al, 2003), or even at the field scale (Llewellyn et al, 2004), results that could not be explained by geographic distance alone. Such differences may well be due to landscape heterogeneity, involving factors including climate, host plants and aphid life cycle type, and mark the basis of this study.

The geographic scale that influences individuals or populations of herbivorous insects largely depends on the ability of the species in question to migrate along with the distribution of their host plants (e.g. Westphal et al, 2003). Whilst aphid species with restricted or narrow, discrete habitats, for example the tansy aphid, Macrosiphoniella tanacetaria (Kaltenbach) (Massonnet et al, 2002) and the blackberry-grain aphid, Sitobion fragariae (Walker) (Loxdale and Brookes, 1990), are thought not to be very migratory as shown from molecular genetic studies, other aphids like S. avenae appear to be highly migratory, as inferred from both its peak abundance in 12.2. $\mathrm{m}$ suction traps as well as from molecular genetic data (Woiwod et al, 1988; Loxdale et al, 1985). Such migratory flight behaviour and ability should, at equilibrium, lead to a homogenous allelic population structure over large distances as a result of continuous gene flow between populations, assuming the forces of migration are greater than the locally differentiating forces of selection and drift.

To test these assumptions, we compared the population genetic structure of $S$. avenae field populations within and between regions in Germany. In addition, each field surrounding landscape structure was analysed at different spatial scales. As flight activity is at maximum during the summer, we compared the consistency of particular aphid genotypes in single fields at different times with the elevation profile of the field surrounding landscape to estimate whether landscape structure could influence the migration dynamics of a highly aerially-mobile species. In effect, and very differently from previous studies investigating the population biology of cereal aphids, especially S. avenae, with other parameters such as latitude and climate (e.g. Llewellyn et al, 2003), we hypothesised that patterns in intraspecific variation that are consistent over years might be explained by constant environmental conditions such as landscape structure rather than annual changing variables like winter climate conditions. Therefore, we have used a hierarchical sampling regime including both 
field and regional scale for two and three collections during summer time over two consecutive years to test whether landscape structure can indeed explain patterns in genotypic diversity, population genetic structure and aerial migration. Agronomic traits and the complexity of landscapes surrounding a large number of winter wheat fields were used in order to elucidate the population parameters in relation to environmental heterogeneity. As winter climate is known to effect genotypic diversity (see above), field populations in two regions of central Germany with similar climate were compared during the summer growing season when all S. avenae life cycle types reproduce asexually (Simon et al, 2002). A third region from northern Germany was also included to investigate whether a more geographically-distant region, but with a comparable landscape structure, would reveal a different genotypic diversity or population structure. The local treatment of wheat fields by insecticide applications was also included as a component potentially influencing the clonal diversity.

\section{Materials and Methods}

\section{Aphid sampling}

S. avenae adults were collected from 31 wheat fields (Triticum aestivum L.) sampled in two regions in central Germany (Lower Saxony (LS) 51 ${ }^{\circ} 32^{\prime} \mathrm{N}, 9^{\circ} 55^{\prime} \mathrm{O}, \mathrm{n}=17$ fields and Hesse (H) $50^{\circ} 46^{\prime} \mathrm{N}, 8^{\circ} 32^{\prime} \mathrm{O}, \mathrm{n}=14$ fields, Figure 1) and from a single location in Northern Germany (Hamburg, NG, N 53 27’, 10²' E) in 2001 and from a sub-sample of 12 fields in 2002. All aphids were collected in cereals during the summer around the maximum abundance of this aphid species, and including the period of flight activity.

In the first year of the study, a total of 1172 individuals were collected from central Germany from mid-June 2001, when plants were fully flowering (7 fields LS and 13 fields $\mathrm{H}$ ), and on a second occasion during the period mid-July 2001 (16 fields region LS and 13 fields region $\mathrm{H}$ ) when plants were at the milky ripe growth stage. In addition, 67 and 25 individuals were collected from region NG at the end of June and mid July 2001, respectively. In the following year, 562 aphids were sampled in central Germany at the beginning of June at the stage of ear development (in the following text, labelled 'June I'), end of June at milky ripe growth stage (labelled 'June II') and during mid-July 2002 at the begin of plant senescence, including five fields in region $\mathrm{H}$ and seven fields in region LS. From northern Germany (region NG), a single collection of 92 individuals was made on the 23 June 2002. 


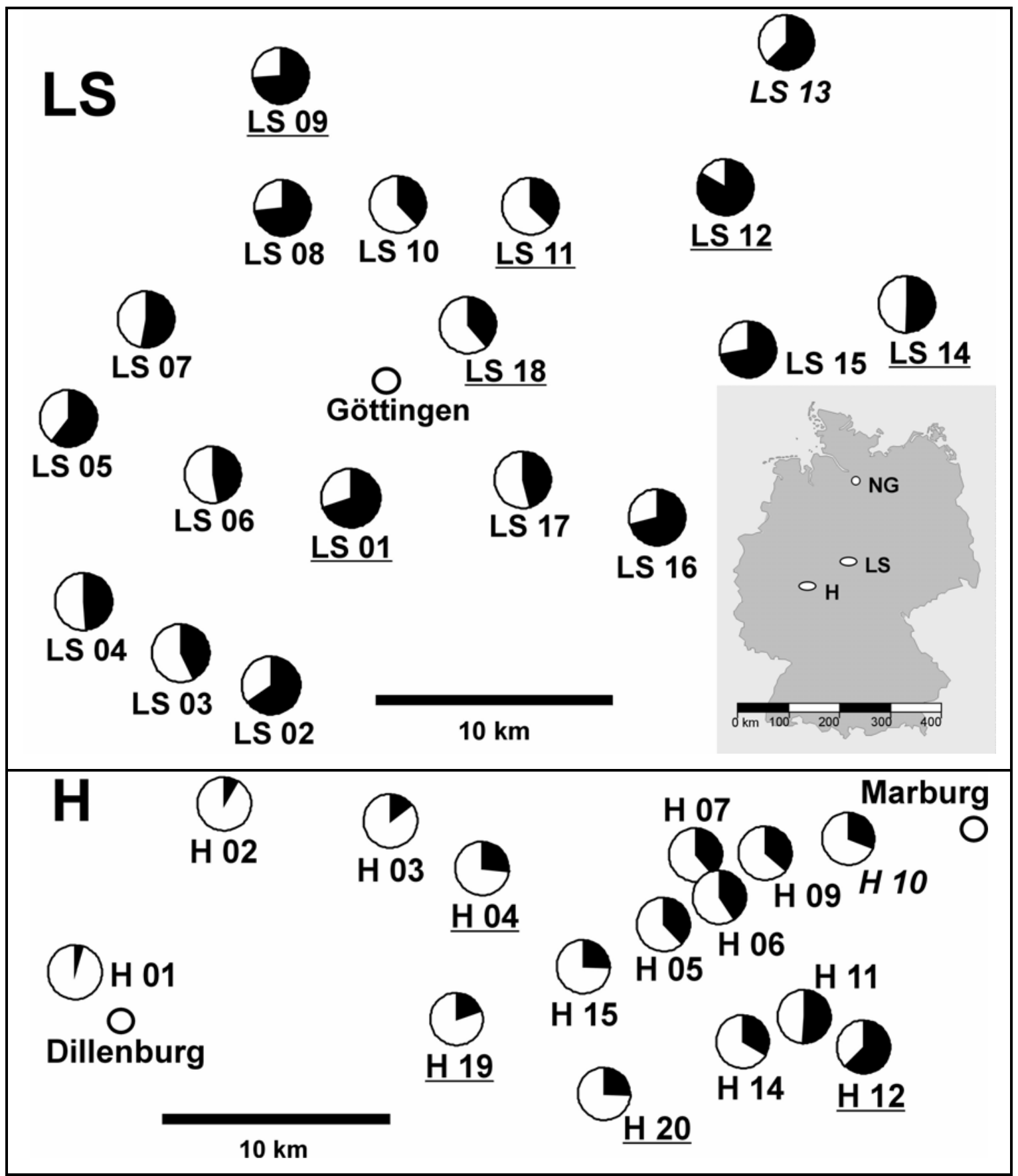

Fig. 1 Locations of wheat fields studied in northern Germany (NG, single wheat field, $60 \%$ arable land) and central Germany (region Lower Saxony, LS, N = 18 and region Hesse, H, N = 15). For locations in central Germany, the relative amount of arable land (black colour) is shown at a scale of $4 \times 4 \mathrm{~km}$. All fields were sampled in 2001 (except those exclusively sampled in 2002 named in italics) and a sub-set was sampled in both years (underlined).

Each field sample, defined as a 'population', included between 19 and 36 individuals (24 \pm 3.4 SD on average) that were scored for both alleles and genotypes. These individuals were taken from sweep-net samples along transects through the centre of the field along field rows, 
excluding the outer margins by at least three metres. A distance of at least two metres was kept between sample units. From each unit, in order to minimise re-sampling of individuals of the same clone and hence, obtain a representative sample of the genetic variance present, only one adult female S. avenae was chosen at random. All individuals were stored at $-20{ }^{\circ} \mathrm{C}$ prior to DNA extraction (see below). Aphid abundance was estimated for all fields in central Germany by counting 8 x 5 shoots, excluding outer field margins.

\section{Geographic distance and landscape structure}

The geographical distance between fields varied between 2 - $39 \mathrm{~km}$ within a region (Figure 1), and between $106-168 \mathrm{~km}$ between regions in central Germany. The field in northern Germany (NG) was separated from central German regions by 216 km (LS) and 318 km (H), respectively.

Data on land-use was derived from the official German land-use database (ATKIS, Amtliches Topographisch-Kartographisches Informationssystem; Hessische Verwaltung für Regionalentwicklung, Kataster und Flurneuordnung, Wiesbaden and Landesvermessungsamt \& Geobasisinformationen Niedersachsen, Hannover). Land-use data for the region in northern Germany was kindly provided by Dr. Andreas Rinker (Hamburg). ATKIS data were transformed into a $20 \mathrm{~m}$ grid and reclassified to six land-use types: arable land, grassland, forest, settlement, water, and 'others'. Study sites were selected using the computer-aided sampling and landscape characterisation tool, CAS (CAS: ENVIRO, http://www.geoextend.com) to obtain a reproducible and representative selection of wheat fields differing in a defined surrounding landscape structure (Behrens et al, 2001). From the transformed ATKISdata, quadratic landscape sectors surrounding each of the study sites were analysed at different spatial scales ranging from $250-4000 \mathrm{~m}$ in increments of $250 \mathrm{~m}$ in 2001, and from $500-4000 \mathrm{~m}$ in increments of $500 \mathrm{~m}$ in 2002. At all spatial scales, the percentage cover of the major land-use types (arable land, grassland, forest) was calculated. The perimeter-area ratio (L-PAR), described the ratio of size and shape of all areas with distinct land-use. In addition, a data base on topography was used, derived from the 'Digital Elevation Model' (DEM; Hessische Verwaltung für Regionalentwicklung, Kataster und Flurneuordnung, Wiesbaden; Landesvermessungsamt + Geobasisinformationen Niedersachsen, Hannover, Germany). From this database, the mean height-profile ('mean slope') was calculated for landscapes in central Germany. The slope was assessed as the first derivation of a surface calculated as mean slope of the vertical and horizontal axis of the DEM. The calculation 
followed Horn (1981). Digital terrain analysis and further GIS work was performed using CAS and ArcView 3.2 (ESRI).

The regression analyses of all 4000 x 4000 m landscape squares of all fields sampled in central Germany, revealed that the parameter 'amount of arable land' showed a highly significant negative linear relationship to all other parameters $\left(F_{1,27}=26.73-102.89\right.$, all $P<$ $0.001, r^{2}=0.498-0.792$, Power $>0.80$ ) which in turn showed a highly significant positive linear relationship among each other $\left(F_{1,27}=11.05-64.43\right.$, all $P<0.01, r^{2}=0.290-0.705$, Power $>0.80$ ). Despite the strong correlation of landscape variables, the order of single field locations along the gradient of landscape complexity was not completely fixed, so that single regression analyses could vary dependent of the landscape variable included.

The amount of arable land between single locations ranged from $4.9-83.4 \%$ in 2001 and 16.2 - $84.6 \%$ in 2002 of the total area in a 4000 x $4000 \mathrm{~m}$ square. Detailed land use data were available for the landscape surrounding the 17 studied wheat fields in region LS. The area covered by grain was $64.2 \% \pm 12.3 \mathrm{SD}$ (2001) and $69.2 \% \pm 4.5 \mathrm{SD}$ (2002) on average of the total area of arable land in a landscape sector with a $3000 \mathrm{~m}$ radius, followed by oilseed rape crops, Brassica napus L. (13.3 \% $\pm 6.1 \mathrm{SD} ; 16.7 \% \pm 6.5 \mathrm{SD})$ and sugar beet, Beta vulgaris L. (7.1 \% $\pm 5.2 \mathrm{SD}$; $8.5 \% \pm 6.5 \mathrm{SD})$. The area of arable land with grain crops was significantly positively correlated with the total amount of arable land (2001: $F_{1,17}=49.60, P$ $<0.001, r^{2}=0.756$, Power $=0.990 ; 2002: F_{1,6}=170.3, P<0.001, r^{2}=0.971$, Power $=$ 0.999). Detailed information about crops in region $H$ were not available, but interviews with farmers showed that grain was the preferred crop, followed by oilseed rape, because of the rather poor soil quality in this region. Because not all sites were sampled in all months and years due to fluctuating aphid abundance, fields were chosen to cover a similar gradient in landscape structure in all collections performed and with the means of landscape parameters around all sites sampled being comparable between collections. The average ratio of arable land of all studied landscapes was almost identical in region LS in 2001 (June: $54.7 \% \pm$ 14.7SD; July: $57.8 \pm 15.0$ ) and 2002 (June I: $54.9 \pm 15.4$; June II: $51.7 \pm 22.2$; July: $63.5 \pm$ 24.5). Within region $H$, the ratio of arable land was also consistent over all collections between 2001 (June: $30.2 \pm$ 16.5; July: $30.8 \pm 16.5$ ) and 2002 (June I: $33.2 \pm 20.5$; June II: $35.6 \pm 18.4$; July: $33.9 \pm 20.1$ ). The difference in the amount of arable land between both central German regions was mainly caused by a larger amount of grassland and forests in region $\mathrm{H}$ (available from ATKIS-Data). 


\section{Microsatellite genotyping}

DNA was extracted from individual aphids following the 'salting out' protocol of Sunnucks and Hales (1996). Genotypes were determined at five microsatellite loci: Sm10, Sm11, Sm17, Sa4 $\Sigma$ and S16b (Wilson et al, 2004). Polymerase chain reactions (PCRs) were performed in $10 \mu \mathrm{l}$ volumes containing 0.5 units of recombinant Taq (rTaq TAKARA) polymerase, $\mathrm{Mg}^{2+}$ free reaction buffer, $200 \mu \mathrm{M}$ dNTPs (TAKARA), 5 pmol of each primer (ROTH), 10\% DMSO, $2 \mathrm{mM} \mathrm{Mg}^{2+}$ and $2 \mu \mathrm{l}$ of the ten fold diluted DNA extract (approx. $2-10 \mathrm{ng}$ ) for Sm17 and $2.5 \mathrm{mM} \mathrm{Mg}^{2+}$ and $5.8 \mu \mathrm{l}$ of DNA extract (5.8 - $29 \mathrm{ng}$ ) for all other loci. All PCRs were performed in a BIOMETRA gradient thermocycler. Gel electrophoresis with 6\% denaturating polyacrylamide and silver staining was performed as described in Llewellyn et al (2003). Using five highly variable microsatellites has been proven to be sufficient to discriminate between aphid clones in the genus Sitobion, as 6-10 further primer sets did not discriminate additional multilocus genotypes (Wilson et al, 1999; Haack et al, 2000; Llewellyn et al, 2004;.Figueroa et al, in press)

\section{Statistical analyses}

Genotypic diversity was defined as the number of genotypes divided by sample size (G/N ratio). Regression analyses between genotypic diversity and landscape complexity of the wheat field surrounding areas were performed using a stepwise forward method for all landscape scales using SYSTAT (1998). Tests for deviations from assumptions of variance homogeneity and Kolmogorov-Smirnov tests for deviations from normal distributions and test-power were performed using Sigma-Plot 8.02, SPSS Inc., 1986-2001. $\chi^{2}$-tests were performed to test for changes in frequency of genotypes (SYSTAT, 1998). To reduce the amount of empty cells of contingency tables, all annual unique genotypes, as well as all rare non-uniques were grouped into classes. Comparisons of genotypic diversity between fields with or without insecticide treatment were performed using Kruskal-Wallis tests followed by pairwise Mann Whitney-U tests available in SYSTAT (1998). To calculate the change of genotypes within single fields during the summer, the Sörensen Index was used (cf, Magurran, 2004). This is a qualitative diversity index with $\mathrm{C}_{\mathrm{S}}=2 a /(2 a+b+c)$, where $a=$ total number of genotypes found in both samples, $b=$ the number of genotypes present only in the first sample and $c=$ the number of genotypes present only in the second sample. To balance unequal sample sizes, samples were standardised by randomly excluding individuals from the larger sample. 
Isolation by distance measures $\left(F_{S T} /\left(1-F_{S T}\right)\right)$ between field samples were tested against geographic distance $(\mathrm{km})$ or difference in the relative amount of arable land in the field surrounding landscapes using Mantel tests with 30,000 permutations available in GENEPOP, version 3.4 (Raymond and Rousset, 1995). All tests were performed for multilocus $F_{S T}$ datasets and for each single locus separately with prior tests for deviations from Hardy-Weinberg equilibrium using GENEPOP. Since parthenogenetically-reproducing individuals during summer time influence the estimation of allelic parameters, all 'clonal-copies' were removed for tests involving allelic diversity (see Llewellyn et al, 2003).

\section{Results}

\section{Genotypic diversity and landscape structure}

The genotypic diversity (G/N ratio) of $S$. avenae from all fields of central Germany (region $\mathrm{H}$ \& LS), including the single field from Northern Germany (NG), showed a significant positive linear relationship to the amount of arable land in the field surrounding landscape in 2001 and 2002 (Figure 2 a,c). Within both central German regions, a positive linear relationship to the amount of arable land was observed, but these trends were not significant. Results of both months sampled in 2001 were almost identical (June sample: $F_{1,20}$ $=14.31, P=0.001, r^{2}=0.430$, Power $=0.915$; July sample: $F_{1,29}=16.46, P<0.001, r^{2}=$ 0.370, Power $=0.957)$ and were not significantly different from each other, i.e. the regression between $\left|\mathrm{G} / \mathrm{N}_{\text {June }}-\mathrm{G} / \mathrm{N}_{\text {July }}\right|$ for fields sampled in both months and the amount of arable land was non-significant $\left(F_{1,18}=0.206, P=0.656, r^{2}=0.012\right)$. In addition, genotypic diversity was tested against other landscape parameters (amount of grassland, forest, elevation profile and perimeter-area ratio) in 2001. As expected from the negative correlation between the amount of arable land and amount of grassland and forest, as well as the height profile (mean slope) and the perimeter-area ratio (L-PAR), the genotypic diversity showed a negative significant linear relationship to these parameters; however, less of the variance was explained by regression analyses than by 'arable land' and test power was $<80 \%$. 

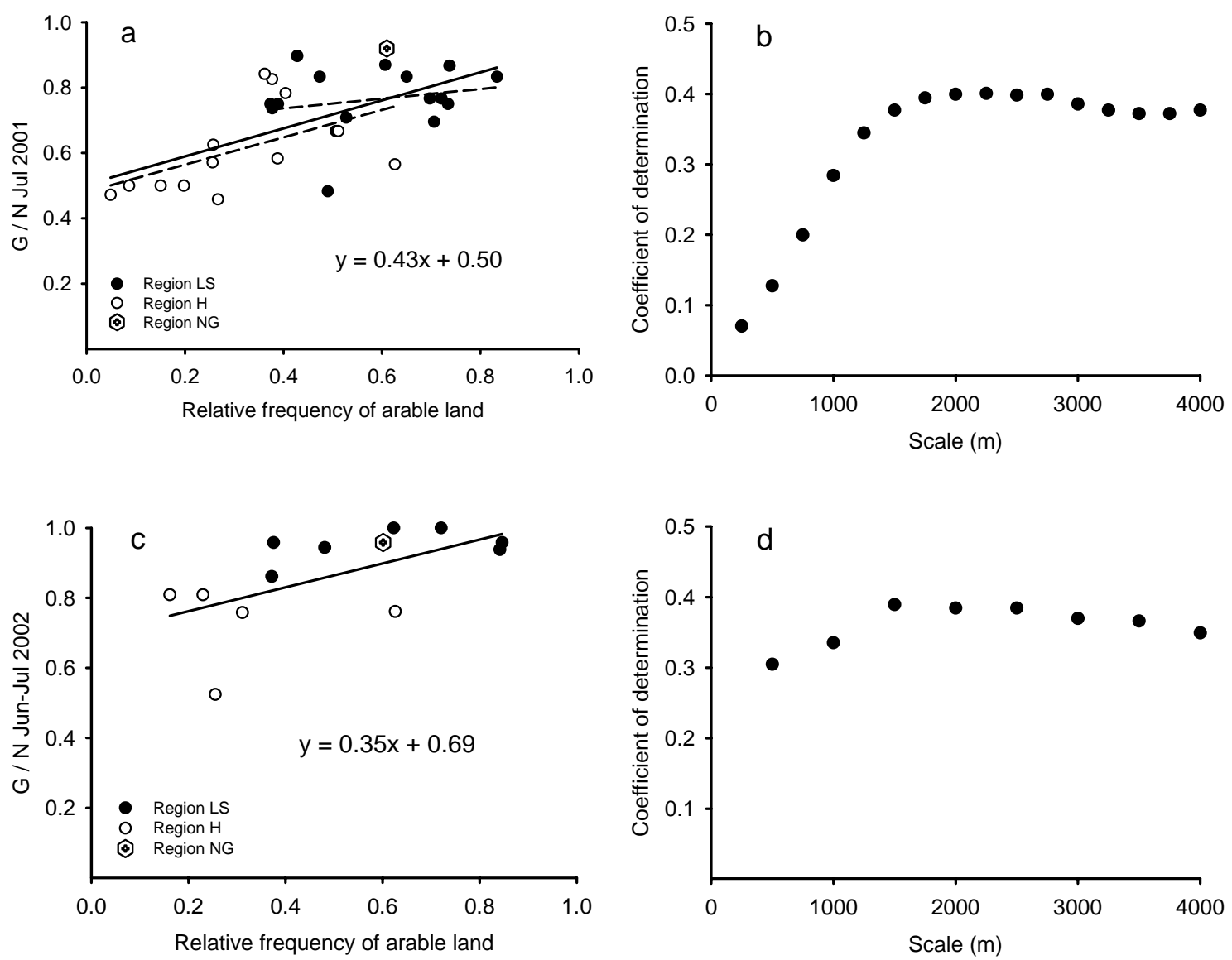

Fig. 2 Scale-dependent relation between genotypic diversity of the grain aphid Sitobion avenae and complexity of landscape in three regions (NG, LS, H) in Germany sampled in July 2001 and June-July 2002. a, c) relative frequency of arable land in the field surrounding landscape scale of $4000 \times 4000 \mathrm{~m}$ in relation to genotypic diversity (G/N, number of genotypes per sample). Regression lines over all samples with significant slopes (straight line) and nonsignificant regressions within regions (dashed lines) are shown. b, d) Coefficients of determination $\left(r^{2}\right)$ for single positive linear regressions between genotypic diversity and proportion of arable land scaled up in increments of $250 \mathrm{~m}$ in 2001 (b) and $500 \mathrm{~m}$ in 2002 (d).

In 2002, the pooled field samples from June to July showed a positive linear relationship between genotypic diversity and the amount of arable land in the surrounding landscape $\left(F_{1,11}\right.$ = 6.22, $P=0.030, r^{2}=0.361$, Power $\left.=0.593\right)$, but the large variation and smaller sample size of fields in 2002 reduced the test power. Furthermore, the genotypic diversity was overall higher in 2002 than in 2001 caused by a smaller number of non-unique genotypes in 2002 compared with 2001, and a larger proportion of unique genotypes in 2002 (Table 1). In the region of Hesse $(\mathrm{H})$, the relative frequency of the seven most common genotypes declined from $52.8 \%$ in 2001 to $34.3 \%$ in 2002 , whilst the number of unique genotypes rose from $26 \%$ to $47.6 \%$. Similar trends were observed in the region of Lower Saxony (LS) (common: 36.9\% 
to $13.6 \%$ and unique: $47.8 \%$ to $73.9 \%$ ) and in Northern Germany (NG) (common $15.3 \%$ to $5 \%$ and unique: $70.7 \%$ to $84.2 \%)$.

Table 1 Genotypes in Germany and their relative abundance in 2001 and 2002. The size of microsatellite alleles for each locus is given in base pairs. $\Sigma$ Rare $=$ sum of all other non-unique genotypes, Unique = unique genotypes in a year sample.

\begin{tabular}{|c|c|c|c|c|c|c|c|}
\hline ID & Sm 10 & Sm11 & Sm17 & S16b & $\mathrm{Sa} 4 \Sigma$ & $\begin{array}{c}\% \\
2001\end{array}$ & $\begin{array}{c}\% \\
2002\end{array}$ \\
\hline $\mathrm{H}$ & 164164 & 144144 & 178178 & 209209 & 162162 & 11.4 & 5.1 \\
\hline 1 & 164166 & 144149 & 178179 & 209274 & 168168 & 10.4 & 7.4 \\
\hline$A$ & 152166 & 144144 & 178178 & 173189 & 156172 & 6.3 & 3.1 \\
\hline$M$ & 164164 & 144144 & 183183 & 173209 & 162162 & 5.5 & 1.0 \\
\hline L & 164166 & 144144 & 179179 & 159173 & 162168 & 3.5 & 0.6 \\
\hline $\mathrm{N}$ & 164254 & 148156 & 178179 & 159205 & 162162 & 3.8 & 2.4 \\
\hline$D$ & 164208 & 144144 & 178178 & 173181 & 156172 & 2.1 & 0.9 \\
\hline$\Sigma$ Rare & & & & & & 13.8 & 5.9 \\
\hline Unique & & & & & & 43.1 & 73.7 \\
\hline
\end{tabular}

Despite the annual change in clonal diversity, the number of common genotypes was larger in region H compared with regions LS and NG in both years. The relation of genotypic diversity to landscape structure was scale dependent, with small landscape sectors explaining less of the variation than larger ones (Figure $2 \mathrm{~b}, \mathrm{~d}$ ) and was significant for scales $>2 \mathrm{~km}$. The scale-effect was similar, but less obvious in 2002, as landscape structure parameter were only calculated in 500m steps, excluding the smallest $(250 \mathrm{~m})$.

\section{Seasonal development of genotypes during summertime}

As the genotypic diversity measured by the $\mathrm{G} / \mathrm{N}$ ratio did not differentiate between single genotypes, the development and spread of single genotypes during summer time was analysed. Eleven genotypes were sampled from all regions and in both years. Of these, six genotypes were common with a frequency of $2-11 \%$ and $0.6-7.4 \%$ in the total sample for 2001 and 2002, respectively (Table 1). Another genotype, ' $\mathrm{H}$ ' was common in both central German regions, but was absent in region NG, where the number of sampled common genotypes was rather low (0.0 - $4.3 \%$ in 2001 and $0-1.7 \%$ in 2002). In central Germany, 
the common genotypes were found in $74.9 \% \pm 5.9 \mathrm{SE}$ of all 31 fields in central Germany 2001 and in $57.1 \% \pm$ 9.9SE of 12 fields sampled in 2002 .
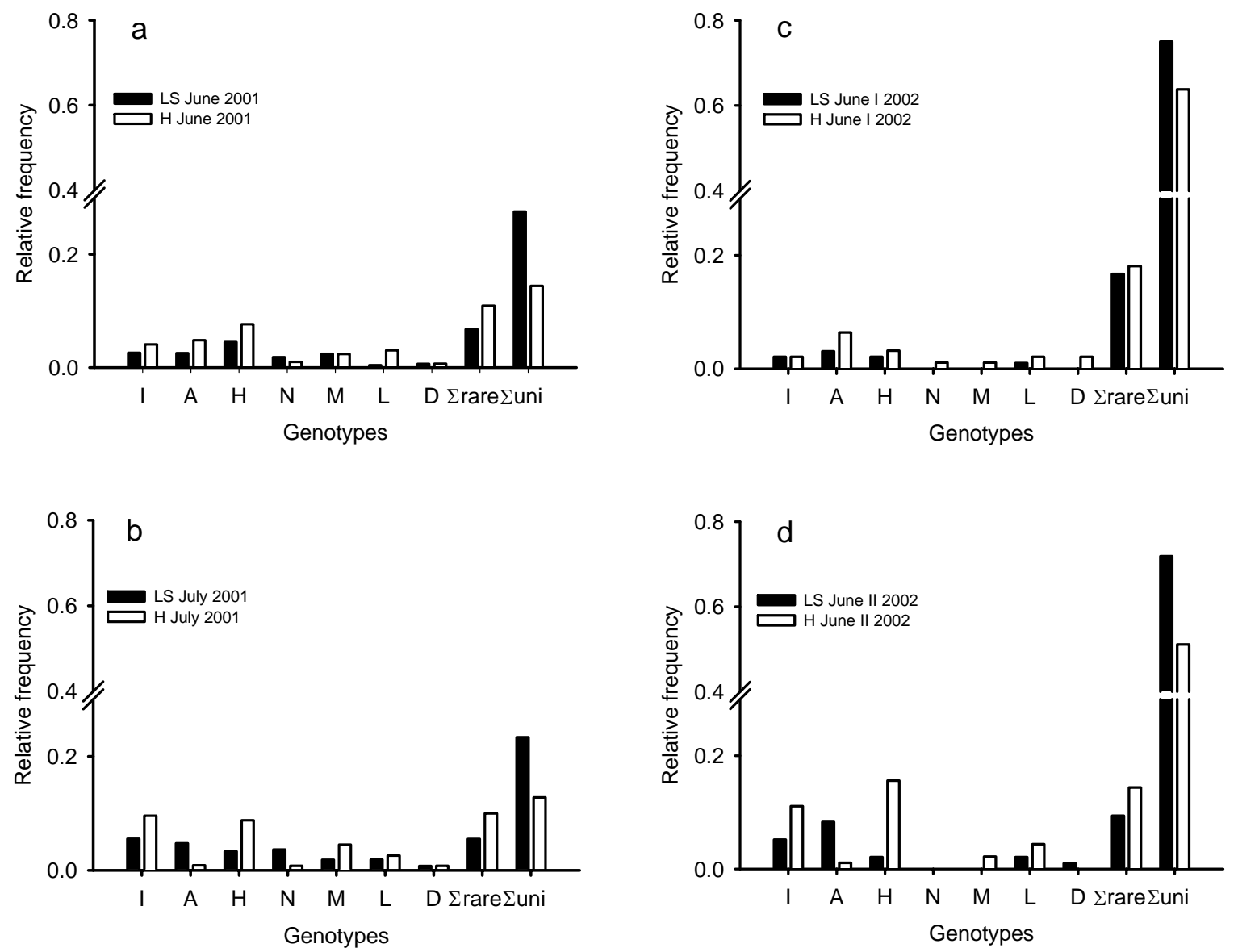

Fig. 3 Relative frequency of genotypes in central Germany (region $\mathrm{H}$ and LS) in two samples in 2001 and three samples in 2002. The most common genotypes were named in capital letters, ' $\Sigma$ rare' $=$ sum of the residual non-unique genotypes and ' $\Sigma$ uni' = sum of individuals with a unique genotype in central Germany in 2001 and 2002 respectively.

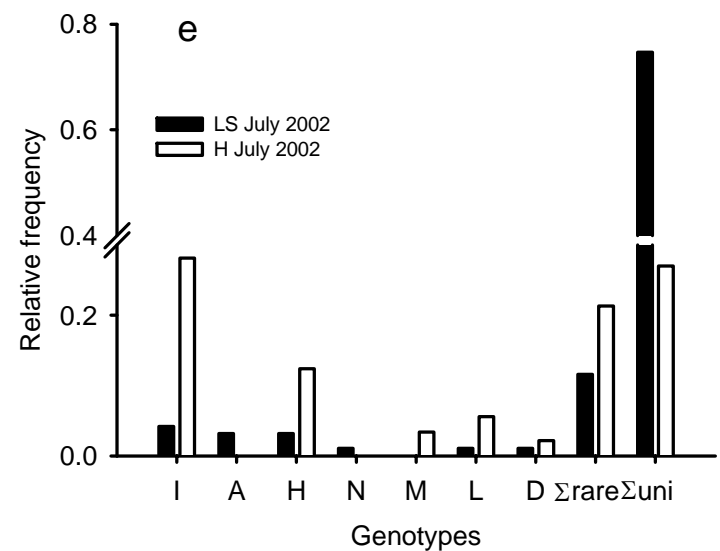

The relative frequencies of the seven most common genotypes, the remaining non-unique genotypes and unique genotypes did not change significantly in frequency in region LS from June to July in both years (Figure 3 a-e). However, between both central German regions, significant differences in the relative frequency of genotypes were observed, except in June 
2002 (2001: June: $\chi^{2}=40.71$, df $=8, P<0.001$, July: $\chi^{2}=36.58$, df $=8, p<0.001$; July 2002: $\chi^{2}=55.03, \mathrm{df}=8, P<0.001$ ). This result was caused by a larger number of non-unique genotypes in region $\mathrm{H}$ compared with region LS. Further, only in region $\mathrm{H}$ were significant changes in genotypic composition observed during the summer in both years (June to July 2001: $\chi^{2}=36.58, \mathrm{df}=8, P<0.001$; June I to July 2002: $\chi^{2}=48.89$, $\mathrm{df}=8, P<0.001$ ). This was caused by an increase of genotype ' $\mathrm{I}$ ' and ' $\mathrm{M}$ ' in region $\mathrm{H}$ from June to July in both years, whilst the number of individuals of genotype ' $A$ ' and the unique genotypes decreased (Figure 3 a-e). These shifts in genotype composition in region $\mathrm{H}$ may have been caused by changes in abundance of aphids; however regression analyses between the genotypic diversity of single field samples (G/N ratio) and aphid abundance (mean aphids/tiller) were non significant for both central German regions, sampling dates and both years of study (data not shown). The average abundance of aphids collected from all fields was similar between both central German regions in all collections performed in both years. However, genotypic diversity was different between regions and changed independently from aphid abundance within both years, except in region LS in 2002, where an inverse pattern of genotypic diversity to abundance was observed (Table 2).

Table 2 Abundance and genotypic diversity (G/N ratio = number of multilocus genotypes in a sample) during peak abundance of $S$. avenae in wheat fields in central Germany in two consecutive years.

\begin{tabular}{lcccc}
\hline & \multicolumn{2}{c}{ Mean S. avenae / tiller \pm SE } & \multicolumn{2}{c}{$\mathrm{G} / \mathrm{N}$} \\
\hline Sample & $\mathrm{LS}$ & $\mathrm{H}$ & $\mathrm{LS}$ & $\mathrm{H}$ \\
2001 June & $0.04 \pm 0.01$ & $0.04 \pm 0.01$ & 0.710 & 0.405 \\
2001 July & $0.33 \pm 0.07$ & $0.23 \pm 0.03$ & 0.567 & 0.356 \\
2002 June I & $0.14 \pm 0.05$ & $0.30 \pm 0.08$ & 0.948 & 0.884 \\
2002 June II & $1.41 \pm 0.31$ & $1.49 \pm 0.26$ & 0.854 & 0.700 \\
2002 July & $0.20 \pm 0.04$ & $0.19 \pm 0.08$ & 0.937 & 0.517 \\
\hline
\end{tabular}

Another factor that could have contributed to regional differences in genotype development was the application of insecticide. None of the fields in region $\mathrm{H}$ were treated with insecticides in 2001, which is typical for that region as determined following interviews with farmers. In 2002, only one field in region $\mathrm{H}$ was treated. In region LS, a region with intensive land use, insecticides were applied during the early crop bloom in nine of seventeen fields in 2001, and five of seven fields in 2002. The field in region NG was sprayed in both 
years. Thus, the use of insecticides possibly contributed to differences in genotypic diversity and parthenogenetic proliferation of aphid clones during the summer. In July 2001, a sufficient number of treated and untreated fields were sampled in region LS to test for the influence of insecticides on genotypic diversity. Within region LS, no significant differences were found between the two groups of fields with regard to the $\mathrm{G} / \mathrm{N}$ ratio of all genotypes per sample, unique genotypes or the seven most common genotypes. Only when all untreated fields from region $\mathrm{H}$ were included in the analysis was the $\mathrm{G} / \mathrm{N}$ ratio of unique genotypes per sample found to be significantly different $\left(\chi_{\text {approx }}^{2}=5.467, P=0.019\right)$.

One of the sprayed fields in region LS was treated with insecticides one week before the first collection (Fig. 4, I1), and a second field between two collections (Figure 4, I2). Insecticide application before both samples did not lead to a higher turn over-ratio of genotypes between both samples compared with untreated fields, but spraying between both samples possibly reduced the number of shared genotypes between both samples.

\section{Migration of genotypes within a season in regard to landscape structure}

Based on the data set of 2001, the number of shared genotypes in field samples from June and July was tested against landscape structure parameters for six fields in region LS and 12 fields in region $\mathrm{H}$ (Figure 4).

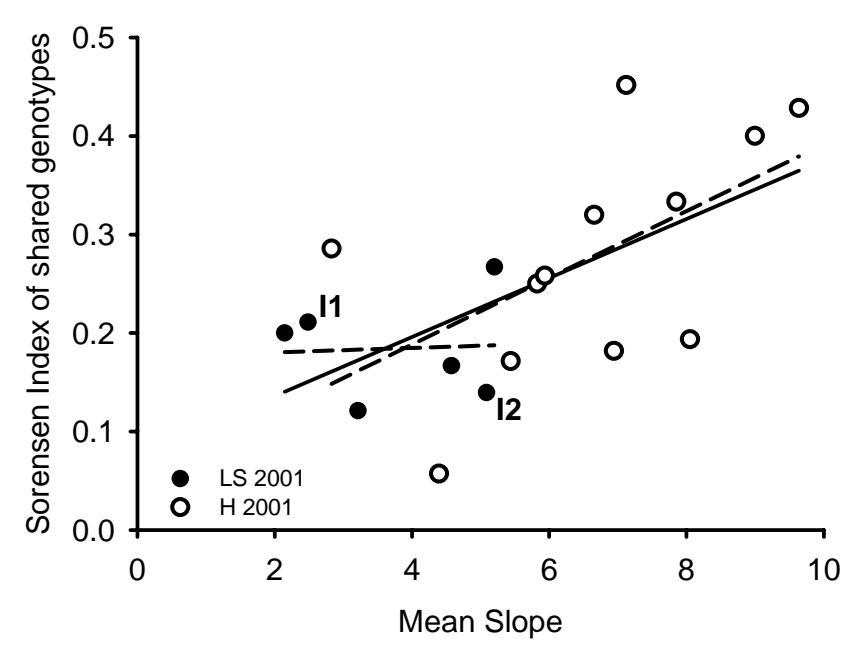

Fig. 4 Consistency of genotypes in wheat fields between two sample series in 2001. No significant relationships were found within both regions (dashed lines), but for the total dataset a positive significant linear relationship to the height profile of the field surrounding landscapes at a scale of 4000 x 4000 m (straight line) was observed. 
The Sorensen Index of genotypic similarity for all bi-monthly sampled fields showed a significant positive linear relationship to the height profile (mean slope) of the surrounding landscape (Figure 4; $F_{1,16}=9.39, P=0.007, r^{2}=0.370$, Power $=0.781$ ). This result was dependent almost exclusively on the fields within region $\mathrm{H}\left(F_{1,10}=9.39, P=0.060, r^{2}=\right.$ 0.310 , Power $=0.470$ ), whereas fields from region LS all showed a high turn-over ratio independent of the elevation profile $\left(F_{1,5}=0.01, P=0.914, r^{2}=0.003\right)$. In 2002, for all three comparisons between temporal samples, positive but non significant relationships between the consistency of genotypes and the mean slope were observed (data not shown).

\section{Population differentiation by geographic distance and landscape structure}

Population differentiation was analysed using pairwise multilocus $F_{\mathrm{ST}} /\left(1-F_{\mathrm{ST}}\right)$ between fields and tested against either geographic distance $(\mathrm{km})$ or differences in the relative amount of arable land in the field surrounding landscape.

In 2001, the populations from central Germany were significant isolated from each other by geographic distance (June: $P=0.032$; July: $P=0.009$ ) and by differences in landscape structure (June: $P=0.013$; July: $P=0.009$ ). Results were still significant even if all field comparisons within central German regions were included. Both central German regions were separated from Northern Germany only in the July sample by geographic distance $(P=0.006)$ and landscape structure ( $P=0.036$ ), but only in case of comparisons within central German regions were excluded. In 2002, northern German S. avenae population were not separated from central German populations in terms of genetic structure, whereas these regional populations appeared isolated from each other in the June II sample $\left(P_{\mathrm{km}}=0.008, P_{\text {arable }}=\right.$ 0.003), although not in June I and July. These results were still significant including all comparisons within central German regions.

Heterozygote deficits occurred at locus Sm17 in 67.7 \% of all fields from central Germany in 2001, whereas in 2002, virtually no populations from central German regions were found to deviate from Hardy Weinberg equilibrium (HWE). In northern Germany, no deviations from HWE were recorded. The analysis of isolation by distance for single loci revealed that Sm11, Sa4S and S16b contributed most to the significant results between regions in 2001, whereas Sm17 only contributed to isolation by difference in landscape structure between H and LS in June 2001. Therefore, F-statistics were not influenced by deviations from HWE. Within central German regions, no isolation by geographic distance 
nor landscape structure was observed in either sampling year, bar one example of significant isolation by landscape structure between fields within region LS in June $2001(P=0.032)$.

\section{Discussion}

\section{Genotypic diversity and landscape structure}

Of all landscape parameters tested, the amount of arable land explained most of the variation in genotypic diversity. Thus, a large habitat area of simple structured landscapes included a larger number of genotypes. Even so, these results have to be interpreted carefully, since within both central German regions, the relationship was not significant, yet showed the same trend within the two regions. Fields from western central Germany contributed most to the positive relation between genotypic diversity and landscape structure, possibly by fields covering a larger gradient in landscape structure. Because of this, locations within both region might not be differentiated enough to detect an effect of landscape structure on genotypic diversity. Secondly, as the positive relationship between landscape structure and genotypic diversity was only significant in the combined regional data set, other factors beside landscape structure could differentiate regional genotypic diversity. Thirdly, local migrations of winged aphid morphs could diminish the landscape effect within a region.

The ability of $S$. avenae to move randomly within a region was supported by the observation that larger scales $\left(4-16 \mathrm{~km}^{2}\right)$ explained more of the variation than small scales. The influence of large scales on insects with a large foraging distance has been reported for common species of bumblebees (Westphal et al, 2003) and for honeybees (Apis mellifera L.) (Steffan-Dewenter et al, 2002) at scales up to $28 \mathrm{~km}^{2}$, whilst solitary bees or above ground nesting wasps with a foraging distance of several hundred metres were dependent on landscape context at scales $<1.0 \mathrm{~km}^{2}$ (Steffan-Dewenter, 2003). Hence, local migrations of winged summer aphid morphs could explain the large variation in genotypic diversity and observed lack of population differentiation within a region.

Another variable that was found to be correlated with landscape structure was farming practice. However, we found no evidence for the impact of insecticides on genotypic diversity and within seasonal dynamics of genotypic composition at the field scale. Further, no evidence was found for the presence of insecticide resistant strains as found in other aphids (e.g. the peach-potato aphid, Myzus persicae (Sulzer), Foster et al, 2002). Resistant strains should lead to a lower genotypic diversity in intensive sprayed regions (structured 
population), although in fact the opposite was observed in the present study on S. avenae. On the other hand we cannot exclude the possibility that 'clonal copies' have been reduced at the regional scale by frequent use of insecticides at different locations.

One explanation for the difference between genotypic diversity and homogenous aphid abundance between regions could have been the sampling method. To estimate abundance, all individuals on inspected tillers were counted, whereas for molecular analyses, single aphids were taken from different field plots independent to colony size on single plants. Therefore, frequently detected genotypes had already dispersed within and between fields, a behaviour which was earlier posited from field observations by both Dean (1973) and Holmes (1988).

The changes in genotypic diversity between years indicated that winter climate might outweigh the landscape effect in regions with frequent cold winters. If this is indeed so, the landscape effect might be best studied in regions with permanent mild winters to exclude this important variable.

\section{Seasonal development of genotypes during summertime}

The total genotypic diversity (G/N ratio) appeared to be rather consistent within a season. Yet analysis of the changes in frequency of single multilocus genotypes revealed the $\mathrm{G} / \mathrm{N}$ ratio to be at a steady-state, with some genotypes increasing and others decreasing in abundance over the summer. This pattern occurred in both sampling years, but only in region $\mathrm{H}$ with a complex landscape structure, which could be explained either by limited dispersal of proliferating genotypes due to migration barriers or by migration between different hostplants that were present in different amounts in complex and simple landscapes. Such contrary changes of genotype frequencies have also been reported in the rose aphid, Macrosiphum rosae (L.), (Tomiuk and Woehrmann, 1981) and for parthenogenetic populations of the Lonchopterid fly Dipsa bifurcata (Niklasson et al, 2004), although the latter species did not show regional variation as was observed for the grain aphid (present study). These results give further support for clonal selection during the parthenogenetic phase of cyclic parthenogens, particularly for the grain aphid, Sitobion avenae, as was recently proposed by Llewellyn et al (2004).

The decrease of unique genotypes during the summer could be explained by parthenogenetic proliferation of all genotypes. Thus because clones reproduce asexually during the growing season, any decrease in sample genotypic diversity should be inversely related to aphid abundance. However, this pattern was only observed in region LS in 2002. In 
all other cases, the G/N ratio continuously declined with time and was different between central German regions. In contrast to changes in genotypic diversity, aphid abundance was independent from differences in landscape structure. This corresponds to observations on several highly mobile species were abundance was not influenced by habitat size or connectivity (Tscharntke et al, 2002).

From our results, we conclude that studies on the spread and frequency of single genotypes should definitely consider the seasonal dynamics. The reason for the observed variation in summer time have yet to be evaluated both by comparing different host-plant populations during the complete plant growing season as well as by laboratory experiments on differences in clonal characters.

\section{Population differentiation or 'super-population'?}

No S. avenae population differentiation was expected in the area of Germany, as earlier studies of this aphid had shown that migration appeared to occur over large distances (certainly within a range of $650 \mathrm{~km}$ as determined from suction trapped samples in mainland Britain; see Llewellyn et al, 2003), thereby preventing the genetic isolation of populations. Therefore, large geographic distances are seemingly necessary to separate populations, e.g. between England and Spain separated by about $800 \mathrm{~km}$ (Loxdale et al, 1985), or between France and Romania separated by about 1600 km (Papura et al, 2003).

In agreement with these expectations, the present results show that several non-unique genotypes were distributed over almost all sites and regions of Germany in two consecutive years. Our observation of single common clones on wheat support the observations of Haack et al (2000) who found, using the same sampling method, two common S. avenae multilocus genotypes on maize (Zea mays L.) over two consecutive years, despite strong variation in aphid abundance within a season and between years. However, these particular genotypes were not recorded during our study in Germany.

Two of the most common genotypes found by us shared the same alleles at four loci (as far as can be ascertained from a literature comparison) to long persistent genotypes in England (clone 114(F < 96) and 53(S.UK94) (Llewellyn et al, 2003). Those individuals that appeared in more than one year were produced asexually. But it is questionable whether these genotypes migrate annually or just persistent at these locations without exchanging individuals for several years. 
The analyses of isolation by distance clearly indicates that the main German S. avenae populations tested are not permanently isolated from each other, probably due to a high level of inter-population gene flow. Within both central German regions, no significant isolation was observed within a distance of $<50 \mathrm{~km}$, as earlier found by Loxdale and Brookes (1990) for the holocyclic sister species, $S$. fragariae. In addition, there was no isolation by distance between samples from central and northern Germany (except in July 2001) and significant results were not consistent over two years. However, the significant isolation by distance/landscape between central German regions in both collections in 2001 and one in 2002 does provide evidence for temporarily non-random distribution of alleles/genotypes at the regional scale. Whatever the causal factor/s for these results, the apparent isolation of populations is not explained by geographic distance in correspondence with the results of Papura et al (2003), who found separated populations in Romania independent of geographic distance. Our results show that different regional factors enhance differences in population genetic structure at the regional scale, but long distance migration might prevent the permanent isolation of populations between both central regions in Germany.

\section{Acknowledgements}

This work was supported by the German Ministry of Education and Science (BMBF). We are especially grateful to Thorsten Behrens, Tobias Purtauf and Jens Dauber (Giessen) for providing the landscape structure data and field sites in Hesse, and Andreas Rinker (Kiel) for providing landscape data from northern Germany and Carsten Thies (Goettingen) for help with site selection in Lower Saxony. Aphid collections from northern Germany were kindly provided by Katharina Lohaus (Goettingen). We thank Dr. Ian Denholm, Rothamsted Research, and the two anonymous peer reviewers for their helpful comments, which have much improved the manuscript. 


\title{
Coexistence of sexual and asexual populations of the grain aphid, Sitobion avenae (F.) under variable climate conditions in Central Europe
}

\author{
Lars REIMER ${ }^{1}$, Hugh D. LOXDALE ${ }^{2}$, Stefan VIDAL ${ }^{1}$ \\ ${ }^{1 .}$ Institute of Plant Pathology and Plant Protection, Goettingen University, Grisebachstrasse 6, 37077 \\ Goettingen, Germany; ${ }^{2}$ Plant and Invertebrate Ecology Division, Rothamsted Research, Harpenden, \\ Hertfordshire, AL5 2JQ, UK
}

\begin{abstract}
Cyclic parthenogens are model organisms to study the influence of environmental factors on intraspecific variability, since both the coexistence of asexual and sexual lineages and population genetic structure can be investigated. The present study concerns the examination of S. avenae populations from wheat fields in three regions in Germany with variable winter climate and from a single region in southern Hungary (which has severe winters) over three consecutive years. Unique genotypes were dominant in northern Germany, Hungary and after cold winters, in central Germany, revealing sex to be the predominant mode of reproduction in these particular populations. The analyses of genotype frequency and of genetic structure of 'unique' genotypes in comparison with 'non-unique' genotypes, gave evidence for the existence of intermediate life-cycles in regions with variable winter climate in agreement with earlier model predictions and laboratory test results. However, the occurrence of obligate asexual lineages ('super-clones') and the consistently larger proportion of asexual clones in western Germany on the one hand, and consistently high diversity in northern Germany on the other, could not be readily explained by the variable winter conditions. We propose northern Germany and southern Hungary to be the climatic limits to the spread of anholocyclic clones, and that regional climatic peculiarities are probably more important when considering the distribution of aphid genotypes than larger geographic (i.e. global) influences. This has also been shown by us for aphid abundance, which varied between regions, independent of winter climate and the occurrence of asexual lineages.
\end{abstract}




\section{Introduction}

Aphids are seen as ideal model organisms in studies of the coexistence of different life-cycles within a species (Simon et al, 2002). Beside the cyclic parthenogenetic lineages which, depending on climate, have an additional annual obligatory sexual generation after numerous parthenogenetic generations (holocyclic), other individuals are obligate asexual clones (anhoholcyclic). In some aphid species, including the grain aphid, Sitobion avenae (F.), individuals with an intermediate life-cycle occur (Dedryver et al, 1998), which reproduce asexually but produce in addition relatively few male and female offspring, or males only (androcyclic).

The intraspecific variation in life-cycles cycles enables aphid species to benefit both from parthenogenesis and sexual recombination. Cyclic parthenogenesis comprises a high reproductive capacity of viviparous clones during summertime (Maynard Smith, 1978; Helden and Dixon, 2002), whilst sexual recombination during autumn allows adaptation to cold climates, along with bringing together favourable genes, and the elimination of recurrent mildly deleterious mutations (e.g. West et al, 1999; Loxdale and Lushai, 2003).

According to the general model of geographic parthenogenesis (Vandel, 1928), aphids show an inverse pattern to the expectation that asexuals should dominate under harsh environmental conditions. This is because of frost resistant eggs being produced only after sexual recombination, whilst viviparous asexuals are frost susceptible (Knight and Bale, 1986).

Various models predict that aphid lineages with an intermediate life-cycle should be of advantage under unpredictable climate conditions (Rispe and Pierre, 1998 and Rispe et al, 1998; Halkett et al, 2004). As this combination of reproductive modes should be the optimum for each individual in regions with variable winter climate conditions, it is of interest whether all lineages show a 'plastic' life-cycle that includes capabilities to produce either an annual sexual generation or continuing parthenogenesis throughout winter time. If so, this should lead to frequent genotypes that persist so long as winters are mild and are replaced by other genotypes after cold winters, because of sexual recombination. However, field surveys in central Asia with cold winters do suggest the occurrence and survival of anholocyclic lineages of S. avenae (Mueller, 1977). Similar, previous studies from Germany have given conflicting evidence as to the influence of winter climate on clonal diversity, by evaluating the potential mode of reproduction of single $S$. avenae clones under laboratory conditions (Weber, 1985; but see Wientgen et al, 1994 and Hoeller, 1990). From these various findings we hypothesise that holocyclic and anholocyclic lineages could coexist in a heterogeneous environment 
differing in space (distribution of resources, migration barriers, winter refugees) and time (seasonal development of host-plants, annual climate changes). One pre-requisite for such coexistence is a fast colonisation rate of suitable habitats by migration.

The grain aphid, S. avenae, is a particularly suitable 'model' organism to investigate the influence of winter climate on life-cycles as it is autoecious (i.e. it feeds on one group of host plants only -wild and cultivated grasses, Poaceae; Hille Ris Lambers, 1939; Dixon, 1998) and therefore, is independent of the distribution of a winter host (primary host). However, hostplant adaptation of single clones of this aphid species is still under discussion (Haack et al, 2000; Lushai et al, 2002; but see Papura et al, 2003).

We here analyse the effect of winter temperatures on the population genetic structure and clonal diversity of wheat populations of $S$. avenae in four regions of differing climate within Central Europe over a three year period with yearly changes in winter temperatures. In effect, we close the geographic gap (so to speak) between previous studies which have employed microsatellites to study winter climate effects on grain aphid populations from both Western and Eastern Europe (e.g. Simon et al, 1999; Dedryver et al, 1998; Haack et al, 2000; Papura et al, 2003).

In our study, we have used five polymorphic microsatellites to identify $S$. avenae genotypes under field conditions and determined the consistency or change of genotype frequencies over consecutive years. Further, analyses of linkage disequilibrium and deviations from Hardy-Weinberg equilibrium (HWE) were performed on the group of unique genotypes which are thought to originate from sexual reproduction and the group of non-unique genotypes which should include the majority of asexual lineages. If anholocyclic and holocyclic lineages coexist separately under variable climate conditions, these groups should be well defined in terms of their genetic structuring (Delmotte et al, 2002; Vorburger et al, 2003; Papura et al, 2003), whereas in the case of intermediate life-cycles these differences should be less obvious. As population dynamics might influence clonal diversity, we have additionally compared aphid abundance directly with winter climate.

\section{Materials and Methods}

\section{Aphid samples}

A total of 2459 adult S. avenae were collected from autumn-sown wheat fields in two regions of central Germany (region Lower Saxony LS and region Hesse H) and one region in northern 
Germany (region NG near Hamburg) from 2001 to 2003. In addition, aphids were collected from one region in southern Hungary (HU) in 2002 and 2003 (Figure 1).

Distances between regions were more than $100 \mathrm{~km}$ (Table 1) and each region included one (NG) to several wheat fields (LS, H, HU, Table 2) that were distributed over an area with a diameter of $<50 \mathrm{~km}$. Aphids were sampled using a sweep-net (samples from Germany) or by shaking them into an upturned umbrella (Hungary). All collections were made along transects through fields and excluding field margins of three metres. Individual aphids were chosen randomly from each sampled field plot separated by at least two metres to minimise sampling of genotypes from local aphid colonies.

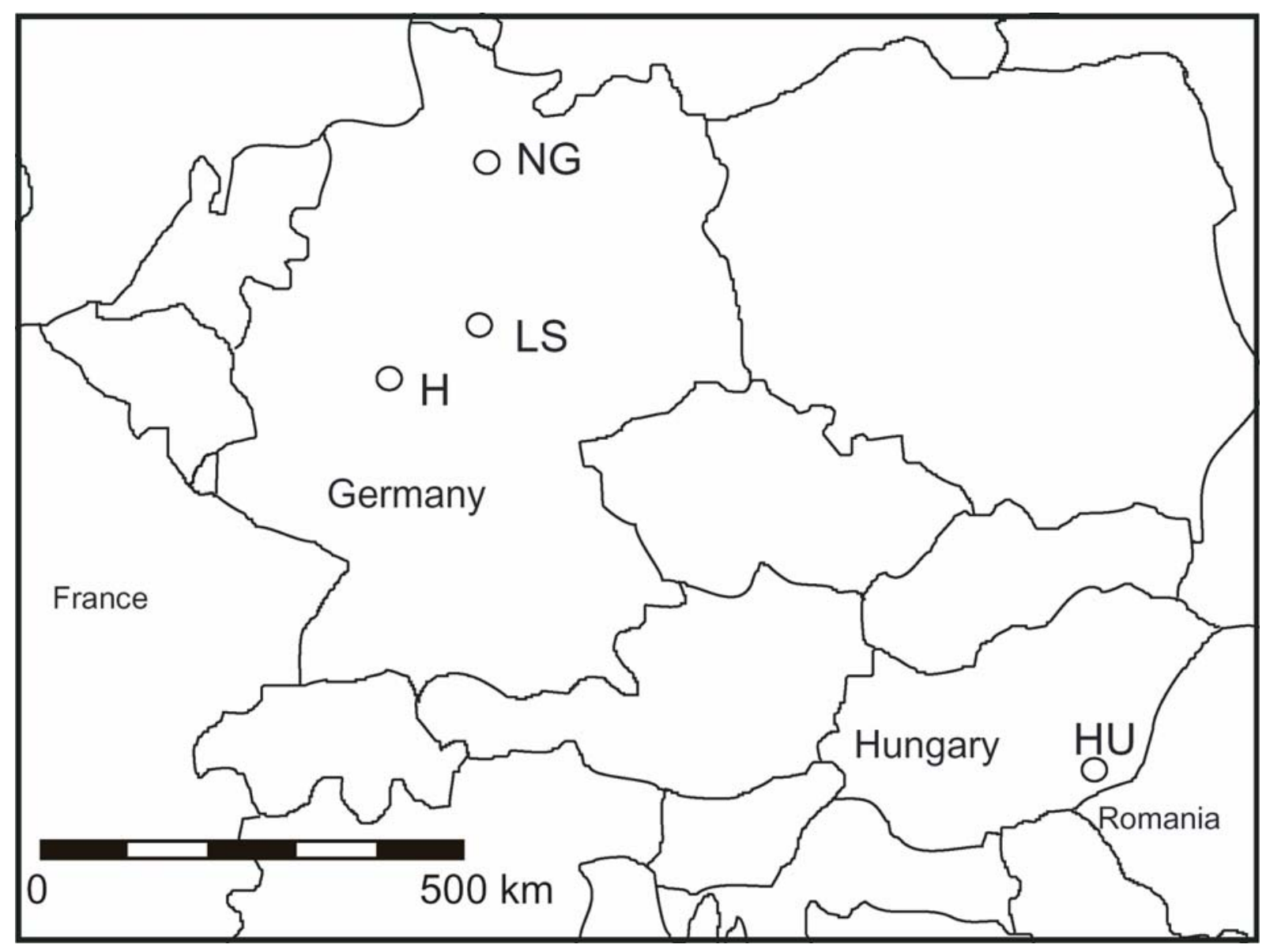

Fig. 1 Locations of S. avenae populations sampled in 2001 in Germany (Hesse ' $H$ ' with the regional centre located at $50^{\circ} 46^{\prime} \mathrm{N}, 8^{\circ} 32^{\prime} \mathrm{E}$, Lower Saxony 'LS' with the centre at 51 $32^{\prime} \mathrm{N}, 9^{\circ} 55^{\prime} \mathrm{E}$ and northern Germany ,'NG', 5327’ N, 10¹2' E) and 2002 - 2003 (Germany and Hungary, 'HU' centre at $\left.46^{\circ} 15^{\prime} \mathrm{N}, 20^{\circ} 31^{\prime} \mathrm{E}\right)$.

All aphids were collected in one to three sampling series during the time of peak abundance in winter-sown wheat, that is from June to July in Germany and around the end of 
May in Hungary. A single sample at one winter-wheat field in region LS was performed on the 6 November 2002 using a modified leaf blower.

Aphid abundance was estimated for all fields in Germany by counting 8 x 5 shoots, excluding outer field margins, whilst in Hungarian samples it was roughly estimated as the number of aphids per tiller from 80-110 plants. Abundance data from northern Germany were based on weekly time series of single tiller counts in 2002 and 2003. No aphid counts were performed in region NG in 2001 as the field was treated with insecticides prior to sampling.

The life-cycles of two distinct clones were determined by transferring aphids to autumn conditions in climate chambers for three months according to the method of Hoeller (1990).

Table 1 Geographic distances in kilometres $(\mathrm{km})$ between the centre of studied regions (below the diagonal) and between wheat fields within regions from 2001 to 2003.

\begin{tabular}{lllll}
\hline & NG & LS & H & HU \\
\hline NG & 0 & & & \\
LS & 216 & $<39$ & & \\
H & 318 & 137 & $<32$ & \\
HU & 1092 & 964 & 1006 & $<43$ \\
\hline
\end{tabular}

\section{Winter climate}

The temperature data for the period from October to April were provided by the 'Wetterstation Weendelsbreite' (University Göttingen) for region LS, the 'Hessisches Landesamt für Umwelt und Geologie', Dillenburg station for region $\mathrm{H}$, 'Deutscher Wetterdienst', Grambeck station, for region NG, and Hodmezovasarhely (Plant Health Service) for region HU. Daily mean temperatures were not available for northern Germany nor for southern Hungary. Therefore, the daily mean temperature for northern Germany and Hungary was calculated from daily minimum and maximum temperatures. To evaluate the error of these estimates, exact daily mean temperatures calculated from half hour intervals were compared with the estimated daily mean temperature for both central German regions for which complete data sets were available. Differences between calculations for single days were small, but we rejected calculations of day degrees based on estimated daily mean temperature for time periods larger than a week, as errors accumulated. 
From laboratory studies it is known that aphid mortality is dependent on both temperature and time (Knight and Bale, 1986; Powell and Bale, 2004). Based on these findings, we defined winter temperature by the number of frost days $\left(\mathrm{T}_{\mathrm{MAX}}<0{ }^{\circ} \mathrm{C}\right)$ from October to March and the number of cold periods, i.e. periods with a daily mean temperature below $-4^{\circ} \mathrm{C}$ over a consecutive period of six or more days.

\section{Microsatellite genotyping}

DNA was extracted from individual adult aphids as per Sunnucks and Hales (1996). Genotypes were determined at five microsatellite loci: Sm10, Sm11, Sm17, Sa4 $\Sigma$ and S16b (Wilson et al, 2004). Polymerase chain reactions (PCRs) were performed in $10 \mu$ l volumes containing 0.5 units of recombinant Taq (rTaq TAKARA) polymerase, $\mathrm{Mg}^{2+}$-free reaction buffer, $200 \mu \mathrm{M}$ dNTPs (TAKARA), 5 pmol of each primer (ROTH), 10\% DMSO, $2 \mathrm{mM}$ $\mathrm{Mg}^{2+}$ and $2 \mu \mathrm{l}$ of the ten fold diluted DNA extract (approx. $2-10 \mathrm{ng}$ ) for Sm17 and $2.5 \mathrm{mM}$ $\mathrm{Mg}^{2+}$ and $5.8 \mu \mathrm{l}$ of DNA extract (6 - $30 \mathrm{ng}$ ) for all other loci. All PCRs were performed in a BIOMETRA gradient thermocycler. Gel electrophoresis with 6\% denaturating polyacrylamide and silver staining was performed as described in Llewellyn et al (2003). Allele sizes were estimated using a sequencing size ladder, prepared by sequencing the pGEM-3Zf(+) vector (PROMEGA) using the 'Thermo Sequenase Cycle Sequencing Kit' (USB).

\section{Statistical analyses}

Genotypic diversity was defined as the proportion of the number of all multilocus genotypes detected within a sample of sample size $\mathrm{N}$ (G/N ratio). All multilocus genotypes, identified at five microsatellite loci that occurred more than once in the total sample were named with capital letters and form the group of 'non-unique' genotypes, whilst singletons within the total sample were named 'unique'. Clonal equitability (evenness) within the group of non-unique genotypes was calculated as the effective number of clones (Kimura and Crow, 1964) divided by the number of clones, $\left(1 / \Sigma p_{\mathrm{i}}{ }^{2}\right) / \mathrm{N}_{\text {non-unique, }} p_{\mathrm{i}}$ being the frequency of the $i$ th clone in a sample (Menken et al, 1995).

To estimate the overall population differentiation in terms of genetic structure between all regions and years, samples were arranged as follows: initially, all clonal copies were removed from each region and year to avoid a bias by 'clonal-copies' from asexual (apomictic 
parthenogenetic) reproduction during summertime and secondly, as there were large differences in the number of sampled locations and hence a unbalanced sampling design between regions and years, all analyses were performed for an unbalanced as well as a balanced design. This was achieved by randomly excluding all genotypes of larger collections up to a total of 78 genotypes, that is the number of genotypes of the smallest sample tested. Analysis of Molecular Variance (AMOVA, Excoffier et al, 1992, available in ARLEQUIN 2.000, Schneider et al, 2000) was performed for all regional samples nested by years.

$F_{\text {ST }}$ values were estimated after Weir and Cockerham (1984) and tests for significance by 4000 permutations were performed using ARLEQUIN. As several samples showed deviations from Hardy-Weinberg equilibrium, we additionally performed exact tests for population differentiation (Raymond and Rousset, 1995; Goudet et al, 1996) using ARLEQUIN, with 10,000 markov chain steps and 1,000 dememorisation steps. Multilocus $F_{\text {IS }}$ values were calculated after Weir and Cockerham (1984) using the program FSTAT (Goudet, 2001). Tests for deviations from Hardy-Weinberg equilibrium (HWE), including tests for the alternative hypotheses of heterozygote deficit and excess were performed using GENEPOP 3.4 (Raymond and Rousset, 1995). Linkage disequilibrium was analysed using GENEPOP, with levels of significance corrected for pairwise comparisons (Sokal and Rohlf, 1995), if not stated otherwise. 


\section{Results}

\section{Winter climate and abundance of Sitobion avenae}

The winter climate of southern Hungary was unusually mild before the first year of study, but colder than that of regions in Germany in the two following winters (Figure 2). Within central Germany, the winter temperatures declined in the observed period, with more frost days in region LS than $\mathrm{H}$. In northern Germany, the situation was different. The winters of the first and the last year of the study were colder than those in central Germany, whereas the winter of the second year was slightly milder than those in central Germany (Figure 2).
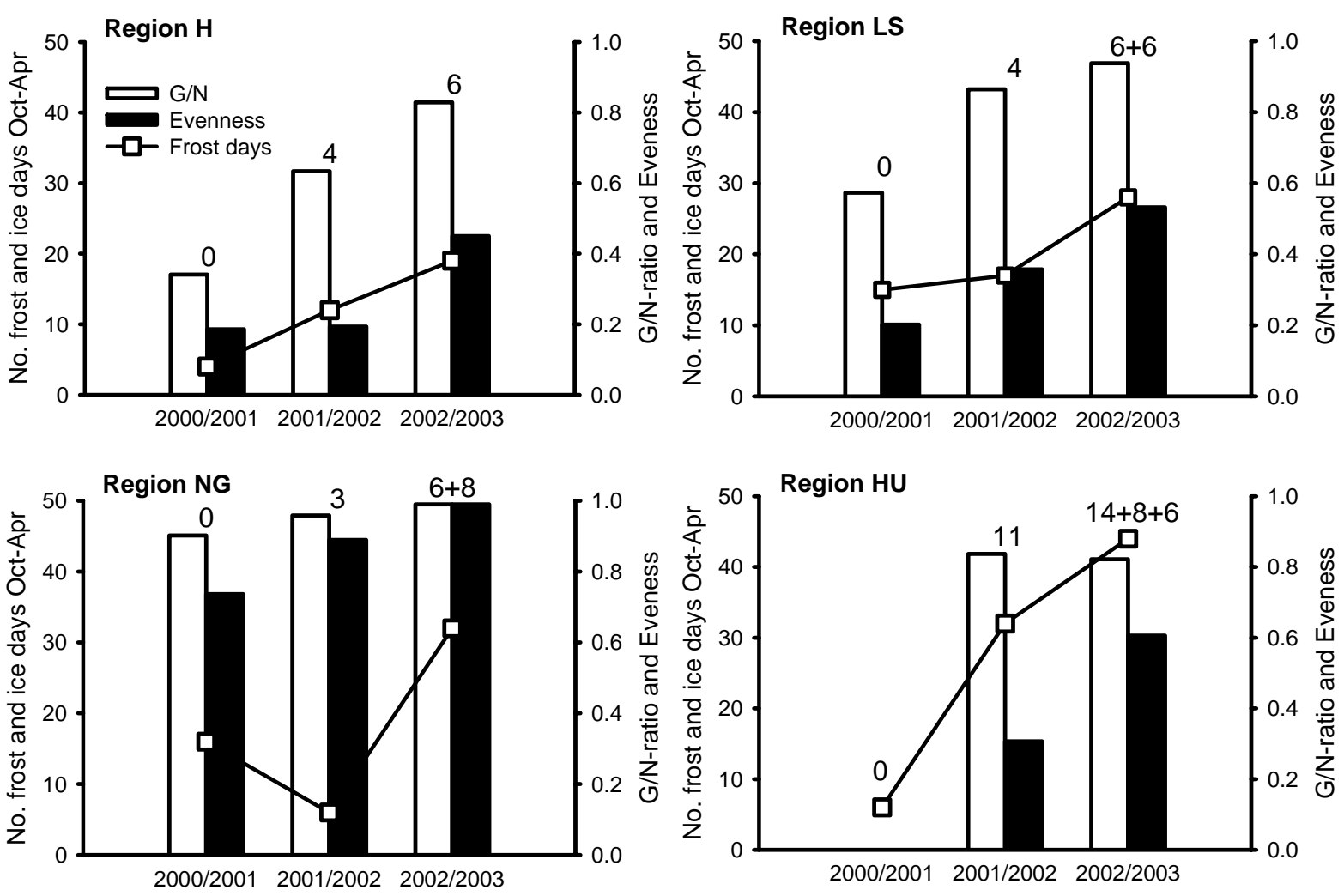

Figure 2 Genotypic diversity in comparison to winter climate. Relative frequency of genotypes (G/N ratio, open bars), evenness of the distribution of non-unique genotypes (closed bars), number of frost days ( $\mathrm{T}_{\mathrm{MAX}}<0^{\circ} \mathrm{C}$, open circles) and number of consecutive days with a daily mean temperature below $-4^{\circ} \mathrm{C}$ (days for each separate cold period above bars) are shown for $S$. avenae wheat field populations collected in central Germany (H and LS), northern Germany (NG) and southern Hungary (NG) in three consecutive years (no data were available for Hungary in 2001). 
S. avenae abundance was low in central Germany and Hungary with less than one aphid per tiller in all years of the study (Table 2), except in region $\mathrm{H}$ in 2003, where after two preceding milder winters, a higher number of aphids was observed after the cold winter of 2003 with an average 2.6 aphids per tiller. The highest density was observed in northern Germany (Table 1).

Table 2 Population genetic structure and abundance of Sitobion avenae from central (region $\mathrm{H}$ and LS), northern Germany (NG) and from southern Hungary (HU). $\mathrm{N}_{\text {loc }}, \mathrm{N}_{\text {coll }}$, $\mathrm{N}_{\text {Ind }}, \mathrm{N}_{\text {Genot }}=$ number of locations, collections between June and July, individuals and genotypes. $F_{\text {IS }}$ multilocus estimates were calculated after Weir and Cockerham (1984) for five microsatellite loci. $\mathrm{LD}=$ number of significant linkage disequilibria of ten comparisons between five loci, corrected for type error I (uncorrected significant results in brackets). For $F_{\mathrm{IS}}$ and LD 'One copy per genotype per region/sampling date' data-sets were used. Estimated abundance of aphids per tiller (range of collection means).

\begin{tabular}{|c|c|c|c|c|c|c|c|}
\hline Region \& year & $\mathrm{N}_{\text {loc }}$ & $\mathrm{N}_{\text {coll }}$ & $\mathrm{N}_{\text {Ind }}$ & $\mathrm{N}_{\text {Genot }}$ & $\begin{array}{l}\mathrm{F}_{\mathrm{IS}} \\
\text { multilocus }\end{array}$ & LD & Abundance \\
\hline NG 2001 & 1 & 2 & 92 & 83 & $+0.017 \mathrm{NS}$ & $0(3)$ & n.a. \\
\hline NG 2002 & 1 & 1 & 120 & 115 & -0.003 NS & $0(0)$ & 8.7 \\
\hline NG 2003 & 1 & 1 & 84 & 84 & $+0.108 *$ & $0(0)$ & 2.3 \\
\hline H 2001 & 14 & 2 & 606 & 207 & $+0.081 *$ & $1(2)$ & $0.04-0.23$ \\
\hline H 2002 & 5 & 3 & 274 & 173 & $+0.074 \mathrm{NS}$ & $1(2)$ & $0.34-1.98$ \\
\hline H 2003 & 5 & 1 & 117 & 97 & $+0.020 \mathrm{NS}$ & $0(0)$ & 2.55 \\
\hline LS 2001 & 17 & 2 & 566 & 325 & $+0.086 *$ & $0(3)$ & 0.04-0.33 \\
\hline LS 2002 & 7 & 3 & 288 & 248 & $+0.028 \mathrm{NS}$ & $0(2)$ & $0.14-1.81$ \\
\hline LS 2003 & 5 & 1 & 129 & 121 & $+0.083 *$ & $0(0)$ & 0.49 \\
\hline HU 2002 & 4 & 1 & 92 & 77 & $+0.055 \mathrm{NS}$ & $0(1)$ & $<1$ \\
\hline HU 2003 & 5 & 1 & 101 & 83 & $+0.002 \mathrm{NS}$ & $0(0)$ & $<1$ \\
\hline
\end{tabular}

\section{Population genetic structure}

One hundred and fifteen alleles were detected in the total sample from all regions and years.

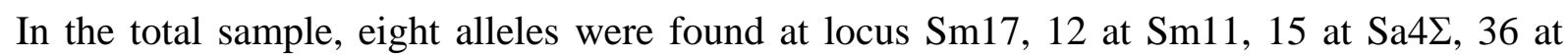


Sm10 and 44 at S16b. Within years, the majority of all alleles were shared between all regions from Germany and Hungary (Figure 3 a-c).

a)

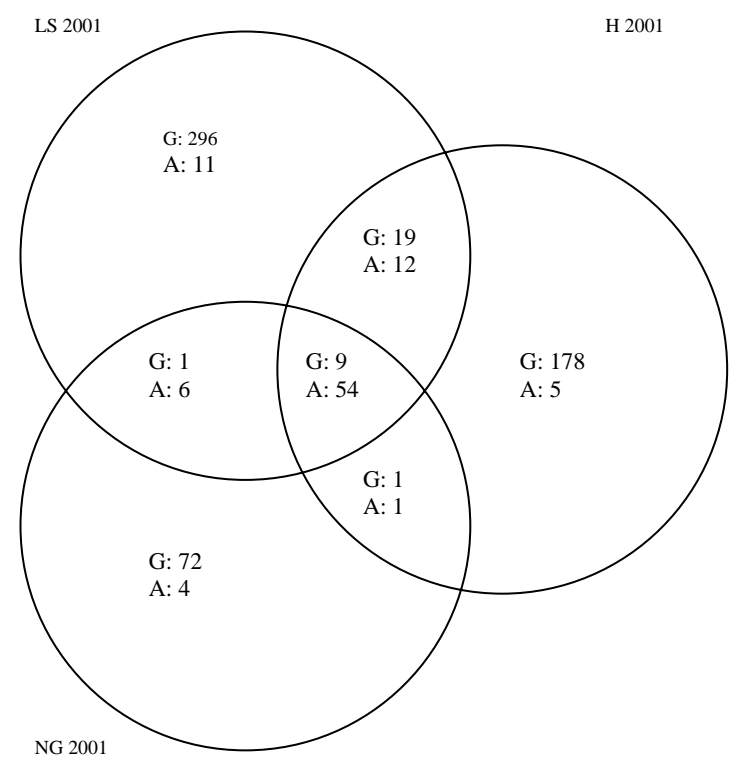

b)

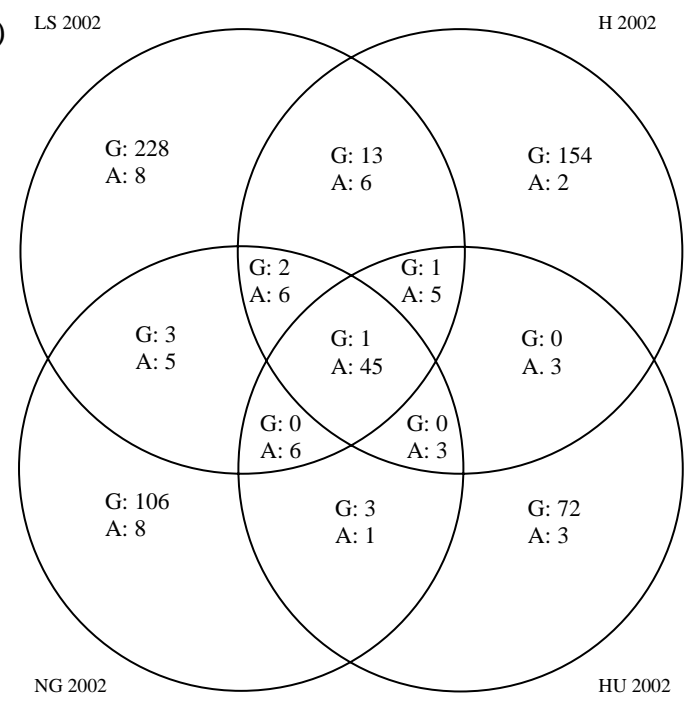

Fig. 3 Venn diagrams showing the alleles (A) and genotypes (G) present in combinations of different samples in four regions (central Germany LS and H, northern Germany NG and southern Hungary HU) in the three consecutive years from 2001 (a), 2002 (b) and 2003 (c).

b) In addition to the combinations shown, the following overlaps occurred: two genotypes and one allele shared exclusively between region 'NG' and ' $\mathrm{H}$ ' and three alleles between 'LS' and 'HU'.

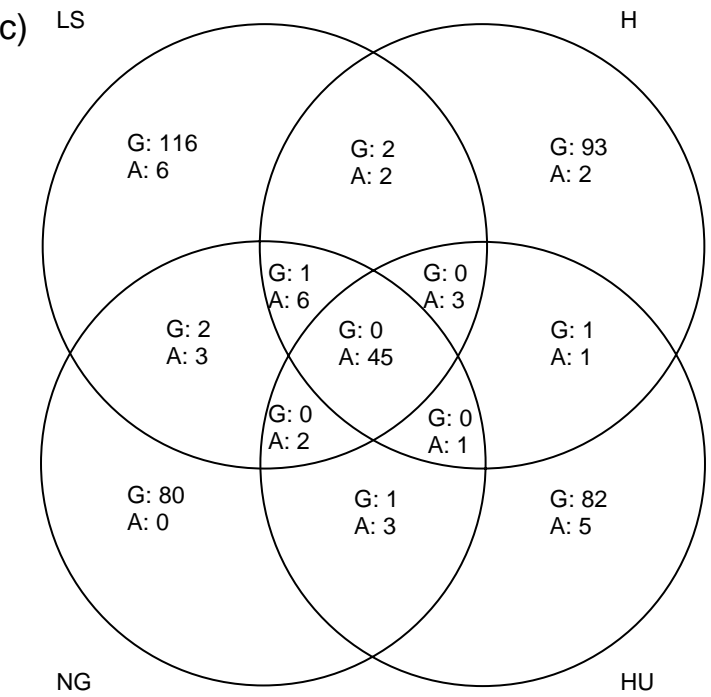

c) In addition one genotype and three alleles shared exclusively between region 'NG' and $\mathrm{H}$ and three alleles were shared between 'LS' and 'HU'.

The proportions of alleles shared between regions varied to a minor extent over three consecutive years (39-47\% of all 115 alleles in the total sample) and less than 12 alleles were 'private' for a single region and year (Figure 3 a-c). The $F_{\mathrm{ST}}$ values for the unbalanced sample including all single-copy genotypes from all regions and years were significant only 
between regions NG in 2001 and 2003, H 2001 and LS 2002, and between regions H 2001 and HU 2002 and 2003. Exact tests for population differentiation were significant between regions H 2001 and LS 2002, HU 2002 and 2003, and LS 2002 and HU 2002. The data set corrected for sample size revealed significant differences between region H 2001 and seven of all eleven samples, and between regions NG 2001 and NG 2003. In contrast to the unbalanced sample, all exact tests for population differentiation were insignificant. Although sample size and the limited number of observed loci could have affected the results, the region of western central Germany $(\mathrm{H})$ was differentiated from all other regions, and populations from central Germany appeared to be separated genetically from Hungarian ones. However, in both sampling designs and test statistics, no significant population differentiation was observed between samples from northern Germany (region NG) and southern Hungary (region HU). Only samples from northern Germany showed a differentiation by years.

The AMOVA between all regions grouped by years, after eliminating all genotypic copies from each yearly sampled region, also failed to reveal any significant difference between regions and years, although the balanced design revealed a differentiation between regions close to significance $(p=0.055)$. Both analyses showed more population differentiation between regions than between years.

Linkage disequilibrium in the yearly samples of a region was significant only in populations from region $\mathrm{H}$ and LS in 2001 (Table 2) following sequential Bonferroni correction. Without correction, some loci pairs showed significant linkage in these regions in addition in 2002, but not in 2003. Three pairs of loci were linked in northern Germany (NG) in 2001, but none after correction for pairwise comparisons and no linkage was observed in 2002 and 2003. Positive multilocus $F_{I S}$ and heterozygote deficits were frequent in all regions and years, differing between loci and samples made within a year (data not shown), but no specific pattern in space nor time was apparent (Table 2). A heterozygote excess was never observed in any sample.

\section{Influence of winter climate on genotypic diversity}

Of the 2459 adult S. avenae collected from three years and all regions, 1346 were of unique genotype. The remainder shared 105 non-unique genotypes (see Appendix, Table A). The proportion of the number of all genotypes to sample size was $\mathrm{G} / \mathrm{N}=0.55$, i.e. roughly each second sampled individual had a new genotype. Between regions and years however, 
genotypic diversity varied over a range of $\mathrm{G} / \mathrm{N}=0.34$ in region $\mathrm{H} 2001$ to all individuals being unique in region NG 2003 (Figure 2).

In central Germany, genotypic diversity ( $\mathrm{G} / \mathrm{N}$ ratio) and evenness of non-unique genotypes was higher in region LS than in region $\mathrm{H}$, but both parameters increased following successive colder winters over three years (Figure 2). The same pattern was observed in Hungary, although genotypic diversity was high in both years. In northern Germany, the highest genotypic diversity of all regions was observed, although winter climate was less cold and showed a large variation between years. Furthermore, the evenness in distribution of nonunique genotypes increased consistently over the sampling years, although winter climate varied (Figure 2).

A closer examination of single genotype frequencies (Table 3) shows that overall, most non-unique genotypes were absent in seasons following cold winters (e.g. genotypes ' $\mathrm{H}$ ' and ' $M$ ') which led to an increase in the $G / N$ ratio. Other common genotypes declined in frequency (e.g. genotype 'I', 'N', 'L'), as seen in the increase in evenness as single dominant genotypes became as rare as other non-unique genotypes. Accordingly, the number of shared genotypes between regions declined from 2001 to 2003 (Figure 3 a-c). However, genotype ' $\mathrm{N}$ ' was observed in Hungary in both years and was found in all regions, except in northern Germany in 2003. In addition, three other rare genotypes were shared between Hungary and Germany in single years. Beside genotype ' $N$ ', there was only one genotype (' $K$ ') that occurred in all five Hungarian locations exclusively in 2003, but was not found in the previous year in Hungary and was absent in Germany. 
Table 3 Frequency distribution of genotypes in Germany and Hungary (H, LS Central Germany, NG Northern Germany, HU Southern Hungary). ID: Single genotypes with an absolute frequency in the total sample of $\mathrm{N}>3(\mathrm{I}-\mathrm{U})$, sum of all genotypes with $\mathrm{n}=3, \mathrm{n}=2$ and $\mathrm{n}=1$ respectively.

\begin{tabular}{|c|c|c|c|c|c|c|c|c|c|c|c|}
\hline \multirow[b]{2}{*}{ ID } & \multicolumn{3}{|c|}{ Region $\mathrm{H}$} & \multicolumn{3}{|c|}{ Region LS } & \multicolumn{3}{|c|}{ Region NG } & \multicolumn{2}{|c|}{ Region HU } \\
\hline & 2001 & 2002 & 2003 & 2001 & 2002 & 2003 & 2001 & 2002 & 2003 & 2002 & 2003 \\
\hline I & 13.7 & 13.6 & 6.8 & 8.1 & 3.8 & 1.6 & 3.3 & 1.7 & 1.2 & - & - \\
\hline $\mathrm{H}$ & 16.5 & 10.3 & - & 7.8 & 2.4 & - & - & - & - & - & - \\
\hline A & 5.8 & 2.3 & 6.8 & 7.2 & 4.9 & 4.7 & 4.3 & - & - & - & - \\
\hline M & 6.9 & 2.2 & - & 4.4 & - & - & 2.2 & 0.8 & - & - & - \\
\hline $\mathrm{N}$ & 1.8 & 0.4 & 0.9 & 5.3 & 0.4 & - & 3.3 & 1.7 & - & 15.2 & 2.2 \\
\hline $\mathrm{L}$ & 5.6 & 4 & 0.9 & 2.5 & 1.4 & 0.8 & - & 0.8 & - & - & - \\
\hline $\mathrm{D}$ & 2.5 & 1.5 & 5.1 & 1.6 & 0.7 & - & 2.2 & - & - & 1.1 & - \\
\hline $\mathrm{Gi}$ & 2.5 & 1.5 & - & 0.2 & - & - & - & - & - & - & - \\
\hline B & 1.2 & 0.7 & 1.7 & 0.9 & 0.3 & - & 1.1 & - & - & - & - \\
\hline E & 1.2 & 1.1 & - & 0.4 & 0.7 & - & 1.1 & - & - & - & 1.1 \\
\hline C & 1 & 0.4 & - & 0.7 & - & - & - & 0.8 & - & - & - \\
\hline $\mathrm{F}$ & 1 & 0.7 & 0.9 & 0.5 & - & - & - & - & - & - & - \\
\hline GJ & 1.5 & 0.7 & - & - & - & - & - & - & - & - & - \\
\hline AA & 0.8 & 0.7 & - & 0.2 & - & - & - & - & - & - & - \\
\hline GA & 0.8 & 0.4 & - & 0.4 & - & - & - & - & - & - & - \\
\hline $\mathrm{R}$ & 0.8 & - & - & 0.5 & - & - & - & - & - & - & - \\
\hline $\mathrm{Nx}$ & 0.5 & - & - & 0.5 & - & - & - & - & - & 1.1 & - \\
\hline $\mathrm{Y}$ & 0.3 & 0.4 & - & 0.7 & - & - & - & - & - & - & - \\
\hline YA & 0.5 & 0.4 & - & 0.4 & - & - & - & - & - & - & - \\
\hline EA & - & - & - & 0.2 & - & - & 1.1 & 0.8 & - & 2.2 & 2.2 \\
\hline EC & 0.3 & 0.4 & - & 0.4 & 0.3 & - & - & - & - & - & - \\
\hline ID & - & - & - & 1.1 & - & - & - & - & - & - & - \\
\hline $\mathrm{Q}$ & 0.5 & 0.4 & - & - & 0.7 & - & - & - & - & - & - \\
\hline$X$ & 0.2 & - & - & 0.4 & 0.3 & - & 1.1 & - & - & - & - \\
\hline HX & 0.2 & - & - & 0.5 & - & 0.8 & - & - & - & - & - \\
\hline $\mathrm{K}$ & - & - & - & - & - & - & - & - & - & - & 6.5 \\
\hline RA & 0.7 & 0.4 & - & - & - & - & - & - & - & - & - \\
\hline $\mathrm{W}$ & 0.3 & 0.4 & - & 0.2 & - & - & 1.1 & - & - & - & - \\
\hline Z & 0.8 & - & - & - & - & - & - & - & - & - & - \\
\hline ED & 0.2 & - & - & - & - & 0.8 & - & 1.7 & - & 1.7 & - \\
\hline EJ & - & - & - & 0.2 & - & - & - & 0.8 & 1.2 & 1.1 & - \\
\hline GK & 0.7 & - & - & - & - & - & - & - & - & - & - \\
\hline IC & - & 0.7 & - & - & 0.7 & - & - & - & - & - & - \\
\hline $\mathrm{J}$ & - & - & - & 0.4 & 0.7 & - & - & - & - & - & - \\
\hline LA & 0.3 & - & - & 0.4 & 0.7 & - & - & - & - & - & - \\
\hline $\mathrm{U}$ & 0.2 & - & - & 0.5 & - & - & - & - & - & - & - \\
\hline$\Sigma \mathrm{n}=3$ & 2.1 & 5.1 & 2.6 & 1.8 & 4.2 & 2.3 & 3.3 & 2.5 & 4.8 & - & 1.1 \\
\hline$\Sigma \mathrm{n}=2$ & 2.6 & 3.7 & 5.1 & 3.9 & 4.5 & 0.8 & 5.4 & 3.3 & 4.8 & 2.2 & 6.5 \\
\hline$\Sigma \mathrm{n}=1$ & 26 & 47.6 & 69.2 & 47.8 & 73.9 & 86.8 & 70.7 & 84.2 & 88.1 & 76.1 & 80.4 \\
\hline
\end{tabular}


The analyses of the genetic structure of non-unique and unique genotypes in Germany revealed that unique genotypes tended to show positive inbreeding coefficients and heterozygote deficits, and less linkage disequilibria than the group of non-unique genotypes (Table 4).

Table 4 Analysis of ,single copy‘ genotypes in Germany (region H, LS and NG), divided in common $(\mathrm{n}>1)$ and unique $(\mathrm{n}=1)$ genotypes. Given are FIS-values for single loci $(* \mathrm{p}$ value $<0.05$, ***highly significant, $\mathrm{p}<0.001$ ) and the number of significant pairwise comparisons of linkage disequilibrium between 5 loci.

\begin{tabular}{lllllll}
\hline & 2001 & \multicolumn{5}{c}{2002} \\
\hline & $\mathrm{n}>1$ & $\mathrm{n}=1$ & $\mathrm{n}>1$ & $\mathrm{n}=1$ & $\mathrm{n}>1$ & $\mathrm{n}=1$ \\
Sm10 & $+0.126 \mathrm{NS}$ & $+0.070 * *$ & $-0.035 \mathrm{NS}$ & $+0.041 \mathrm{NS}$ & $-0.102 \mathrm{NS}$ & $+0.013 \mathrm{NS}$ \\
Sm11 & $+0.052 \mathrm{NS}$ & $+0.064 *$ & $-0.011 \mathrm{NS}$ & $+0.049 \mathrm{NS}$ & $-0.092 \mathrm{NS}$ & $-0.014 \mathrm{NS}$ \\
Sm17 & $+0.340 * * *$ & $+0.174 * * *$ & $+0.232 * *$ & $+0.075 *$ & $+0.230 \mathrm{NS}$ & $+0.240 * *$ \\
S16b & $-0.034 \mathrm{NS}$ & $+0.036 * *$ & $-0.072 \mathrm{NS}$ & $+0.023 \mathrm{NS}$ & $-0.022 \mathrm{NS}$ & $+0.124 * *$ \\
Sa45 & $+0.145 *$ & $+0.010 \mathrm{NS}$ & $+0.135 \mathrm{NS}$ & $-0.008 \mathrm{NS}$ & $-0.064 \mathrm{NS}$ & $+0.013 \mathrm{NS}$ \\
H deficit & 2 & 4 & 1 & 1 & 0 & 2 \\
H excess & $\mathrm{NS}$ & $\mathrm{NS}$ & $\mathrm{NS}$ & $\mathrm{NS}$ & $\mathrm{NS}$ & $\mathrm{NS}$ \\
Multilocus $F_{\text {IS }}+0.114 *$ & $+0.065 *$ & $+0.037 \mathrm{NS}+0.033 *$ & $-0.022 \mathrm{NS}$ & $+0.077 *$ \\
LD & 4 & 1 & 2 & 0 & 0 & 0 \\
\hline
\end{tabular}

As none of the parameters alone separated unique from non-unique genotypes in all years, the consistency of non-unique genotypes and the recapture of unique genotypes over three years was analysed for central Germany (region H and LS), where most of the nonunique genotypes were found. The sample collected from central Germany in 2001 included 1172 individuals, of which 453 were unique. In the following two years, only 23 of these genotypes (5.1\%) were rediscovered and all at a low frequency (5\%) of all individuals collected in 2002 and 2003, i.e. less than six individuals per genotype. On the other hand, 15 of the 51 non-unique genotypes in central Germany in 2001 failed to be detected in the following two years. Genotype 'I' was the most common genotype in Germany and the only one that was present in all German regions and all years, but was absent in Hungarian samples. This genotype declined in frequency from western to eastern central Germany towards northern Germany. In an additional sample in region LS in November 2002, it was the only genotype found on winter wheat, and, as genotype ' $L$ ', did not produce sexual 
morphs under simulated autumn conditions. These results, together with the observed differences in genetic structure between unique and non-unique genotypes, support the view that the group of unique genotypes largely includes individuals with a sexual generation, whereas non-unique genotypes represent asexual lineages, with additional genotypes of intermediate life-cycles in both groups, as indicated by yearly variation in parameters of genetic structure and clonal composition.

\section{Discussion}

Winter climate and aphid life-cycle \& abundance

In this study, no evidence was found that mild winters lead to a higher aphid abundance in the following year, although anholocyclic genotypes were common after mild winters. Instead, the lowest aphid densities were observed in central Germany after the mild winter of 2000/2001. Therefore, factors other than winter climate were predominantly acting upon population size and leading to regional differences (Carter et al, 1982; Dewar and Carter, 1984). The population from northern Germany showed the highest abundance, independent of winter temperatures. In broad agreement with our results, a higher abundance of grain aphids was also found in autumn populations at coastal sites in England with sandy soils and with early sowing dates (Foster et al, 2004). In England, Maudsley (1993) reported that after three years with mild winters which allowed aphid numbers to build up to produce large populations, a following cold winter led to an outbreak, probably because of the prolonged crop growing period in the following year. In our study, this effect was observed only in central Germany in region $\mathrm{H}$, but not in all other regions. The regional differences found in abundance and the result that asexual clones do not necessarily lead to higher aphid abundance, clearly need to be taken into account when predicting the population dynamics of this aphid species, especially in relation to pest outbreaks.

\section{Genetic structure of S. avenae populations}

The overall homogenous distribution of alleles over central Europe and the non-differentiated populations of northern Germany and southern Hungary suggest that gene flow was sufficient to prevent genetic isolation of populations over large distances in the time period surveyed. However, we did not observe a single large panmictic population from northern Germany to 
southern Hungary. The observation that populations from central Germany (region H) in 2001 showed differentiation to all other populations tested, whereas samples from northern Germany and Hungary were undifferentiated, indicates that population differentiation in this aphid species is driven by factors other than geographic distance. The unequal distribution of asexuals in central Germany, especially in western central Germany in 2001, could have led to 'apparent population differentiation', as asexual genotypes that have spread over a large area could lead to an over-representation of different allele combinations. The site from northern Germany showed a population differentiation in time. Genotypic diversity was consistently high in all years and yet single asexual genotypes were unlikely to cause this result, but farming practice was converted at this particular site from conventional to extensive management in 2002 (K. Lohaus, pers. comm.).

Hungarian and German populations sampled from wheat, paralleled the genetic structure in terms of deviations from HWE of populations from France, sampled from the same host plant. All wheat populations of S. avenae (Haack et al, 2000; present study) showed positive $F_{\text {IS }}$ values resulting in a significant heterozygote deficit, in contrast to samples from barley, maize and wheat volunteers in France tested by Haack et al (2000). These results make host plant adaptation likely (but see Papura et al, 2003). Alternatively life-cycle composition could lead to these results, as cyclic parthenogenetic $S$. avenae populations often show a heterozygote deficit, whilst asexual populations are characterised by negative $F_{I S}$ and heterozygote excess (Papura et al, 2003; Figueroa et al, in press), a phenomena observed also in other aphid species (Delmotte et al, 2002; Vorburger et al, 2003). Our results are partially in agreement with these observations, especially if unique genotypes (predominantly sexuals) and non-uniques (predominantly asexuals) were separated. However, data from those samples that showed the highest number of common (asexual) genotypes showed the highest heterozygote deficits. Furthermore, yearly variation in linkage disequilibrium and deviations from HWE indicated that some aphid lineages had an intermediate life-cycle.

In predominantly asexual populations on maize in France, strong linkage disequilibrium and heterozygote excess was observed (Papura et al, 2003). Likewise, in the present study, a trend towards linked loci was found within populations containing a large proportion of nonunique genotypes, including those persistent over years. Even so, the lack of heterozygote excess and the consequent decline in linkage in the group of non-uniques surviving colder winters suggests that this group changed in genotypic composition between years and hence did not exclusively include obligate asexuals. This would fit with the expectation that clones with an intermediate life-cycle should be present under variable winter climate conditions, 
although they were in fact shown to coexist with completely parthenogenetic lineages. In this context, it is interesting that $S$. avenae populations from Chile, that were thought to be anholocyclic, showed no linkage disequilibrium at all, but did display a low genotypic diversity and heterozygote excess (Figueroa et al, in press), yet three of five loci were identical in both studies. The different population genetic structure of Chilean populations could result from occasional sexual recombination or founder effects, as suggested by the authors (Figueroa et al, in press). The latter hypothesis is supported by the observation of the total lack of larger alleles at locus Sm10 (> 179bp) in Chilean populations in comparison with English or German populations (Figueroa et al, in press; Llewellyn et al, 2003; present study).

\section{Influence of winter climate on genotypic diversity}

In contrast to allelic distribution, the presence and frequency of genotypes was dependent on spatial and temporal changes within and between seasons. Within central German regions, some asexual genotypes became absent or decreased in frequency during successive colder winters. This study showed that the evenness of distribution of non-unique genotypes is a sensitive parameter for detecting the decline of dominant genotypes. These observations for central Germany are in agreement with laboratory test results by Weber (1985) who found exclusively holocyclic clones in region LS after a cold winter similar to the temperatures recorded in the winter of 2002/2003. Together with the observation of high genotypic diversity in Hungary (continental climate), our results are in agreement with those of Papura et al (2003) and the model predictions of Rispe and Pierre (1998) and Rispe et al (1998).

Southern Hungary and northern Germany might represent the climatic border for the spread of asexual clones, as perhaps only a few cold tolerant, persistent genotypes found in Germany occurred in this area. A recent laboratory study on a single S. avenae clone (Powell and Bale, 2004) proved that first instar nymphs and newly pre-reproductive adults were able to rapidly cold harden, without fitness costs and survive at low frequency even at a temperature of $-11^{\circ} \mathrm{C}$. Hoeller (1990) observed that first instar larvae could survive short periods of cold down to $-19{ }^{\circ} \mathrm{C}$ under field conditions, and were killed only when a second cold period followed. Accepting variability in cold tolerance between different genotypes, the observed consistent genotypes in Hungary and northern Germany could have partially survived the cold winters. In Hungary, a few genotypes were detected (these results) that were also found in Germany, including the common genotype ' $\mathrm{N}$ ', found in Hungary in both years of study. Likewise, Papura et al (2003) found three genotypes in western Romania in two 
consecutive years, $100 \mathrm{~km}$ east of the region sampled in the present study, but not in eastern Romania. Unfortunately, no data were available from southern Hungary in 2001 after an exceptionally mild winter. We speculate that genotype ' $N$ ' could have been rather common in that year and survived as a minor proportion of the population the subsequent cold winter.

Despite the general influence of cold winters reducing asexual lineages, some results and depending of the region studied - could not be explained by winter climate. At first, a rather high proportion of anholocyclic lineages were detected in central Germany, which was confirmed for two clones, 'I' and 'L'. Furthermore, genotypes 'I' and 'A' were similar to two common genotypes found in England and France and genotype ' $\mathrm{I}$ ' seems to be limited in spread to Scotland, whereas genotype 'A' was found almost 10 years ago in France and occurred throughout Britain (Llewellyn et al, 2003; present study, see Appendix Table A). These anholocyclic clones either were more cold tolerant than previously thought (see above) or were the result of an non-adaptive immigration from warmer climates, which does not fit the model expectation of an intermediate life-cycle in varying climates.

Second, a consistent high genotypic diversity was observed in northern Germany, although the winter climate was mild in the second winter of the study and common genotypes were present in the previous summer, but became rare after the mild winter. Either northern Germany is dependent on immigration of anholocyclic genotypes (Hoeller, 1990; Loxdale et al, 1985) or these genotypes did successfully reproduce but were distributed over a large area by typically strong winds in that region.

Third, the rather poor fit of changes in genotypic diversity to winter temperatures in both central German regions in the first two years of the study indicates that other environmental factors acting on a regional scale besides winter climate could well be responsible for the observed differences in distribution of genotypes, - for example, landscape structure (data will be published elsewhere). Central Germany is closer to regions with a mild winter climate than northern Germany, which could explain the low frequency of asexual genotypes in the latter region. In an earlier study from eastern central Germany, 78.9\% of 52 S. avenae clones were found to be anholocyclic, although the preceding winter was comparable cold compared with that of 2002/2003. As former studies could not discriminate between individual clones (i.e. using multilocus markers as now employed), it is possible that one or a few clones which had survived the cold winter and proliferated extensively during the following summer were thereupon repeatedly tested in the laboratory to give an inaccurate picture of life cycle success in relation to climate as a result of the abundance of clonal copies. 
The four commonest genotypes in Chile including 'Sa1', also found in France ('G6'), were different to the genotypes collected in England and earlier French samples as well as to genotypes collected in central Europe (Figueroa et al, in press; present study), indicating that the origin of Chilean clones is unlikely to be central Europe. So far, no 'superclone' has been found with a worldwide distribution. All recent studies indicate that several asexual common clones exist in Europe which partially overlap in their geographic distribution, similar to closely related species with hybrid zones. Further research is necessary to verify the consistency or spread of these clones, as well as studies investigating fitness differences between clones, including a joined European-wide data base.

\section{Acknowledgements}

Aphids collections and abundance data from northern Germany were kindly provided by Katharina Lohaus (Goettingen) and from Hungary by Stefan Toepfer (CABI-Bioscience, Switzerland). Site selection was supported by Carsten Thies (Goettingen), Tobias Purtauf (Giessen) and Julia Morzfeld (Goettingen). Aphid life-cycle tests were performed by Hussein Alkhedir (Goettingen). We thank two anonymous peer reviewers for their helpful comments. This work was supported by the German Ministry of Education and Science (BMBF, Code 01LC0020). 


\section{Discussion}

Patterns of intraspecific genetic variation result from interactions among both historical and contemporary processes. The advent of molecular markers enables scientists to investigate both. Historical processes can be studied by analysing changes in genetic structure and distribution of populations. This is of particular value for studies on small insect species that have a high reproduction rate and potential of dispersal. Flying aphids were collected from suction traps over the last four decades (Taylor et al. 1980). The analysis with molecular markers could reveal further insights in population dynamics and genetics of aphids.

In this study we focused on the contemporary processes shaping populations of the grain aphid, Sitobion avenae, which is an ideal model organism to study the impact of environmental forces at different spatial and temporal scales. A hierarchical sampling design over different spatial scales and three consecutive years was used for observations of patterns in life-cycle variation between years and regions under variable winter climate conditions as well as changes in clonal diversity within a plant growing season.

The results indicated a high geneflow over a large area $(>1000 \mathrm{~km})$ for this species. However, subtle substructuring between regional populations was observed, which could not be explained with isolation by geographic distance. Overall the populations from Germany and Hungary sampled from wheat fields revealed heterozygote deficits as was observed previously in wheat populations from France (Haack et al. 2000). However, heterozygote excess was observed from French $S$. avenae populations collected from maize (Haack et al. 2000). Although some clones were common on different host-plants, these results indicated a population substructuring by host plants. Therefore, to study the impact of other environmental forces on intraspecific variation, we compared populations sampled from a single host-plant. Clonal diversity was determined by two factors, winter climate and landscape structure. Cold winter climate effectively reduced the number of 'functional parthenogens' as revealed by empirical data of clonal presence/absence between years and their proportions within a region characterised by genetic structure (deviations from HardyWeinberg equilibrium and linkage disequilibrium). The latter parameters were not characterising non-unique genotypes and unique genotypes consistent over three years and clonal composition remarkably changed, probably because of lineages with an intermediate life-cycle present in both groups of unique and non-unique genotypes. This is partially in agreement with model expectations by Rispe et al. 1998, Rispe \& Pierre 1998 and Halkett et 
al. 2004). However, we have proven the existence of anholocyclic clones under variable climate conditions, which could only be explained either by non-adaptive immigration from warmer climate regions or a higher cold tolerance of particular clones than previously thought. From different perspectives we showed that differences in clonal diversity and genetic structure between regions separated by more than $100 \mathrm{~km}$ was apparent, which could not be explained by winter climate alone. The regions in central and northern Germany included wheat fields with surrounding landscape structure along a gradient of landscape complexity. As clonal diversity was showing a positive linear relationship to simple structured landscapes, landscape structure might contribute to clonal diversity synergistically to climate differences. The regional differences in clonal diversity will not allow to generate a simple model of life-cycle determination by winter climate alone. Before creating such a 'regional model' it is necessary to identify the size of 'regional populations'. We were able to limit the size of a geographic area, where populations are rather homogenous to a distance of $50 \mathrm{~km}$. The phenomenon that most of the genetic variation of herbivorous insects and pathogenic fungi is already found at the field scale (Via 1990, Morzfeld 2004) is supported by the present study. Recent new statistical approaches that move beyond average summary statistics like multivariate ordinations of pairwise differentiation statistics using principal coordinates and multidimensional scaling (e.g. Lessa 1990, Zhivotovsky et al. 2003, present study) or methods aimed at maximising among strata genetic variance (SAMOVA, Dupanloup et al. 2002) and recently Population Graphs (Dyer \& Nason 2004) will help to gain deeper insights into fine scale population structure. However, the analyses of population genetic structure should include as many microsatellite loci as possible, as each locus only contains a limited variation and possibly is not neutral to selection or is embedded in functional processes in the genome. The scientific progress in molecular research will enable scientists to gather more information from larger populations and including more marker loci to encompass both large sample sizes and the possibility for assignment tests of single individuals/clones to populations.

Molecular markers are useful tools to study the 'wax and wane' of clones (Llewellyn et al. 2003), i.e. to observe the results of dispersal, proliferation and mortality of clones under field conditions. Previous research on aphids revealed that the shape of population dynamics is rather similar between years, but abundance is varying (Veenker 2000, Hasken 2001, Haack et al. 2000). These recurrent seasonal patterns of development and dispersal of single aphid clones are the result of an oscillating process in clonal development during the parthenogenetic development in summer time. This was observed for other insect species 
(Tomiuk \& Woehrmann 1981, Niklasson et al. 2004), however regional differences of clonal oscillation have been reported for the first time (present study). We showed that clonal diversity in total was density independent and that a large proportion of 'functional parthenogens', including anholocyclic clones, not necessarily result in a high aphid abundance. However, changes in frequency of single clones within a plant growing season, were density dependent for single clones dependent on regional factors, whilst distribution patterns of other clones were density independent. Moreover, geographical barriers (hills and forest area) affected the local consistency of all clones sampled within single wheat fields within a season.

The present study laid the foundations for further monitoring of Sitobion avenae clones under variable climate and landscape conditions. To determine the causal factors that lead to seasonal patterns in clonal diversity and the spread of 'superclones' (Vorburger et al. 2003), the genetic and phenotypic variation of clones has to be studied experimentally. These results can be combined with observed dispersal patterns from our field observations. The recent studies indicate that several asexual common clones exist in Europe that overlap partially in their geographic distribution, similar to closely related species with hybrid zones. Further research is necessary to varify the consistency or spread of these clones, as well as studies investigting fitness differences between clones, including a joined data base. The results of both detailed monitoring of clones in the field and information of their physiology will clarify whether the success of clonal organisms can be explained by intraclonal variation or by migration of indifferent clones to favourable environments. As the grain aphid might be at the beginning of speciation, more knowledge is necessary about single clone host-plant adaptations both from laboratory performance tests and from field observations.

Despite the usefulness of molecular markers to detect patterns of population composition in the field, detailed research on physiological adaptations of clones and direct field observations are still necessary to avoid incomplete interpretations of population genetics data. For example laboratory studies on the life-cycle of $S$. avenae revealed single clones that include both asexual and sexual lineages. The identification of identical individuals in the field therefore cannot detect the whole clone and is restricted to the identification of 'functional parthenogens'. In addition, life-cycles of the observed common clones should be tested in the laboratory to determine whether these clones have the potential to outbreed by producing additional sexual morphs. To estimate whether selection could act on different colour morphs in S. avenae (Dedryver et al. 1994), e.g. via different susceptibility to natural 
enemies (Ankersmit et al. 1981, 1986) it has to be clarified to what extend clones inherit a stable colour phenotype, which will be topic of further research.

This study revealed by the use of molecular markers that aphids are not distributing randomly over large scales. Clearly, annual recurrent patterns in clonal diversity are dependent on climate and landscape structure. As we pointed out the regional size of homogenous 'population units', further research should include different regions, including varying landscape and winter climate characteristics to create a model for life-cycle composition and dispersal of this aphid species. As we have shown that geneflow is high enough to prevent genetic isolation between single regions, this aphid species would be an ideal organism to study at large geographic scales. A European data base of $S$. avenae clones could be created as microsatellites provide highly reproducible results. These further steps will enhance the chance of effective control of this pest species and moreover this species could become a model organism to observe changes in climate and land use management. 


\section{Appendix}

Table A Alleles (in bp) scored at five microsatellite loci for all multilocus genotypes with an absolute frequency > 1 sampled in Central Europe from 2001 to 2003 (N 01-03). Genotype 'E' is made up of the most common alleles at each locus. *identical at four loci (including Sm12, data not shown) to genotype 53(S.UK94) found in England 1994-1998 and France, ** to genotype (114 (F < 96)) found in England 1997 and 1998 and France prior to 1996 (Llewellyn et al, 2003).

\begin{tabular}{|c|c|c|c|c|c|c|c|c|c|c|c|}
\hline ID $n>1$ & Sm10 & $\operatorname{Sm} 10$ & Sm11 & Sm11 & Sm17 & Sm17 & S16B & S16B & 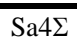 & $\mathrm{Sa} 4 \Sigma$ & N 01-03 \\
\hline$I^{*}$ & 164 & 166 & 144 & 149 & 178 & 179 & 210 & 275 & 162 & 168 & 194 \\
\hline $\mathrm{H}$ & 164 & 164 & 144 & 144 & 178 & 178 & 210 & 275 & 162 & 162 & 175 \\
\hline A ** & 152 & 166 & 144 & 144 & 178 & 178 & 173 & 189 & 156 & 172 & 115 \\
\hline M & 164 & 164 & 144 & 144 & 183 & 183 & 173 & 210 & 162 & 162 & 77 \\
\hline $\mathrm{N}$ & 164 & 254 & 148 & 156 & 178 & 179 & 160 & 206 & 162 & 162 & 67 \\
\hline $\mathrm{L}$ & 164 & 166 & 144 & 144 & 179 & 179 & 160 & 173 & 162 & 168 & 66 \\
\hline D & 164 & 208 & 144 & 144 & 178 & 178 & 173 & 181 & 156 & 172 & 39 \\
\hline Gi & 164 & 164 & 144 & 149 & 178 & 180 & 173 & 210 & 162 & 170 & 20 \\
\hline B & 160 & 164 & 144 & 149 & 178 & 178 & 173 & 210 & 162 & 168 & 18 \\
\hline $\mathbf{E}$ & 164 & 164 & 144 & 144 & 178 & 178 & 173 & 173 & 162 & 162 & 16 \\
\hline C & 160 & 164 & 144 & 144 & 178 & 183 & 173 & 275 & 162 & 170 & 12 \\
\hline $\mathrm{F}$ & 164 & 164 & 144 & 144 & 178 & 183 & 210 & 244 & 162 & 170 & 12 \\
\hline GJ & 164 & 168 & 144 & 144 & 180 & 180 & 236 & 275 & 162 & 170 & 11 \\
\hline $\mathrm{AA}$ & 152 & 166 & 144 & 144 & 178 & 178 & 173 & 189 & 156 & 156 & 9 \\
\hline GA & 164 & 164 & 144 & 144 & 180 & 180 & 173 & 275 & 162 & 162 & 8 \\
\hline $\mathrm{R}$ & 164 & 164 & 144 & 144 & 180 & 183 & 173 & 210 & 162 & 162 & 8 \\
\hline $\mathrm{Nx}$ & 164 & 164 & 148 & 156 & 178 & 179 & 160 & 206 & 162 & 162 & 7 \\
\hline $\mathrm{Y}$ & 164 & 164 & 144 & 144 & 178 & 180 & 173 & 173 & 162 & 162 & 7 \\
\hline YA & 164 & 168 & 144 & 144 & 178 & 180 & 210 & 210 & 162 & 162 & 7 \\
\hline EA & 164 & 164 & 144 & 144 & 178 & 178 & 173 & 189 & 162 & 162 & 6 \\
\hline EC & 164 & 164 & 144 & 144 & 178 & 178 & 173 & 210 & 162 & 162 & 6 \\
\hline ID & 164 & 166 & 144 & 149 & 178 & 179 & 212 & 283 & 162 & 168 & 6 \\
\hline $\mathrm{Q}$ & 164 & 168 & 144 & 144 & 178 & 178 & 173 & 232 & 162 & 162 & 6 \\
\hline $\mathrm{X}$ & 164 & 164 & 144 & 149 & 178 & 178 & 173 & 173 & 162 & 162 & 6 \\
\hline $\mathrm{AC}$ & 152 & 164 & 144 & 149 & 178 & 178 & 189 & 206 & 156 & 168 & 5 \\
\hline HX & 164 & 164 & 144 & 144 & 178 & 178 & 212 & 275 & 162 & 162 & 5 \\
\hline K & 152 & 164 & 144 & 147 & 179 & 184 & 173 & 177 & 166 & 170 & 5 \\
\hline RA & 164 & 164 & 144 & 149 & 180 & 183 & 173 & 210 & 162 & 170 & 5 \\
\hline W & 186 & 198 & 144 & 149 & 178 & 178 & 199 & 206 & 162 & 168 & 5 \\
\hline Z & 164 & 166 & 144 & 144 & 178 & 179 & 210 & 275 & 162 & 168 & 5 \\
\hline ED & 164 & 164 & 144 & 144 & 178 & 178 & 173 & 246 & 162 & 162 & 4 \\
\hline EJ & 164 & 164 & 144 & 148 & 178 & 178 & 173 & 199 & 162 & 162 & 4 \\
\hline GK & 164 & 168 & 144 & 144 & 183 & 183 & 173 & 210 & 162 & 170 & 4 \\
\hline IC & 164 & 166 & 144 & 149 & 178 & 179 & 173 & 210 & 162 & 168 & 4 \\
\hline $\mathrm{J}$ & 164 & 166 & 144 & 144 & 178 & 178 & 173 & 210 & 162 & 162 & 4 \\
\hline
\end{tabular}


Table A Continued

\begin{tabular}{|c|c|c|c|c|c|c|c|c|c|c|c|}
\hline ID $n>1$ & Sm10 & Sm10 & Sm11 & Sm11 & Sm17 & Sm17 & S16B & S16B & Sa $4 \Sigma$ & 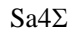 & N 01-03 \\
\hline LA & 164 & 166 & 144 & 144 & 178 & 179 & 160 & 173 & 162 & 168 & 4 \\
\hline $\mathrm{U}$ & 164 & 164 & 144 & 144 & 183 & 183 & 173 & 210 & 162 & 170 & 4 \\
\hline EB & 164 & 164 & 144 & 144 & 178 & 178 & 173 & 197 & 162 & 162 & 3 \\
\hline $\mathrm{EE}$ & 164 & 164 & 144 & 144 & 178 & 178 & 173 & 275 & 162 & 162 & 3 \\
\hline $\mathrm{EF}$ & 164 & 166 & 144 & 144 & 178 & 178 & 173 & 275 & 162 & 162 & 3 \\
\hline EH & 166 & 168 & 144 & 144 & 178 & 178 & 173 & 173 & 162 & 162 & 3 \\
\hline EI & 164 & 164 & 144 & 148 & 178 & 178 & 173 & 173 & 162 & 162 & 3 \\
\hline EL & 164 & 164 & 144 & 149 & 178 & 178 & 173 & 210 & 162 & 162 & 3 \\
\hline EN & 164 & 164 & 144 & 149 & 178 & 178 & 210 & 275 & 162 & 162 & 3 \\
\hline EV & 164 & 166 & 144 & 144 & 178 & 178 & 173 & 173 & 162 & 172 & 3 \\
\hline EX & 164 & 166 & 144 & 148 & 178 & 178 & 173 & 173 & 162 & 162 & 3 \\
\hline EY & 164 & 164 & 144 & 149 & 178 & 178 & 173 & 238 & 162 & 162 & 3 \\
\hline FC & 164 & 164 & 144 & 144 & 178 & 183 & 173 & 210 & 162 & 162 & 3 \\
\hline FD & 164 & 164 & 144 & 144 & 178 & 183 & 173 & 210 & 162 & 170 & 3 \\
\hline $\mathrm{FE}$ & 164 & 164 & 144 & 144 & 178 & 183 & 173 & 173 & 170 & 170 & 3 \\
\hline FI & 164 & 164 & 144 & 144 & 178 & 183 & 173 & 173 & 162 & 162 & 3 \\
\hline FJ & 164 & 164 & 144 & 148 & 178 & 183 & 173 & 173 & 162 & 162 & 3 \\
\hline IA & 164 & 166 & 144 & 149 & 178 & 178 & 160 & 173 & 162 & 162 & 3 \\
\hline LC & 164 & 164 & 144 & 144 & 179 & 179 & 160 & 197 & 168 & 172 & 3 \\
\hline LE & 164 & 166 & 144 & 149 & 178 & 179 & 160 & 173 & 168 & 168 & 3 \\
\hline LF & 164 & 166 & 149 & 149 & 178 & 179 & 160 & 173 & 168 & 172 & 3 \\
\hline NG & 164 & 254 & 144 & 144 & 178 & 178 & 173 & 268 & 162 & 162 & 3 \\
\hline $\mathrm{P}$ & 164 & 164 & 144 & 149 & 178 & 178 & 173 & 173 & 156 & 162 & 3 \\
\hline V & 164 & 166 & 144 & 148 & 178 & 178 & 173 & 173 & 156 & 162 & 3 \\
\hline AB & 152 & 166 & 144 & 144 & 178 & 178 & 173 & 189 & 156 & 174 & 2 \\
\hline AD & 164 & 166 & 144 & 144 & 178 & 178 & 173 & 189 & 156 & 172 & 2 \\
\hline BA & 164 & 164 & 144 & 149 & 178 & 178 & 173 & 173 & 162 & 168 & 2 \\
\hline DC & 166 & 166 & 144 & 144 & 178 & 178 & 173 & 181 & 156 & 172 & 2 \\
\hline EG & 164 & 166 & 144 & 144 & 178 & 178 & 210 & 210 & 162 & 162 & 2 \\
\hline EK & 164 & 164 & 144 & 149 & 178 & 178 & 173 & 189 & 162 & 162 & 2 \\
\hline EM & 164 & 164 & 144 & 149 & 178 & 178 & 210 & 210 & 162 & 162 & 2 \\
\hline EO & 166 & 166 & 144 & 149 & 178 & 178 & 173 & 173 & 162 & 162 & 2 \\
\hline EP & 166 & 190 & 144 & 149 & 178 & 178 & 208 & 275 & 162 & 162 & 2 \\
\hline EQ & 164 & 164 & 148 & 149 & 178 & 178 & 173 & 206 & 162 & 162 & 2 \\
\hline ER & 164 & 164 & 149 & 149 & 178 & 178 & 173 & 173 & 162 & 162 & 2 \\
\hline ES & 164 & 164 & 144 & 144 & 178 & 178 & 173 & 189 & 162 & 168 & 2 \\
\hline ET & 164 & 166 & 144 & 144 & 178 & 178 & 173 & 173 & 162 & 168 & 2 \\
\hline EU & 164 & 164 & 144 & 148 & 178 & 178 & 160 & 173 & 162 & 168 & 2 \\
\hline EW & 164 & 164 & 144 & 144 & 178 & 179 & 173 & 173 & 162 & 162 & 2 \\
\hline EZ & 164 & 168 & 148 & 149 & 178 & 178 & 173 & 173 & 162 & 172 & 2 \\
\hline FA & 164 & 164 & 144 & 144 & 178 & 183 & 173 & 189 & 162 & 162 & 2 \\
\hline FG & 164 & 164 & 144 & 144 & 178 & 183 & 210 & 283 & 162 & 162 & 2 \\
\hline $\mathrm{FH}$ & 164 & 164 & 144 & 149 & 178 & 183 & 173 & 210 & 162 & 162 & 2 \\
\hline FK & 164 & 164 & 144 & 144 & 178 & 183 & 173 & 283 & 162 & 162 & 2 \\
\hline FZ & 164 & 166 & 149 & 149 & 178 & 183 & 173 & 245 & 168 & 170 & 2 \\
\hline G & 164 & 164 & 144 & 149 & 178 & 178 & 173 & 173 & 162 & 170 & 2 \\
\hline
\end{tabular}


Table A Continued

\begin{tabular}{|c|c|c|c|c|c|c|c|c|c|c|c|}
\hline ID $n>1$ & $\operatorname{Sm} 10$ & Sm10 & Sm11 & Sm11 & Sm17 & Sm17 & S16B & S16B & $\mathrm{Sa} 4 \Sigma$ & 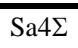 & N 01-03 \\
\hline$\overline{\mathrm{GL}}$ & 164 & 168 & 144 & 144 & 183 & 183 & 173 & 275 & 162 & 170 & 2 \\
\hline GM & 164 & 164 & 144 & 144 & 178 & 181 & 173 & 173 & 156 & 162 & 2 \\
\hline GN & 164 & 166 & 144 & 144 & 178 & 181 & 173 & 238 & 162 & 162 & 2 \\
\hline GO & 164 & 164 & 144 & 149 & 178 & 178 & 173 & 214 & 162 & 170 & 2 \\
\hline HY & 164 & 164 & 144 & 144 & 178 & 178 & 212 & 268 & 162 & 162 & 2 \\
\hline IB & 164 & 166 & 144 & 149 & 178 & 178 & 173 & 173 & 162 & 162 & 2 \\
\hline IE & 164 & 166 & 144 & 156 & 178 & 179 & 173 & 189 & 162 & 168 & 2 \\
\hline IF & 164 & 164 & 148 & 149 & 178 & 178 & 173 & 210 & 162 & 162 & 2 \\
\hline JA & 164 & 164 & 144 & 144 & 178 & 178 & 173 & 189 & 162 & 162 & 2 \\
\hline LB & 166 & 166 & 144 & 149 & 178 & 179 & 160 & 173 & 162 & 168 & 2 \\
\hline LD & 164 & 284 & 144 & 144 & 178 & 179 & 160 & 230 & 162 & 168 & 2 \\
\hline MA & 164 & 168 & 144 & 144 & 183 & 183 & 173 & 210 & 162 & 162 & 2 \\
\hline MB & 166 & 166 & 144 & 149 & 183 & 183 & 173 & 216 & 162 & 162 & 2 \\
\hline MX & 164 & 164 & 144 & 144 & 183 & 183 & 173 & 173 & 162 & 162 & 2 \\
\hline $\mathrm{O}$ & 166 & 166 & 144 & 144 & 178 & 178 & 210 & 275 & 162 & 162 & 2 \\
\hline PA & 164 & 164 & 144 & 144 & 178 & 178 & 173 & 173 & 156 & 162 & 2 \\
\hline QA & 164 & 168 & 144 & 149 & 178 & 178 & 173 & 232 & 162 & 162 & 2 \\
\hline QB & 164 & 168 & 144 & 149 & 178 & 178 & 173 & 189 & 162 & 162 & 2 \\
\hline S & 164 & 168 & 144 & 149 & 182 & 183 & 173 & 173 & 168 & 172 & 2 \\
\hline UB & 164 & 164 & 144 & 144 & 183 & 183 & 210 & 268 & 162 & 170 & 2 \\
\hline VA & 164 & 166 & 144 & 144 & 178 & 178 & 173 & 238 & 156 & 162 & 2 \\
\hline VB & 164 & 164 & 144 & 148 & 178 & 178 & 173 & 210 & 156 & 162 & 2 \\
\hline VC & 164 & 164 & 144 & 148 & 178 & 178 & 173 & 173 & 156 & 162 & 2 \\
\hline Total & & & & & & & & & & & 1112 \\
\hline
\end{tabular}


Table B Collection of $S$. avenae in winter wheat fields in two regions, Hesse $(\mathrm{H})$ and Lower Saxony (SN) in June and July 2001. N-S $\mathrm{S}_{\max }=$ pair of fields with maximum North-South distance (coordinates); $\mathrm{W}-\mathrm{O}=$ pair of fields with maximum West-East distance; $\mathrm{D}_{\max }, \mathrm{D}_{\min }, \mathrm{D}_{\text {mean }}=$ maximum, minimum and mean distance between all pairwise compared fields.

\begin{tabular}{lccccccc}
\hline & $\mathrm{H}$ & $\mathrm{H}$ & $\mathrm{SN}$ & $\mathrm{SN}$ & $\mathrm{H}$ & $\mathrm{SN}$ \\
& June & July & June & July & $\begin{array}{c}\text { June }+ \\
\text { July }\end{array}$ & $\begin{array}{c}\text { June }+ \\
\text { July }\end{array}$ & Total \\
\hline $\mathrm{N}_{\text {fields }}$ & 13 & 13 & 7 & 16 & 14 & 17 & 31 \\
& $50^{\circ} 48 \mathrm{~N}$ & $50^{\circ} 48 \mathrm{~N}$ & $51^{\circ} 39 \mathrm{~N}$ & $51^{\circ} 39 \mathrm{~N}$ & $50^{\circ} 48 \mathrm{~N}$ & $51^{\circ} 39 \mathrm{~N}$ & $51^{\circ} 39 \mathrm{~N}$ \\
$\mathrm{~N}-\mathrm{S}_{\max }$ & $50^{\circ} 42 \mathrm{~N}$ & $50^{\circ} 42 \mathrm{~N}$ & $51^{\circ} 25 \mathrm{~N}$ & $51^{\circ} 25 \mathrm{~N}$ & $50^{\circ} 42 \mathrm{~N}$ & $51^{\circ} 25 \mathrm{~N}$ & $50^{\circ} 42 \mathrm{~N}$ \\
& $8^{\circ} 17 \mathrm{O}$ & $8^{\circ} 17 \mathrm{O}$ & $9^{\circ} 51 \mathrm{O}$ & $9^{\circ} 45 \mathrm{O}$ & $8^{\circ} 17 \mathrm{O}$ & $9^{\circ} 45 \mathrm{O}$ & $8^{\circ} 17 \mathrm{O}$ \\
${\mathrm{W}-\mathrm{O}_{\max }}^{\circ} 42 \mathrm{O}$ & $8^{\circ} 42 \mathrm{O}$ & $10^{\circ} 6 \mathrm{O}$ & $10^{\circ} 16 \mathrm{O}$ & $8^{\circ} 42 \mathrm{O}$ & $10^{\circ} 16 \mathrm{O}$ & $10^{\circ} 16 \mathrm{O}$ \\
$\mathrm{D}_{\max }$ & 31.6 & 31.6 & 27.0 & 38.3 & 31.6 & 38.8 & 167.6 \\
& 1.8 & 1.8 & 4.0 & 4.0 & 1.8 & 4 & 106 \\
$\mathrm{D}_{\min }$ & 12.4 & 12.0 & 16.3 & 17.2 & 12.2 & 17.2 & 131.6 \\
& $(0.8)$ & $(0.7)$ & $(1.4)$ & $(0.7)$ & $(0.7)$ & $(0.7)$ & $(0.8)$ \\
\hline $\mathrm{D}_{\text {mean }}(\mathrm{SE})$ & & & & & & & \\
\hline
\end{tabular}


Table C Wheat field locations within the regions in central (LS and H) and northern Germany (NG) sampled in June (I) and/or July (II) in 2001 with amount of arable land, grassland, forest (\%), index for size and shape of fields (perimeter-area ratio, L-PAR) and height profile ('mean slope') of each field surrounding landscape in a 4000 x 4000 m square. Fields were grouped by amount of arable land ('Class'). In addition, incidence of insecticide applications during earring of wheat, the number of genotypes present in a sample $\left(\mathrm{N}_{\mathrm{g}}\right)$ and the number of sampled adult $S$. avenae $\left(\mathrm{N}_{\mathrm{i}}\right)$ were listed. n.a. = data not available.

\begin{tabular}{|c|c|c|c|c|c|c|c|c|c|}
\hline Field (Date) & Class & $\begin{array}{c}\text { Arable } \\
\text { land [\%] }\end{array}$ & $\begin{array}{c}\text { Grassland } \\
\text { [\%] }\end{array}$ & $\begin{array}{c}\text { Forest } \\
\text { [\%] }\end{array}$ & L-PAR & $\begin{array}{l}\text { Mean } \\
\text { Slope }\end{array}$ & $\begin{array}{c}\text { Insecticide } \\
\text { applied }\end{array}$ & $\mathrm{N}_{\mathrm{g}}$ & $\mathrm{N}_{\mathrm{i}}$ \\
\hline H $01 \quad$ (I \& II) & $\mathrm{A}$ & 4.9 & 31.0 & 41.1 & 0.017 & 6.943 & no & 25 & 58 \\
\hline H 02 (I \& II) & A & 8.6 & 30.2 & 43.0 & 0.014 & 9.638 & no & 22 & 48 \\
\hline Н 03 (I \& II) & A & 15.0 & 23.2 & 48.7 & 0.018 & 8.051 & no & 28 & 46 \\
\hline H 19 (I \& II) & A & 19.8 & 18.1 & 52.2 & 0.019 & 8.995 & no & 21 & 44 \\
\hline H 04 (II) & B & 26.7 & 24.4 & 42.0 & 0.018 & 5.643 & no & 10 & 24 \\
\hline H 05 (I \& II) & B & 37.7 & 17.8 & 31.8 & 0.020 & 5.439 & no & 32 & 45 \\
\hline H 07 (I \& II) & $\mathrm{B}$ & 38.8 & 13.7 & 44.1 & 0.016 & 5.937 & no & 28 & 46 \\
\hline Н 09 (I \& II) & B & 36.2 & 12.5 & 48.0 & 0.015 & 7.121 & no & 26 & 42 \\
\hline H 14 (I) & B & 33.4 & 14.0 & 43.9 & 0.014 & 6.313 & no & 16 & 23 \\
\hline H 15 (I \& II) & B & 25.7 & 15.1 & 46.7 & 0.017 & 7.851 & no & 26 & 46 \\
\hline H 20 (I \& II) & $\mathrm{B}$ & 25.6 & 16.5 & 54.9 & 0.013 & 6.654 & no & 22 & 44 \\
\hline LS 10 (I \& II) & B & 37.7 & 6.5 & 35.2 & 0.012 & 5.201 & no & 26 & 39 \\
\hline LS 11 (II) & B & 37.3 & 20.0 & 37.4 & 0.012 & 3.481 & no & 24 & 32 \\
\hline LS 18 (II) & B & 38.9 & 16.1 & 35.4 & 0.016 & 5.253 & $?$ & 18 & 24 \\
\hline H 06 (I \& II) & $\mathrm{C}$ & 40.4 & 13.1 & 42.5 & 0.016 & 5.826 & no & 28 & 46 \\
\hline H 11 (I \& II) & $\mathrm{C}$ & 51.1 & 10.4 & 31.9 & 0.014 & 4.395 & no & 34 & 48 \\
\hline LS 03 (I \& II) & $\mathrm{C}$ & 42.8 & 11.5 & 42.7 & 0.014 & 4.574 & no & 38 & 51 \\
\hline LS 04 (II) & $\mathrm{C}$ & 49.0 & 16.3 & 28.9 & 0.014 & 5.718 & yes & 14 & 29 \\
\hline LS 06 (I \& II) & $\mathrm{C}$ & 47.4 & 16.2 & 31.8 & 0.014 & 3.214 & no & 37 & 42 \\
\hline LS 07 (II) & $\mathrm{C}$ & 52.8 & 18.9 & 24.1 & 0.012 & 3.999 & yes & 17 & 24 \\
\hline LS 14 (II) & $\mathrm{C}$ & 50.6 & 17.2 & 24.4 & 0.015 & 4.170 & yes & 16 & 24 \\
\hline LS 17 (I) & $\mathrm{C}$ & 45.5 & 9.2 & 39.9 & 0.014 & 6.220 & yes & 19 & 24 \\
\hline H 12 (I \& II) & $\mathrm{D}$ & 62.6 & 11.9 & 16.3 & 0.017 & 2.830 & no & 24 & 46 \\
\hline LS 01 (II) & $\mathrm{D}$ & 69.7 & 6.6 & 4.2 & 0.009 & 0.840 & no & 23 & 30 \\
\hline LS 02 (I \& II) & $\mathrm{D}$ & 65.0 & 12.9 & 15.0 & 0.015 & 5.088 & yes & 40 & 48 \\
\hline LS 05 (II) & $\mathrm{D}$ & 60.7 & 15.5 & 18.6 & 0.012 & 4.830 & yes & 20 & 23 \\
\hline LS 08 (II) & $\mathrm{D}$ & 73.4 & 4.4 & 12.9 & 0.009 & 1.499 & yes & 15 & 19 \\
\hline LS 09 (I \& II) & $\mathrm{D}$ & 73.7 & 6.7 & 15.7 & 0.008 & 2.148 & no & 42 & 54 \\
\hline LS 12 (II) & $\mathrm{D}$ & 83.4 & 5.0 & 7.1 & 0.008 & 2.774 & yes & 20 & 24 \\
\hline LS 15 (II) & $\mathrm{D}$ & 72.1 & 14.0 & 14.1 & 0.011 & 1.982 & yes & 23 & 30 \\
\hline LS 16 (I \& II) & $\mathrm{D}$ & 70.6 & 9.1 & 14.4 & 0.009 & 2.486 & yes & 34 & 46 \\
\hline NG $\quad$ (I \& II) & & 60.1 & 11.1 & 22.5 & n.a. & n.a. & yes & 83 & 92 \\
\hline
\end{tabular}


Table D Arithmetic mean of landscape parameters for central German regions, calculated from $4000 \mathrm{x}$ $4000 \mathrm{~m}$ squares of all locations sampled in regions, Hesse (H) and Lower Saxony (SN) in June and July 2001. $\mathrm{N}_{\text {fields }}=$ no. of fields with $S$. avenae collections; 1 = percentage of arable land and grassland in the field surrounding landscape, average (SE) over fields sampled per region and date; 2 = mean slope and standard deviation of all fields in the surrounding landscape; 3 = mean of the L-PAR (Ratio of total perimeter of fields and the total area of the landscape sector); $\mathrm{D}_{\max }, \mathrm{D}_{\min }, \mathrm{D}_{\text {mean }}=$ maximum, minimum and mean distance between all pairwise compared fields; $\mathrm{N}_{\text {insecticide app. }}=$ number of fields with insecticide treatment/without treatment between mid-development of the ear (BBCH 55) and begin of bloom (BBCH 61). For the single site from northern Germany (NG) the amount of arable land was $60.1 \%$ in a $4000 \times 4000 \mathrm{~m}$ square.

\begin{tabular}{|c|c|c|c|c|c|c|c|}
\hline & $\begin{array}{c}\mathrm{H} \\
\text { June }\end{array}$ & $\begin{array}{c}\mathrm{H} \\
\text { July }\end{array}$ & $\begin{array}{l}\text { SN } \\
\text { June }\end{array}$ & $\begin{array}{l}\text { SN } \\
\text { July }\end{array}$ & $\begin{array}{c}\mathrm{H} \\
\text { June + } \\
\text { July }\end{array}$ & $\begin{array}{c}\text { SN } \\
\text { June + } \\
\text { July }\end{array}$ & Total \\
\hline $\mathrm{N}_{\text {fields }}$ & 13 & 13 & 7 & 16 & 14 & 17 & 31 \\
\hline arable land \% & 30.8 & 30.3 & 54.7 & 57.8 & 30.5 & 57.1 & 45.1 \\
\hline$(\mathrm{SE})^{1}$ & (4.6) & (4.6) & (5.5) & (3.8) & $(4.2)$ & (3.6) & (3.6) \\
\hline grassland \% & 17.5 & 18.3 & 10.3 & 12.3 & 18.0 & 12.1 & 14.8 \\
\hline$(\mathrm{SE})^{1}$ & (1.9) & (1.9) & (1.3) & (1.3) & (1.8) & $(1.2)$ & $(1.2)$ \\
\hline Slope mean & 6.617 & 6.563 & 4.133 & 3.578 & 6.545 & 3.734 & 5.001 \\
\hline$(\mathrm{SE})^{2}$ & $(0.510)$ & $(0.515)$ & $(0.579)$ & $(0.375)$ & $(0.477)$ & $(0.385)$ & $(0.391)$ \\
\hline Slope SD & 3.863 & 3.873 & 3.148 & 2.635 & 3.884 & 2.767 & 3.271 \\
\hline$(\mathrm{SE})^{2}$ & $(0.262)$ & $(0.262)$ & $(0.500)$ & $(0.255)$ & $(0.243)$ & $(0.274)$ & $(0.209)$ \\
\hline L-PAR & 0.016 & 0.017 & 0.012 & 0.012 & 0.016 & 0.012 & 0.014 \\
\hline$(\mathrm{SE})^{3}$ & $(0.001)$ & $(0.001)$ & $(0.001)$ & $(0.001)$ & $(0.001)$ & $(0.001)$ & $(0.001)$ \\
\hline$D_{\max }$ & 31.6 & 31.6 & 27.0 & 38.3 & 31.6 & 38.8 & 167.6 \\
\hline $\mathrm{D}_{\min }$ & 1.8 & 1.8 & 4.0 & 4.0 & 1.8 & 4 & 106 \\
\hline \multirow{2}{*}{$\mathrm{D}_{\text {mean }}(\mathrm{SE})$} & 12.4 & 12.0 & 16.3 & 17.2 & 12.2 & 17.2 & 131.6 \\
\hline & $(0.8)$ & $(0.7)$ & (1.4) & $(0.7)$ & $(0.7)$ & $(0.7)$ & $(0.8)$ \\
\hline $\mathrm{N}_{\text {insecticide app. }}$ & $0 / 0$ & $0 / 0$ & $3 / 7$ & $9 / 16$ & $0 / 0$ & $10 / 17$ & $10 / 31$ \\
\hline
\end{tabular}




\section{References}

Ankersmit GW, Acreman TM, Dijkman H (1981) Parasitism of colour forms in Sitobion avenae. Entomologia Experimentalis et Applicata, 29, 362-363.

Ankersmit GW, Bell C, Dijkman H, Mace N, Riestra S, Schroeder J, de Visser C (1986) Incidence of parasitism by Aphidius ropalosiphi in colour forms of the aphid Sitobion avenae. Entomologia Experimentalis et Applicata, 40, 223-229.

Apablaza J (1974) Presencia de Macrosiphum (Sitobion) avenae (F.) (Homoptera, Aphididae) en sementeras de trigo en Chile. Ciencia e Investigacion Agraria, 1, 69-70.

Avise JC (1994) Molecular markers: Natural history and Evolution. Chapman and Hall, New York.

Barber MD, Moores GD, Tatchell GM, Vice WE, Denholm I (1999) Insecticide resistance in the current-lettuce aphid, Nasonovia ribisnigri (Hemiptera: Aphididae) in the UK. Bulletin of Entomological research, 89, 17-23.

Bauer B, Schmid B (1996) Spatial and temporal patterns of genetic diversity within species. In: Biodiversity: A Biology of numbers and difference (ed. Gaston KJ), pp. 169-201.

Behrens T, Purtauf T, Wolters V, Köhler W, Dauber J (2001) Study site selection and gradient detection in complex landscapes using an automated patch detection tool (PaDS). In: Belward A, Binaghi E, Brivio PA, Aurelio G, Tosi G (eds) Proceedings of the International Workshop on Geo-Spatial Knowledge Processing of Natural Resource Management. ARTESTAMPA, Daverio, pp. 217-220.

Blackman RL, Eastop VF (1984) Aphids on the World's crops: an identification and information guide. John Wiley and Sons, Chichester.

Carter N, Dixon AFG, Rabbinge R (1982) Cereal aphid populations: Biology, simulation and prediction. Pudoc, Wageningen.

Chao A, Shen TJ (2003a) Non-parametric estimation of Shannon's index of diversity when there are unseen species in sample. Environmental and Ecological Statistics, 10, 429443.

Chao A, Shen TJ (2003b) Program SPADE (Species Prediction And Diversity Estimation). Program and User’s Guide. http://chao.stat.nthu.edu.tw.

Dean GJ (1973) Aphid colonization in spring cereals. Annals of applied Biology, 75, 183-193.

Dean GJ (1974) The overwintering and abundance of cereal aphids. Annals of Applied Biology, 76, 1-7.

DeBarro PJ, Sherrat TM, Carvalho GR, Nicol D, Lyengar A, Maclean N (1994). An analysis of secondary spread by putative clones of Sitobion avenae within a Hampshire wheat field using the multilocus (GATA) 4 probe. Insect Molecular Biology, 3, 253-260. 
DeBarro PJ, Sherratt TN, Carvalho GR, Nicol D, Iyengar A, Maclean N (1995a) Geographic and microgeographic genetic differentiation in two aphid species over southern England using the multilocus (GATA) 4 probe. Molecular Ecology, 4, 375-382.

DeBarro PJ, Sheratt TN, Brookes CP, David O, Maclean N (1995b) Spatial and temporal genetic variation in British field populations of the grain aphid Sitobion avenae (F.) (Hemiptera: Aphididae) studied using RAPD-PCR. Proceedings of the Royal Society, London. Series B, 262, 321-327.

Dedryver CA, Le Gallic JF, Fima F (1994) Local intraspecific variation in the cereal aphid Sitobion avenae F. IOBC Bulletin, 17, 16-19.

Dedryver CA, Le Gallic JF, Gauthier JP, Simon JC (1998) Life-cycle of the cereal aphid Sitobion avenae (F.) polymorphism and comparison of life history traits associated with sexuality. Ecological Entomology, 23, 123-132.

Dedryver CA, Hulle M, Le Gallic JF, Caillaud MC, Simon JC (2001) Coexistence in space and time of sexual and asexual populations of the cereal aphid Sitobion avenae. Oecologia, 128, 379-388.

Delmotte F, Leterme N, Bonhomme J, Rispe C, Simon JC (2001) Multiple routes to asexuality in an aphid. Proceedings of the Royal Society, London. Series B, 268, 2291-2299.

Delmotte F, Leterme N, Gauthier JP, Rispe C, Simon JC (2002) Genetic architecture of sexual and asexual populations of the aphid Rhopalosiphum padi based on allozyme and microsatellite markers. Molecular Ecology, 11, 711-723.

Delmotte F, Sabater B, Leterme N et al. (2003) Phylogenetic evidence for hybrid origins of asexual lineages in an aphid species. Evolution, 57, 1291-1303.

Delorme R, Auge D, Bethenod MT, Villatte F (1997) Insecticide resistance in a strain of Aphis gossypii from Southern France. Pesticide Science, 49, 90-96.

Devonshire AL, Sawicki RM (1979) Insecticide-resistant Myzus persicae as an example of evolution by gene duplication. Nature, 280, 140-141.

Dewar AM, Carter N (1984) Decision trees to assess the risk of cereal aphid outbreakes in summer in England. Bulletin of Entomological Research, 74, 387-398.

Digby PGN, Kempton RA (1987) Multivariate Analysis of Ecological Communities. Chapman and Hall, London.

Dixon AFG, Horth S, Kindlmann, P (1993) Migration in insects: cost and strategies. Journal of Animal Ecology, 62, 182-190.

Dixon AFG (1998). Aphid Ecology, 2nd edn. Chapman \& Hall, Weinheim.

Dong QZ, Wei K, Meng QZ, Wu FZ, Zhang GX, Zong TS, Liu DH (1987) Investigation on long distance migration of grain aphid (Macrosiphum avenae [Fabr.]) in Ningxia.) In chinese. Acta Entomologica Sinica, 30, 277-284. 
Dupanloup I, Schneider S, Excoffier L (2002) A simulated annealing approach to define the genetic structure of populations. Molecular Ecology, 11, 2571-2581.

Dyer RJ, Nason JD (2004) Population Graphs: the graph theoretic shape of genetic structure. Molecular Ecology, doi: 10.1111/j.1365-294X.2004.02177.x, in press.

Excoffier L, Smouse PE, Quattro JM (1992) Analysis of molecular variance inferred from metric distances among DNA haplotypes: application to human mitochondrial DNA restriction data. Genetics, 131, 479-491.

Field LM, Blackman RL (2003) Insecticide resistance in the aphid Myzus persicae (Sulzer): chromosome location and epigenetic effects on esterase gene expression in clonal lineages. Biological Journal of the Linnean Society, 79, 107-113.

Figueroa CC, Simon JC, Le Gallic JF, Prunier-Leterme N, Briones LM, Dedryver CA, Niemeyer HM. Genetic structure and clonal diversity of an introduced pest in Chile, the cereal aphid Sitobion avenae. Heredity, in press.

Foster GN, Blake S, Tones SJ, Barker I, Harrington R (2004) Occurrence of barley yellow dwarf virus in autumn-sown cereal crops in the United Kingdom in relation to field characteristics. Pest Management Science, 60, 113-125.

Foster SP, Harrington R, Dewar AM, Denholm I, Devonshire AL (2002) Temporal and spatial dynamics of insecticide resistance in Myzus persicae (Hemiptera: Aphididae). Pest Management Science, 58: 895-907.

Goldstein DB, Schlötterer C (1999) Microsatellites: evolution and applications, Oxford University Press, Oxford.

Goudet J, Raymond M, de Meeüs T, Rousset F (1996) Testing differentiation in diploid populations. Genetics, 144, 1933-1940.

Goudet J (2001) FSTAT, a program to estimate and test gene diversities and fixation indices (version 2.9.3). Available from http://www.unil.ch/izea/softwares/fstat.html.

Grant A Herron GA, Powis K, Rophail, J (2001) Insecticide resistance in Aphis gossypii Glover (Hemiptera: Aphididae), a serious threat to Australian cotton. Australian Journal of Entomology, 40, 85-89.

Guillemaud T, Mieuzet L, Simon JC (2003) Spatial and temporal genetic variability in French populations of the peach-potato aphid, Myzus persicae. Heredity, 91, 143-152.

Guo SW, Thompson E (1992) Performing the exact test of Hardy-Weinberg proportion for multiple alleles. Biometrics, 48, 361-172.

Haack L, Simon JC, Gauthier JP, Plantegenest M, Dedryver CA (2000) Evidence for predominant clones in a cyclically parthenogenetic organism provided by combined demographic and genetic analyses. Molecular Ecology, 9, 2055-2066. 
Halkett F, Harrington R, Hulle M, Kindlmann P, Menu F, Rispe C, Plantegenest M (2004) Dynamics of production of sexual forms in aphids: theoretical and experimental evidence for adaptive "coin-flipping" plasticity. The American Naturalist, 163, E112-E125.

Hand SC (1989) The overwintering of cereal aphids on Gramineae in southern England, 1977-1980. Annals of Applied Biology, 115, 17-29.

Hardy J (1850) Entomology. IX. The aphides of corn and grasses. 1. Aphis avenae, Linnaeus. North British Agriculturist and Journal of Horticulture, p. 596.

Hasken KH (2001) Der Einfluss von Extensivierung auf das Auftreten von Getreideblattlaeusen und ihren natuerlichen Gegenspielern in Winterweizen, $\mathrm{PhD}$ thesis, University of Goettingen.

Helden AJ, Dixon AFG (2002) Life-cycle variation in the aphid Sitobion avenae: costs and benefits of male production. Ecological Entomology, 27, 692-701.

Hille Ris Lambers D (1939) Contribution to a monograph of the Aphididae of Europe. Temminckia, 4, 1-134.

Hoeller C (1990) Overwintering and hymenopterous parasitism in autumn of the cereal aphid Sitobion avenae (F.) in northern FR Germany. Journal of Applied Entomology, 109, 21-28.

Holmes PR (1988) Mobility of apterous grain aphids Sitobion avenae within wheat fields. Entomolgia Experimentalis et Applicata, 46, 275-279.

Holtkamp RH, Edge VE, Dominiak BC, Walters BJ (1992) Insecticide resistance in Terioaphis trifolii F. Maculata (Hemiptera, Aphididae) in Australia. Journal of Economic Entomology, 85, 1576-1582.

Horn BKP (1981) Hill shading and the reflectance map. Proceedings of the Institute of Electrical and Electronics Engineers IEEE, 69, 14-47.

Irwin ME, Thresh JM (1988) Long-range aerial dispersal of cereal aphids as virus vectors in North America. Philosophical Transactions of the Royal Society, London. Series B, 321, 421-446.

Jarne P, Lagoda PJL, (1996) Microsatellites, from molecules to populations and back. Trends in Ecology and Evolution, 11, 424-429.

Kereiva P, Wennergren U (1995) Connecting landscape patterns to ecosystem and population processes. Nature, 373, 299-302.

Keyghobadi N, Roland J, Strobeck C (1999) Influence of landscape on the population genetic structure of the alpine butterfly Parnassius smintheus (Papilionidae). Molecular Ecology, 8, 1481-1495.

Kimura M, Crow JF (1964) The number of alleles that can be maintained in a finite population. Genetics, 49, 725-738. 
Knight JD, Bale JS (1986) Cold hardiness and overwintering of the grain aphid Sitobion avenae. Ecological Entomology, 11, 189-197.

Lai Y, Sun F (2003) Microsatellite mutations during the polymerase chain reaction: mean field approximations and their applications. Journal of Theoretical Biology, 224, 127-137.

Lessa EP (1990) Multidimensional analysis of geographic genetic structure. Systematic Zoology, 39, 242-252.

Li YC, Korol AB, Fahima T, Beiles A, Nevo E (2002) Microsatellites: genomic distribution, putative functions and mutational mechanisms: a review. Molecular Ecology, 11, 24532465.

Llewellyn KS (2000) Genetic structure and dispersal of cereal aphid populations. $\mathrm{PhD}$ thesis, University of Nottingham.

Llewellyn KS, Loxdale HD, Harrington R, Brookes CP, Clark SJ, Sunnucks P (2003) Migration and genetic structure of the grain aphid (Sitobion avenae) in Britain relates to climate and clonal fluctuation as revealed using microsatellites. Molecular Ecology, 12, 21-34.

Llewellyn KS, Loxdale HD, Harrington R, Clark SJ, Sunnucks P (2004) Evidence for gene flow and local clonal selection in field populations of the grain aphid (Sitobion avenae) in Britain revealed using microsatellites. Heredity, 93, 143-153.

Loxdale HD, Tarr IJ, Weber CP, Brookes CP, Digby PGN, Castañera P (1985) Electrophoretic study of enzymes from cereal aphid populations. III. Spatial and temporal genetic variation of populations of Sitobion avenae (F.) (Hemiptera: Aphididae). Bulletin of Entomological Research, 75, 121-141.

Loxdale HD, Brookes CP (1990) Temporal genetic stability within and restricted migration (gene flow) between local populations of the blackberry-grain aphid Sitobion fragariae in south-east England. Journal of Animal Ecology, 59, 497-514.

Loxdale HD, Hardie J, Halbert S, Foottit R, Kidd NAC, Carter CI (1993) The relative importance of short- and long-range movement of flying aphids. Biological Reviews, 68, 291-311.

Loxdale HD, Lushai G (1998) Molecular markers in entomology (Review). Bulletin of Entomological Research, 88, 577-600.

Loxdale HD (2001) Tracking flying insects using molecular markers. Antenna (Bulletin of the Royal Entomological Society), 25, 242-250.

Loxdale HD, Lushai G (2003a) Rapid changes in clonal lineages: the death of a 'sacred cow'. Biological Journal of the Linnean Society, 79, 3-16.

Loxdale HD, Lushai G (2003b) Maintenance of aphid clonal lineages: images of immortality. Infection, Genetics \& Evolution 3, 259-269. 
Loxdale HD, MacDonald C (2004) Tracking parasitoids at the farmland field scale using microsatellite markers. Proceedings of the international conference and OECD workshop 'Biological Resources \& Migration', Philipps-University, Marburg, Germany, 5 - 8th October, 2003, Springer-Verlag, Berlin \& Heidelberg, pp. 107 -125.

Lushai G, Hardie J, Harrington R (1996) Inhibition of sexual morph production in the birdcherry aphid, Rhopalosiphum padi. Entomolgia experimentalis et applicata, 81, 117119.

Lushai G, Markovitch O, Loxdale HD (2002) Host-based genotype variation in insects revisited. Bulletin of Entomological Research, 92, 159-164.

Lushai G, Loxdale HD, Allen JA (2003) The dynamic clonal genome and its adaptive potential. Biological Journal of the Linnean Society, 79, 193-208.

Magurran AE (2004) Measuring biological diversity. Blackwell Publishing, Malden, Oxford, Victoria.

Massonnet B, Simon JC, Weisser WW (2002) Metapopulation structure of the specialized herbivore Macrosiphoniella tanacetaria (Homoptera, Aphididae). Molecular Ecology, 11, 2511-2521.

Maudsley MJ (1993) Regional differences in the abundance of aphids. PhD thesis, University of East Anglia.

Maynard Smith J (1978) The evolution of sex. Cambridge University press, Cambridge.

Meikle A, Paterson S, Finch RP, Marshall G, Waterhouse A (1999) Genetic characterization of heather (Calluna vulgaris (L.) Hull) subject to different management regimes across Great Britain. Molecular Ecology, 8, 2037-2047.

Menken SBJ, Smit E, Den Nus HCM (1995) Genetical population structure in plants: gene flow between diploid sexual and triploid asexual dandelions (Taraxacum section Ruderalia). Evolution, 49, 1108-1118.

Mercer DR (1979) Flight behaviour of the sycamore aphid Drepanosiphum platanoides Schr. $\mathrm{PhD}$ thesis, University of East Anglia.

Moericke V (1955) Ueber die Lebensgewohnheiten der gefluegelten Blattlaeuse (Aphidina) unter besonderer Beruecksichtigung des Verhaltens beim Landen. Zeitschrift fuer angewandte Entomologie, 37, 29-91.

Moran N (1992) The evolution of aphid life cycles. Annual Review of Entomology, 37, 321348.

Morzfeld J (2004) Einfluss von Landschaftsstrukturen und landwirtschaftlicher Nutzung auf das Auftreten blattpathogener Pilze an Weizen und die genetische Variabilitaet von Mycosphaerella graminis (Anamorph Septoria tritici). doctorate thesis, University of Goettingen. 
Muir RC (1979) Insecticide resistance in the damson-hop aphid, Phorodon humuli, in commercial hop gardens in Kent. Annals of Applied Biology, 92, 1-9.

Mueller FP (1977) Ueberwinterung und Fundatrix der Getreideblattlaus Macrosiphum (Sitobion) avenae (F.). Archiv für Phytopathologie und Pflanzenschutz, 13, 347-353.

Mueller HJ (1964) The relation of recombination to mutational advance. Mutation Research, 1, 2-9.

Newton C, Dixon AFG (1988) The cost of switching from asexual to sexual reproduction in an aphid. Entomologia experimentalis et applicata, 47, 283-287.

Niklasson M, Tomiuk J, Parker ED (2004) Maintenance of clonal diversity in Dipsa bifurcata (Fallen, 1810) (Diptera: Lonchopteridae). I. Fluctuating seasonal selection moulds longterm coexistence. Heredity, 93, 62-71.

Ono M, Swanson JJ, Field LM, Devonshire AL, Steigfried BD (1999) Amplification and methylation of an esterase gene associated with insecticide resistance in greenbugs, Schizaphis graminum (Rodani) (Homoptera: Aphididae). Insect Biochemistry and Molecular Biology, 29, 1065-1073.

Osborne JL, Loxdale HD, Woiwod IP (2002) Monitoring insect dispersal: methods and approaches. In: Dispersal Ecology (eds. Bullock JM, Kenward RE, Hails RS), pp. 2449. British Ecological Symposium, 3-5 April, 2001, Reading University, UK. Blackwell Publishing, Oxford.

Papura D, Simon JC, Halkett F, Delmotte F, Le Gallic JF, Dedryver CA (2003) Predominance of sexual reproduction in Romanian populations of the aphid Sitobion avenae inferred from phenotypic and genetic structure. Heredity, 90, 397-404.

Parish WEG, Bale JS (1993) Effects of brief exposures to low-temperature on the development, longevity and fecundity of the grain aphid Sitobion avenae (Hemiptera, Aphididae). Annals of Applied Biology, 122, 9-21.

Powell SJ and Bale JS (2004) Cold shock injury and ecological costs of rapid cold hardening in the grain aphid Sitobion avenae (Hemiptera: Aphididae). Journal of Insect Physiology, 50, 277-284.

Raymond M, Rousset F (1995) GENEPOP: population genetics software for exact tests and ecumenicism. Release 1.2. Journal of Heredity, 86, 248-249.

Rispe C, Pierre JS (1998) Coexistence between cyclical parthenogens, obligate parthenogens, and intermediates in a fluctuating environment. Journal of Theoretical Biology, 195, 97-110.

Rispe C, Pierre JS, Simon JC, Gouyon PH (1998) Models of sexual and asexual coexistence in aphids based on constraints. Journal of Evolutionary Biology, 11, 685-701.

Russell EP (1989) Enemies hypothesis: a review of the effect of vegetational diversity on predatory insects and parasitoids. Environmental Entomology, 18, 590-599.

Schloetterer C (2000) Evolutionary dynamics of microsatellite DNA. Chromosoma, 109, 365371. 
Schloetterer C, Wiehe T (1999) Microsatellites, a neutral marker to infer selective sweeps. In: Microsatellites: Evolution and Application (eds Goldstein DB, Schlötterer C), pp. 238247. Oxford University Press, Oxford.

Schmidt MH, Lauer A, Purtauf T, Thies C, Schaefer M, Tscharntke T (2003) Relative importance of predators and parasitoids for cereal aphid control. Proceedings of the Royal Society, London. Series B, 270, 1905-1909.

Schneider S, Roessli D, Excoffier L (2000) Arlequin ver. 2.000: A software for population genetics data analysis. Genetics and Biometry Laboratory, University of Geneva, Switzerland.

Simon JC, Baumann S, Sunnucks P, Hebert PDN, Pierre JS, Le Gallic JF, Dedryver CA (1999) Reproductive mode and population genetic structure of the cereal aphid Sitobion avenae studied using phenotypic and microsatellite markers, Molecular Ecology, 8, 531-545.

Simon JC, Rispe C, Sunnucks P (2002) Ecology and evolution of sex in aphids. Trends in Ecology and Evolution, 17, 34-39.

Simon JC, Delmotte F, Rispe C, Crease T (2003) Phylogenetic relationships between parthenogens and their sexual relatives: the possible routes to parthenogenesis in animals. Biological Journal of the Linnean Society, 79, 151-163.

Sokal RR, Rohlf FJ (1995) Biometry: The principals and practice of statistics in biological research. W.H. Freemann, San Francisco.

Steffan-Dewenter I (2003) Importance of habitat area and landscape context for species richness of bees and wasps in fragmented orchard meadows. Conservation Biology, 17, 1036-1044.

Steffan-Dewenter I, Muenzenberg U, Buerger C, Thies C, Tscharntke T (2002) Scaledependent effects of landscape context on three pollinator guilds. Ecology, 83, 14211432.

Sunnucks P, Hales DF (1996) Numerous transposed sequences of mitochondrial cytochrome oxidase I-II in aphids of the genus Sitobion (Hemiptera: Aphididae). Molecular Biology and Evolution, 13, 510-524.

Sunnucks P, England PR, Taylor AC, Hales DF (1996) Microsatellite and chromosome evolution of parthenogenetic Sitobion aphids in Australia. Genetics, 144, 747-756.

Sunnucks P, DeBarro PJ, Lushai G, Maclean N, Hales D (1997) Genetic structure of an aphid studied using microsatellites: cyclic parthenogenesis, differentiated lineages, and host specialization. Molecular Ecology, 6, 1059-1073.

SYSTAT (1998) SPSS Inc. User’s guide, Release 8.0. SPSS Inc., Chicago. 
Taylor LR, French RA, Woiwood IP, Dupuch MJ, Nicklen J (1980) Synoptic monitoring for migrant insect pests in Great Britain and Western Europe I. Establishing expected values for species content, population stability and phenology of aphids and moths. Rothamsted Report for 1980, 2, 41-104.

Thies C, Tscharntke T (1999) Landscape structure and biological control in agroecosystems. Science, 285, 893-895.

Tomiuk J, Woehrmann K (1980) Enzyme variability in populations of aphids. Theoretical and Applied Genetics, 57, 125-127.

Tomiuk J, Woehrmann K (1981) Changes of the genotype frequencies at the MDH-locus in populations of Macrosiphum rosae (L.) (Hemiptera, Aphididae). Biologisches Zentralblatt, 100, 631-640.

Tscharntke T, Steffan-Dewenter I, Kruess A, Thies C (2002) Characteristics of insect populations on habitat fragments: A mini review. Ecological Research, 17, 229-239.

Vandel A (1928) La parthenogenese geographique: contribution a letude biologique de la parthenogenese naturelle. Bulletin Biologique de la France et de la Belgique, 62, 164281.

Van Der Velde M, During HJ, Van De Zande L, Bijlsma R (2001) The reproductive biology of Polytrichum formosum: clonal structure and paternity revealed by microsatellites. Molecular Ecology, 10, 2423-2434.

Vanoverbeke J, and De Meester L, 1997. Among-populational genetic differentiation in the cyclical parthenogen Daphnia magna (Crustacea, Anomopoda) and its relation to geographic distance and clonal diversity. Hydrobiologia, 360,135-142.

Veenker H (2000) Untersuchungen zur Ueberwachung der Intialbesiedlung und Abundanzdynamik der Getreideblattlaeuse mit Hilfe von Saugfallenfaengen, PhD thesis, University of Goettingen.

Via S (1990) Ecological genetics and host adaptation in herbivorous insects: the experimental study of evolution in natural and agricultural systems. Annual Review of Entomology, 35, 421-426.

Vickerman GP, Wratten, SD (1979) The biology and pest status of cereal aphids (Hemiptera: Aphididae) in Europe: a review. Bulletin of Entomological Research, 69, 1-32.

Vorburger C, Lancaster M, Sunnucks P (2003) Environmentally related patterns of reproductive modes in the aphid Myzus persicae and the predominance of two 'superclones' in Victoria, Australia. Molecular Ecology, 12, 3493-3504.

Walters KFA, Dixon AFG (1984) The effect of temperature and wind on the flight activity of cereal aphids. Annals of Applied Biology, 104, 17-26. 
Wangai AW, Plumb RT, Van Emden HF (2000) Effects of sowing date and insecticides on cereal aphid populations and barley yellow dwarf virus on barley in Kenya. Journal of Phytopathology, 148, 33-37.

Watt AD, Dixon AFG (1981) The role of cereal growth stages and crowding in the induction of alatae in Sitobion avenae and its consequences for population growth. Ecological Entomology, 6, 441-447.

Watt AD (1981) Wild grasses and the grain aphid (Sitobion avenae). In: Pests, Pathogens \& Vegetation (ed. J.M. Thresh), pp. 209-305, Pitman, London.

Weber G (1985) On the ecological genetics of Sitobion avenae (F.) (Hemiptera, Aphididae). Zeitschrift für Angewandte Entomologie, 100, 100-110.

Weir BS, Cockerham CC (1984) Estimating F-statistics for the analysis of population structure. Evolution, 38, 1358-1370.

West SA, Lively CM, Read AF (1999) A pluralist approach to sex and recombination. Journal of Evolutionary Biology, 12, 1003-1012.

Westphal C, Steffan-Dewenter I, Tscharntke T (2003) Mass flowering crops enhance pollinator densities at a landscape scale. Ecology letters, 6, 961-965.

Wientgen A, Bigalke A, Bünger J, Fiebig M., Meyer zu Brickwedde W, Pfaff K, Poehling HM (1994) Barely yellow dwarf virus infestation in winter cereals in northern Germany 1990-1992. IOBC Bulletin, 17, 68-88.

Wiktelius S (1984) Long range migration of aphids into Sweden. International Journal of Biometeorology, 28, 185-200.

Wilson ACC, Sunnucks P, Hales DF (1997) Random loss of X chromosome at male determination in an aphid, Sitobion near fragariae, detected using an X-linked polymorphic microsatellite marker. Genetical Research Cambridge, 69, 233-236.

Wilson ACC, Sunnucks P, Hales DF (1999) Microevolution, low clonal diversity and genetic affinities of parthenogenetic Sitobion aphids in New Zealand. Molecular Ecology, 8, 1655-1666.

Wilson ACC, Sunnucks P, Hales DF (2003) Heritable genetic variation and potential for adaptive evolution in asexual aphids (Aphidoidea). Biological Journal of the Linnean Society, 79,115-135.

Wilson ACC, Massonnet B, Simon JC, Prunier-Leterme N, Dolatti L, Llewellyn KS, Figueroa CC, Ramirez CC, Blackman RL, Estoup A, Sunnucks P (2004) Cross-species amplification of microsatellite loci in aphids: assessment and application. Molecular Ecology Notes, 4, 104-109.

Woiwod IP, Tatchell GM, Dupuch MJ, Macaulay EDM, Parker SJ, Riley AM, Taylor MS (1988) Rothamsted Insect Survey: Nineteenth Annual Summary: Suction Traps 1987. Rothamsted Experimental Station Report for 1987, Part 2, Rothamsted Experimental Station, pp. 195229. 
Wolff MA, Abdelaal YAI, Goh DKS, Lampert EP, Roe RM (1994) Organophosphate resistance in the tobacco aphid (Homoptera, Aphididae) - purification and characterization of a resistance-associated esterase. Journal of Economic Entomology, 87, 1157-1164.

Zhan J, Mundt CC, Hoffer ME, McDonald BA (2002) Local adaptation and effect of host genotype on the rate of pathogen evolution: an experimental test in a plant pathosystem. Journal of Evolutionary Biology, 15, 634-647.

Zhivotovsky LA, Rosenberg NA, Feldman MW (2003) Features of evolution and expansion of modern humans, inferred from genomewide microsatellite markers. American Journal of Human Genetics, 72, 1171-1186. 


\section{Acknowledgements}

I am especially grateful to my advisor Prof. Dr. Stefan Vidal for the challenging topic of my dissertation and to the co-reviewer Prof. Dr. Teja Tscharntke

This work was made possible by a lot of helping hands and brains:

Firstly, I thank Steven Lockton for technical advice at the beginning of my studies and Hugh Loxdale and Kate Llewellyn for introduction into the fascinating field of molecular ecology.

Secondly, I thank my colleagues for providing additional data, especially Thorsten Behrens, Tobias Purtauf and Jens Dauber for providing the landscape structure data and field sites in Hesse, Andreas Rinker for providing landscape data from northern Germany, Carsten Thies and Julia Morzfeld for help with site selection in Lower Saxony, Christoph Buerger for GIS-work, Katharina Lohaus for aphid providing aphid samples and abundance data from northern Germany and Stefan Toepfer and his colleagues for providing aphids from Hungary.

I thank Alex Wilson for providing primer S16b and Anne Chao for the program SPADE, as well as Paul Stange for help with computing and Bernd Ulber for his kind support.

I thank Lili Hofman, Anne Kemmling, Andreas Loose, Pia Meyer, Katharina Lohaus and Hussein Alkhedir for their help in the field and in the laboratory.

Manuscripts were greatly improved by Jean-Christophe Simon, Charles Dedryver, Ian Denholm and especially by Hugh Loxdale.

I am especially grateful to all colleagues, especially Joachim Dagg, Joachim Moeser and Isolde Steinbrecher for our very fruitful discussions and my family for their patience when I was talking about aphids all the time. I convinced them to have a closer look on aphids now, before squashing them.

Last but not least I thank all aphids that were sent to artificial harsh winter conditions and for providing their DNA. They really demonstrated to be more than ugly pests but incredible complex organisms.

This work was supported by BMBF (Project 01LC0020). 


\section{Curriculum Vitae}

\section{Persönliche Daten}

Name: $\quad$ Lars Reimer

Wohnhaft: $\quad$ Kastanienweg 3, 57319 Bad Berleburg

Geboren: $\quad$ 25.04.1973 in Düren

Familienstand: ledig

\section{$\underline{\text { Schullaufbahn }}$}

1979-1983

Grundschule am Burgfeld in Bad Berleburg

1983-1992

Johannes-Althusius-Gymnasium in Bad Berleburg

1992

Abitur

\section{Zivildienst}

1992-1993 Pflegedienst in der Rothhaarklinik Bad Berleburg

\section{Universitäre Ausbildung}

$1993-2000$

$1999-2000$

2000

Juni-Sept. 2000

2001-2004

Juli 2004
Studium der Biologie an der Christian-Albrechts-Universität zu Kiel Diplomarbeit:

"Untersuchung ausgewählter Aspekte der Wirts - Parasitoid Interaktionen zwischen Adultparasitoiden und Blattrandkäfern der Gattung Sitona (Coleoptera, Curculionidae)" bei Prof. T. Bauer, in Zusammenarbeit mit Dr. U. Kuhlmann CABI-Bioscience-Centre, Delemont, Schweiz

Diplomabschluß (,sehr gut“)

Wissenschaftliche Mitarbeit in Ungarn (EU- Projekt) zur biologischen Kontrolle von Diabrotica virgifera.

Promotion in Agrarwissenschaften zum Thema 'Clonal diversity and population genetic structure of the grain aphid Sitobion avenae (F.) in central Europe', bei Prof. Dr. Stefan Vidal, Institut für Pflanzenpathologie und Pflanzenschutz, Universität Goettingen Promotion mit Abschluss “ausgezeichnet” 
